SILVIO MIYADAIRA AMÂNCIO

REDUÇÃO DA TAXA DE TRANSMISSÃO DE VÍDEO DIGITAL POR MEIO DA APLICAÇÃO DE SEGMENTAÇÃO DE OBJETOS APLICADO AO ESTUDO DE ABELHAS

SÃO PAULO

2008 
SILVIO MIYADAIRA AMÂNCIO

\section{REDUÇÃO DA TAXA DE TRANSMISSÃO DE VÍDEO DIGITAL POR MEIO DA APLICAÇÃO DE SEGMENTAÇÃO DE OBJETOS APLICADO AO ESTUDO DE ABELHAS}

Dissertação apresentada à Escola Politécnica da Universidade de São Paulo para obtenção de título de Mestre em Engenharia

Área de Concentração:

Sistemas Digitais

Orientador:

Prof. Dr. André Riyuiti Hirakawa 
SILVIO MIYADAIRA AMÂNCIO

REDUÇÃO DA TAXA DE TRANSMISSÃO DE VÍDEO DIGITAL POR MEIO DA APLICAÇÃO DE SEGMENTAÇÃO DE OBJETOS APLICADO AO ESTUDO DE ABELHAS

Dissertação apresentada à Escola Politécnica da Universidade de São Paulo para obtenção de título de Mestre em Engenharia

Área de Concentração:

Sistemas Digitais

Orientador:

Prof. Dr. André Riyuiti Hirakawa

São Paulo

2008 


\section{Amâncio, Silvio Miyadaira}

Redução da taxa de transmissão de vídeo digital por meio da aplicação de segmentação de objetos aplicado ao estudo de abelhas / S.M. Amâncio. -- São Paulo, 2008.

$88 \mathrm{p}$.

Dissertação (Mestrado) - Escola Politécnica da Universidade de São Paulo. Departamento de Engenharia de Computação e Sistemas Digitais.

1.Vídeo (Compressão) 2.Laboratórios virtuais I.Universidade de São Paulo. Escola Politécnica. Departamento de Engenharia de Computação e Sistemas Digitais II.t. 
AUTORIZO A REPRODUÇÃO E DIVULGAÇÃO TOTAL OU PARCIAL DESTE TRABALHO, POR QUALQUER MEIO CONVENCIONAL OU ELETRÔNICO PARA FINS DE ESTUDO E PESQUISA, DESDE QUE CITADA A FONTE. 


\section{FOLHA DE APROVAÇÃO}

Silvio Miyadaira Amâncio

Redução da taxa de transmissão de vídeo digital por meio da aplicação de segmentação de objetos aplicado ao estudo de abelhas

Dissertação apresentada à Escola Politécnica da Universidade de São Paulo para obtenção de título de Mestre em Engenharia

Área de Concentração:

Sistemas Digitais

Aprovado em:

Banca Examinadora

Prof. Dr.

Instituição:

Assinatura:

Prof. Dr.

Instituição:

Assinatura:

Prof. Dr.

Instituição:

Assinatura:

Prof. Dr.

Instituição:

Assinatura: 


\section{DEDICATÓRIA}

Dedico este trabalho a todas as pessoas e instituições que, direta ou indiretamente contribuíram para o meu crescimento pessoal e profissional, em especial à minha família e colegas de faculdade. 


\section{AGRADECIMENTOS}

Ao Prof. Dr. André Riyuiti Hirakawa, pelo seu suporte e ensinamentos durante os anos de convivência, que muito contribuíram para meu crescimento científico e intelectual.

À Escola Politécnica da Universidade de São Paulo, pela oportunidade de realização do curso de mestrado.

À Tereza Cristina Giannini e Sérgio Dias Hilário pelas informações fornecidas durante o processo de coleta de dados no Laboratório de Abelhas.

Ao Instituto de Biociências da Universidade de São Paulo, por ter colocado à disposição o laboratório de abelhas.

Aos meus parentes, colegas e demais colaboradores, em especial aos membros do Laboratório de Automação Agrícola, por seu auxílio no elaboração deste trabalho. 


\begin{abstract}
The use of videos in web based laboratories over computer networks, known as weblabs, is being conducted for bee research as part of the ViNCES (Virtual Network Center of Ecosystem Services) project, a research consortium composed by: LAA (Laboratório de Automação Agrícola da Escola Politécnica) and the Laboratório de Abelhas of the Ecology Department of the Biosciences Institute. ViNCES is a member of Kyatera, a high speed academic computer network which aims at developing aplications and technologies for the Advanced Internet.

The bee weblab, called BBBee, allows the research and observation of the interior of a beehive, in which are collected climate, audio and video data. Real time audio and video are broadcasted over the Internet and through a local network using streaming format. The bandwidth requirements for video transmission are usually high and the video quality after conventional compression standards is, in general, low and can interfere in the biological research. Also, High-Definition video transmission for weblab is planned to be implemented in order to provide better tools for the researcher, which will demand even higher network bandwidth. On this scenario, this work intends to provide a video codification algorithm to enhance the quality of the transmitted images, at the region of interest, and also reduce the transmission and storage requirements for some situations by using segmentation and tracking techniques for videos. A complete CODEC was implemented and tested with actual video, quality and data rates were measured and evaluated using an objective metric. The results of the analysis provided some indications of directions for future enhancements and implementations.
\end{abstract}

Keywords: Weblab, videos, monitoring, compression, segmentation, objects, MPEG, $\mathrm{AVI}$, quality, structural similarity. 


\section{RESUMO}

A utilização de vídeos em laboratórios baseados em redes de computadores (weblabs) para pesquisa de abelhas está sendo conduzida como parte do projeto ViNCES (Virtual Network Center of Ecosystem Services), um consórcio de pesquisa composto pelo LAA (Laboratório de Automação Agrícola da Escola Politécnica da Universidade de São Paulo) e o Laboratório de Abelhas do Departamento de Ecologia do Instituto de Biociências da Universidade de São Paulo. O ViNCES é um membro do Kyatera, uma rede de computadores acadêmica de alta velocidade que tem como objetivos o desenvolvimento de aplicações e tecnologias para a Internet Avançada. Nesse contexto, o Weblab de abelhas, denominado BBBee, permite a realização de pesquisa e observação à distância da entrada de uma colméias, sendo coletadas e transmitidas informações de condições climáticas, de áudio e vídeo.

O áudio e o vídeo da colméia são transmitidos em rede local e pela Internet por meio de streaming em tempo real. Os requisitos de largura de banda para transmissões de vídeo costumam ser elevados, e a qualidade obtida após o processo de compressão convencional, em geral, é baixa, podendo afetar ou dificultar a pesquisa. Além disso, está prevista a transmissão de vídeos de Alta Definição para weblab com o objetivo de melhorar a qualidade da informação, o que irá demandar maior largura de banda. Este trabalho propõe um algoritmo de codificação de vídeo para melhorar a qualidade das imagens transmitidas, ao mesmo tempo em que se reduzem os requisitos de largura de banda de transmissão e armazenagem, por meio da aplicação de técnicas de segmentação e rastreamento de objetos de vídeo. O algoritmo proposto foi implementado e testado utilizando vídeos capturados nas colméias e os resultados das análises em diversas condições são apresentados neste documento.

Para avaliar a qualidade resultante do processo, foi utilizada uma métrica objetiva que permite avaliar a qualidade das imagens em relação às imagens de origem. Os resultados das análises proveram informações e direções para melhorias e futuras implementações.

Palavras-chave: Weblab, vídeos, compressão, monitoramento, segmentação, objetos, MPEG, AVI, qualidade, similaridade estrutural. 


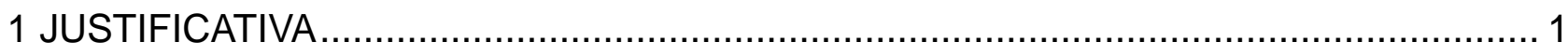

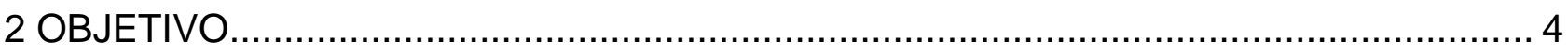

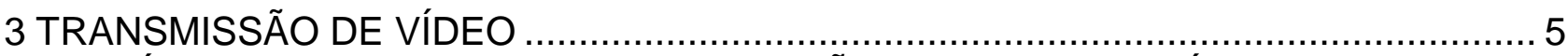

3.1 VÍDEOS E FORMATOS DE COMPRESSÃO DE IMAGEM E VÍDEO DIGITAIS....... 6

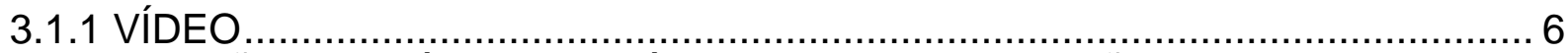

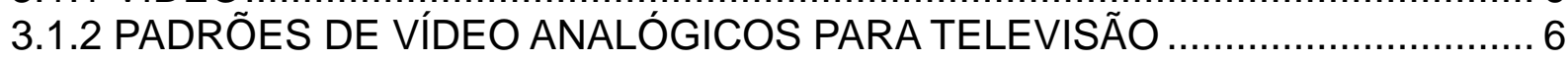

3.1.3 FORMATOS DE IMAGEM DE ORIGEM ……...................................... 7

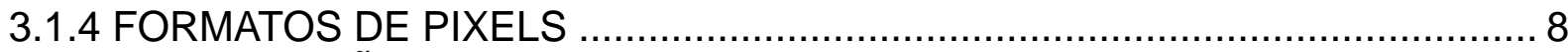

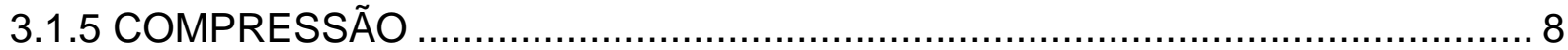

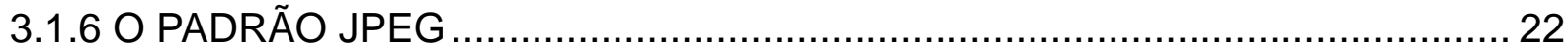

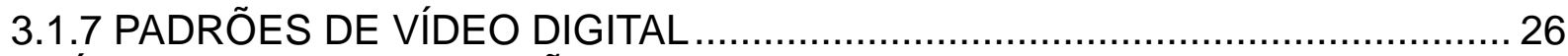

3.2 MÉTRICAS PARA AVALIAĈÃO DE QUALIDADE DE IMAGENS .......................... 38

3.2.1 RELAÇÃO SINAL-RUIIDO DE PICO (PSNR) E ERRO QUADRÁTICO

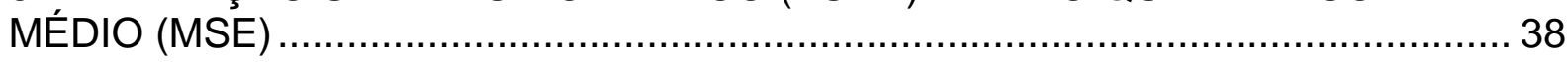

3.2.2 SIMILARIDADE ESTRUTURAL (SSIM) ............................................ 39

3.3 ALGORITMOS DE IDENTIFICAÇÃO E RASTREAMENTO DE OBJETOS EM

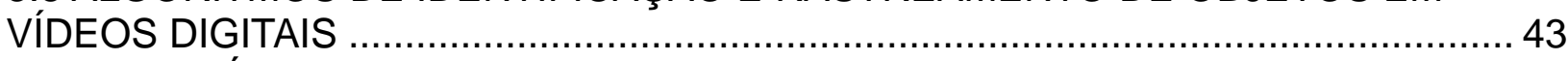

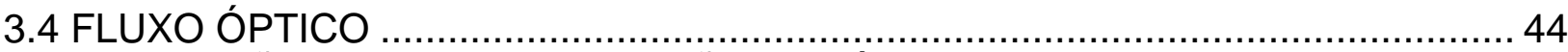

3.5 DISCUSSÃO SOBRE CODIFICAÇÃO DE VÍDEO …….................................. 45

4 ALGORITMO PARA SEGMENTAÇÃO E COMPRESSÃO DE VÍDEO …...................... 47

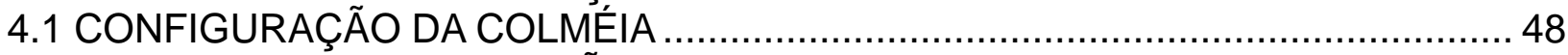

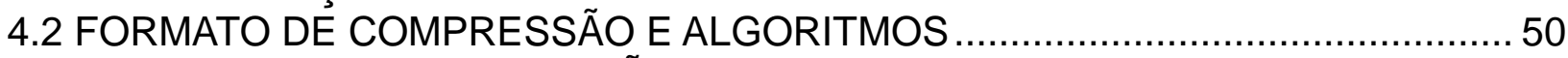

4.3 ALGORITMO DE COMPRESSÃO DESENVOLVIDO …................................ 51

4.4 ALGORITMO DE RECONSTRUÇÃO DESENVOLVIDO....................................... 62

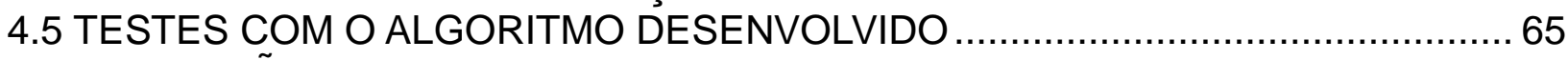

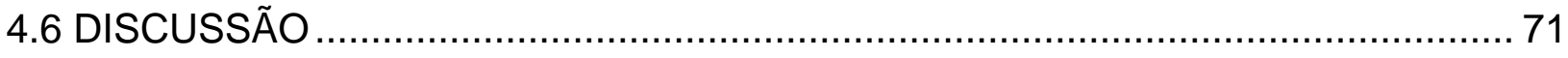

5 CONCLUSÕES E SUGESTÕES PARA TRABALHOS FUTUROS................................ 74

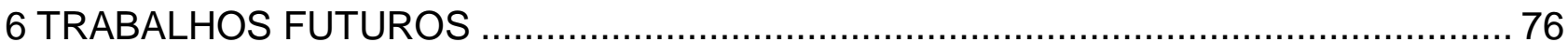

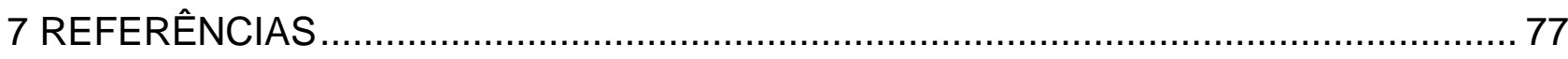




\section{LISTA DE GRÁFICOS}

Grafico 1: Valores de SSIM obtidos para diferentes codecs em um vídeo de resolução de 352x240 pixels (Amâncio, Hirakawa, 2006)

Gráfico 2: Número de quadros do GOPxSSIM

Gráfico 3: Número de quadros do GOPxBitrate

Gráfico 4: Relação SSIMxTamanho final do vídeo comprimido com MPEG4 


\section{LISTA DE FIGURAS}

Figura 1: Árvore de Códigos Huffman

Figura 2: Imagem original (a); 256 cores (b); 16 cores (c); monocromática (d)

Figura 3: Fluxograma do processo de compressão do MPEG (Barjatya, 2004)

Figura 4: Esquerda: quadro de um vídeo de abelhas; direita: quadro do mesmo vídeo 10 quadros ou 0,3 s após o quadro da esquerda.

Figura 5: Diferença entre os quadros da Figura realçada por aumento de contraste

Figura 6: $\quad$ Posições e amostras para 4:2:0

Figura 7: Esquerda: 4:4:4, Direita: 4:2:2

Figura 8: $\quad$ Macroblocos, fatias, imagens e GOPs

Figura 9: Exemplo de estrutura temporal de imagens

Figura 10: Processo de decodificação simplificado

Figura 11: Perfis e seqüências do VC-1

Figura 12: Comparação entre o vídeo sem compressão (a) e após compressão com o WMV9 a 92kbps (b)

Figura 13: Detalhe ampliados da figura 13

Figura 14: Separação de luminância, contraste e alterações estruturais de uma imagem de referência no espaço para um espaço tridimensional

Figura 15: Estrutura da transmissão de vídeo do BBBee

Figura 16: Estrutura do weblab BBBee do Laboratório de Abelhas do IB

Figura 17: Estrutura do algoritmo de compressão desenvolvido

Figura 18: Fluxograma do algoritmo desenvolvido

Figura 19: Detalhe da busca por blocos com movimento 
Figura 20: Estrutura do processo de busca blocos com movimento

Figura 21: Pontos marcados como movimento e mapeamento aos quadros do vídeo

Figura 22: Trecho de vídeo de um bloco do GOP (dimensões de 32×32 pels)

Figura 23: Estrutura do algoritmo de reconstrução desenvolvido

Figura 24: Algoritmo de reconstrução desenvolvido

Figura 25: Imagem do vídeo original (a); imagem após a reconstrução pelo algoritmo (b); representação gráfica do $\operatorname{SSIM}^{\star}(\mathrm{c})$;

Figura 26: Detalhes das imagens da figura 25. 


\section{LISTA DE TABELAS}

Tabela 1: Resoluções dos padrões de TV analógica

Tabela 2: $\quad$ Formatos CIF

Tabela 3: Exemplo de Codificação de Huffman: Probabilidade de símbolos e comprimentos fixos e correspondente de Huffman

Tabela 4: Tipos de quadros e compressão relacionada

Tabela 5: $\quad$ Perfis e níveis do VC-1

Tabela 6: Padrões, resoluções e aplicações típicas

Tabela 7: Estimativa de quantidade de dados gerada para um trecho de $1 \mathrm{~s}$ na resolução de $352 \times 288$ pixels

Tabela 8: Estimativa versus resultados obtidos de quantidades de dados obtidas nas simulações para um trecho de $1 \mathrm{~s}$ de vídeo de resolução de $352 \times 288$ pels

Tabela 9: $\quad$ Alteração de quadros I versus Bitrate e SSIM

Tabela 10: Compressão com o padrão MPEG4 versus SSIM

Tabela 11: Compressão com o padrão MPEG4 x Codec desenvolvido, em resolução de 352×288 pixels.

Tabela 12: Compressão com o padrão MPEG4 x Codec desenvolvido, em resolução de $720 \times 480$ pixels 


\section{LISTA DE SIGLAS}

$\begin{array}{ll}\text { AVI } & \text { Audio-Video Interleave } \\ \text { CIF } & \text { Common Intermediate Format } \\ \text { CODEC } & \text { Coding and Decoding Equipment } \\ \text { DCT } & \text { Discrete Cosine Transform } \\ \text { GOB } & \text { Group of Blocks } \\ \text { GOP } & \text { Group of Pictures } \\ \text { HVS } & \text { Human Visual System } \\ \text { JPEG } & \text { Joint Photographic Experts Group } \\ \text { MPEG } & \text { Moving Picture Experts Group } \\ \text { MB } & \text { Macroblock } \\ \text { NTSC } & \text { National Television Standards Committee } \\ \text { PAL } & \text { Phase Alternating Line } \\ \text { PELS } & \text { Picture elements } \\ \text { PIXELS } & \text { Picture elements } \\ \text { RAM } & \text { Random Access Memory } \\ \text { RGB } & \text { Red-Green-Blue } \\ \text { RLE } & \text { Run Length Encoding } \\ \text { SECAM } & \text { Système en Couleur Avec Mémoire } \\ \text { UHF } & \text { Ultra High Frequency } \\ \text { ViNCES } & \text { Virtual Network Center of Ecosystem Services } \\ \text { VHF } & \text { Very High Frequency } \\ \text { YUV } & \text { Luminance-Bandwidth-Chrominance }\end{array}$




\section{JUSTIFICATIVA}

Os Weblabs, laboratórios de pesquisa disponíveis por meio da Internet são importantes componentes do projeto ViNCES (Virtual Network Center of Ecosystem Services). O projeto ViNCES é um consórcio de laboratórios cujos parceiros: o Laboratório de Automação Agrícola da Escola Politécnica da Universidade de São Paulo - EPUSP; e o Laboratório de Abelhas do Instituto de Biociências da USP IBUSP, realizam pesquisas através de colméias e esfufas, tendo como objetivo o desenvolvimento de tecnologias e aplicações para a Internet Avançada relacionados aos serviços para pesquisa e disseminação de informação em polinização e fotossíntese.

Os weblabs do projeto ViNCES fazem uso da rede de Internet Avançada Kyatera uma rede Internet2 de alta velocidade. Diversas aplicações, abrangendo desde Robótica até Medicina estão planejadas para serem parte do projeto Kyatera. Dentre os recursos providos por esta rede, o desenvolvimento dos Weblabs permite compartilhamento de informações, uso mais eficiente de recursos, colaboração entre grupos de pesquisa, dentre outros. O Webbee, instalado no laboratório de abelhas do IBUSP é um weblab pertencente ao ViNCES que possui bibliotecas e laboratórios virtuais e visa prover um ambiente baseado em Web para pesquisa e educação sobre abelhas nativas, facilitando a realização de experimentos remotos $e$ aumentando o conhecimento da sociedade sobre a importância destas. No webbee, são realizadas a coleta e transmissão de áudio, vídeo e condições de temperatura e umidade obtidas na entrada de uma colméia de abelhas da espécie mandaçaia (Melípona quadrifasciata athidioides). Os dados são utilizados para estudos relacionados ao seu comportamento e disponibilizados no laboratório virtual chamado BBBee.

A transmissão de vídeo da entrada de uma colméia é feita por meio de uma rede Ethernet 10/100 convencional, e através do portal do ViNCES os vídeos são disponibilizados pela Internet. É planejada a transmissão de vídeos de Alta Definição sobre a futura rede de alta velocidade a ser implementada neste laboratório. Nas condições atuais, o vídeo transmitido sofre uma compressão que reduz o volume de dados necessários a sua transmissão, porém, a compressão acarreta severas perdas de qualidade e distorções na apresentação. 
A estrutura de captura, codificação e transmissão de vídeo é composta por uma câmera analógica Sony modelo CCD-PC1 de resolução padrão (352×240 pixels) conectada à entrada de uma placa de captura de vídeo Pinnacle PCTV, instalada em um computador Pentium IV 3.0 GHz, com 1Gb RAM, executando o Windows Media Services e Windows Media Encoder.

\section{IMPEDIMENTOS}

As observações das colméias podem envolver diversas características e comportamento. A partir do trabalho pioneiro de Karl von Frisch, sobre as danças waggle e round que as abelhas da espécie Appis mellifera produzem na comunicação sobre fontes e direções de fontes de recursos, este comportamento vem sendo extensivamente estudado pelos pesquisadores (Hrncir et al, 2000).

Segundo Barth (Barth et al, 2008), ainda é necessário maior conhecimento sobre as propriedades e efeitos comportamentais para um melhor conhecimento sobre a comunicação entre abelhas sem ferrão e suas formas de notificação de fontes de recursos. Em alguns estudos sobre abelhas (Jarau et al 1999), é realizada a aplicação de marcadores sobre as abelhas para identificação, o que pode facilitar a identificação também por vídeo, entretanto esta característica não foi utilizada neste trabalho. Algumas destas observações envolvem a avaliação de informações de posição e orientação das abelhas, podendo ser realizadas utilizando-se o sistema atual. Porém, detalhes que necessitam de visualização com maior nitidez são prejudicados na ocorrência de ruídos tipicamente causados pelos processos de compressão usuais.

Atualmente, a baixa capacidade de transmissão, assim como a insuficiente taxa de compressão provida pelos CODECs (Codificador/Decodificador), dificultam a realização de estudos mais detalhados à distância, uma vez que, para se obter baixas taxas de transmissão, requer-se que seja realizada compressão com perdas. Em muitos casos, o processo de compressão dificulta a visualização do vídeo da colméia e principalmente da movimentação das abelhas. Além da deterioração da qualidade das imagens, é comum a ocorrência de grandes atrasos na entrega do vídeo, ocasionados principalmente pelos processos de compressão e streaming. Por outro lado, em muitos momentos ocorre também a transmissão de vídeos sem 
informações úteis, quando não há movimentação ou quando há movimentação em poucos locais da colméia, condições bastante comuns.

Dentre as particularidades dos vídeos transmitidos no BBBee, podemos citar: a iluminação restrita à tons de vermelho, a grande repetição de imagens principalmente o chamado 'plano de fundo' ou imagem do fundo da colméia, havendo diversos períodos sem movimentação; e a semelhança entre os principais elementos que compõem a cena, as abelhas. Sendo a movimentação das abelhas sobre esta imagem objeto de grande interesse de pesquisa, busca-se prover uma melhor qualidade e resolução especificamente na região em que as mesmas se encontram. Diversas características do comportamento das abelhas ainda não podem ser observadas por meio das ferramentas de vídeo atual, como por exemplo, movimentações e vibrações típicas de comunicação que ocorrem a freqüências da ordem de $225 \mathrm{~Hz}$ (Hrncir et al, 2008), outras como contagem e observação da movimentação, poderiam ser simplificadas através da aplicação de algoritmos de rastreamento e contagem. 


\section{OBJETIVO}

Este trabalho propõe a aplicação de técnicas de processamento de imagens que ajudem na identificação e segmentação de objetos de vídeo automaticamente, gerando um algoritmo de compressão para ser aplicado aos vídeos das colméias, em particular da movimentação das abelhas na entrada destas colméias, como forma de melhorar a qualidade dos vídeos.

Deseja-se que tal algoritmo seja simples e ao mesmo possa proporcionar melhorias de qualidade nas regiões em que ocorre movimentação (ROI - Region of Interest) além disso o algoritmo permite que sejam reduzidos os volumes de dados a serem transmitidos em situações de pouca ou nenhuma movimentação. Para o processo de reconstrução do vídeo, um algoritmo análogo foi proposto.

Com a aplicação do CODEC proposto, pretende-se demonstrar que é possível, por meio da aplicação de um algoritmo simples, realizar a transmissão e a recomposição dos vídeos de abelhas com melhor qualidade no que se refere à observação das regiões de interesse, provendo assim maior qualidade do weblab para os pesquisadores. 


\section{TRANSMISSÃO DE VÍDEO}

Diversos fatores impactam na qualidade dos vídeos que são transmitidos via Internet, como taxa de transmissão, confiabilidade do meio, tipo de compressão envolvida, taxa de compressão, resolução, dentre outros. Alguns dos principais tópicos relacionados ao processo de transmissão de vídeo são relacionados nos seguintes itens:

3.1 VÍDEOS E FORMATOS DE COMPRESSÃO DE IMAGEM E VÍDEO DIGITAIS

3.1.1 VÍDEO

3.1.2 PADRÕES DE VÍDEO ANALÓGICOS PARA TELEVISÃO

3.1.3 FORMATOS DE IMAGEM DE ORIGEM

3.1.4 FORMATOS DE PIXELS

3.1.5 COMPRESSÃO

3.1.6 O PADRÃO JPEG

3.1.7 PADRÕES DE VÍDEO DIGITAL

3.1.7.1 MPEG1

3.1.7.2 MPEG2

3.1.7.3 MPEG 4

3.1.7.4 AVI

3.1.7.5 WMV/VC1

3.2 MÉTRICAS DE QUALIDADE DE VÍDEOS DIGITAIS

3.2.1 MÉTRICAS PARA AVALIAÇÃO DE QUALIDADE DE IMAGENS

3.2.1.1 RELAÇÃO SINAL-RUÍDO DE PICO E ERRO QUADRADO MÉDIO

3.2.1.2 SIMILARIDADE ESTRUTURAL (SSIM)

3.3 ALGORITMOS DE SEGMENTAÇÃO DE VÍDEO

3.4 ALGORITMOS DE IDENTIFICAÇÃO E RASTREAMENTO DE OBJETOS EM VÍDEOS DIGITAIS

3.5 FLUXO ÓPTICO 


\subsection{VÍDEOS E FORMATOS DE COMPRESSÃO DE IMAGEM E VÍDEO DIGITAIS}

\subsubsection{VÍDEO}

Uma sucessão ordenada e rápida de imagens relacionadas, em um fluxo contínuo produz a impressão de movimento (Gill et al, 2003). Por exemplo, em um filme de cinema são mostradas imagens em seqüência a uma taxa de 24 quadros por segundo. Na televisão, as imagens são ainda decompostas em linhas e pontos, que sofrem uma varredura ponto a ponto na forma de linhas horizontais, a taxas mais velozes para produzir de 25 a 30 imagens por segundo, sendo alguns quadros entrelaçados para obter as taxas desejadas. Para se obter melhores aspectos com relação à luminosidade e cintilação, dois tipos de varredura de linhas são utilizados em aparelhos de TV normalmente:

- Varredura Progressiva, em que todas as linhas são varridas seqüencialmente;

- Varredura Entrelaçada, em que as linhas pares e ímpares são varridas alternadamente.

\subsubsection{PADRÕES DE VÍDEO ANALÓGICOS PARA TELEVISÃO}

O número de linhas de um quadro e o número de quadros por segundo são determinados por três padrões de difusão de vídeo. Os padrões de vídeo de televisão analógicos são incompatíveis entre si e os mais utilizados são (Gill et al, 2003):

NTSC: National Television Standards Committee, usado principalmente nos EUA e Japão;

PAL: $\quad$ Phase Alternating Line usado na Europa, Asia, Austrália, América do Sul e Brasil (PAL-M);

SECAM: Système en Couleur Avec Mémoire utilizado na França.

A Tabela 1 apresenta as especificações do número de linhas e quadros para cada padrão de vídeo de televisão. 
Tabela 1: Resoluções dos padrões de TV analógica

\begin{tabular}{cccc} 
& NTSC & PAL & SECAM \\
\hline Linhas & 525 & 625 & 625 \\
\hline Quadros & $30(29,97)$ & 25 & 25
\end{tabular}

Os sinais de vídeo utilizados atualmente nos diversos padrões da televisão analógica, conhecidos como vídeo composto, utilizam como portadoras ondas eletromagnéticas de Ultra Alta Freqüência (UHF - Ultra High Frequency) e portadoras de Freqüência Muito Alta (VHF - Very High Frequency), nas quais tipicamente são utilizados de 4 a $6 \mathrm{MHz}$ de largura de banda para transmissão do sinal de vídeo de um canal.

Para o padrão NTSC, um sinal de freqüência de $3.58 \mathrm{MHz}$ é utilizado como portadora para transmissão da cor, chamada de subportadora de cor, que define a cor nos diversos pontos que compõem a imagem. No padrão PAL, a subportadora é de $4,43 \mathrm{MHz}$.

O sistema SECAM, desenvolvido e utilizado pela França, transmite dois componentes de cor alternadamente com cada linha, sendo bastante similar e compatível (em P\&B) com o sistema PAL. Entretanto, o SECAM apresenta dificuldades com relação a mixagem e esmaecimento. O NTSC apresenta como problema as variações de cores. O padrão PAL utilizado no Brasil (PAL-M) consiste na temporização do NTSC com cores PAL.

\subsubsection{FORMATOS DE IMAGEM DE ORIGEM}

Vídeos digitais também são compostos por imagens ou quadros atualizados a determinadas taxas. Cada imagem é composta por um número de amostras, em geral referidas como pixels ou pels (picture elements), que são os menores elementos de imagem que podem ser processados individualmente para serem mostrados em uma tela (Puri, 2000).

As diversas resoluções possíveis se referem ao número de pontos mostrados na tela, em geral, iguais ao número de pontos de luminância $(\mathrm{Y})$ da imagem. A Tabela 2 apresenta as taxas de transmissão para as resoluções CIF (Common Intermediate Format) que apresentam formatos populares para resoluções de luminância. 
Tabela 2: Formatos CIF

\begin{tabular}{lccccc} 
& Sub - CIF & QCIF & CIF & 4CIF & 16CIF \\
\hline Largura (Y) & 128 pels & 176 pels & 352 pels & 704 pels & 1408 pels \\
\hline Altura (Y) & 96 pels & 144 pels & 288 pels & 576 pels & 1152 pels \\
\hline $\begin{array}{l}\text { Taxa de bits não } \\
\text { comprimido (Mbits/s) }\end{array}$ & 4,4 & 9,1 & 37 & 146 & 584
\end{tabular}

\subsubsection{FORMATOS DE PIXELS}

O formato de vídeo utilizado para armazenar a informação é também conhecido como formato de pixel. Os dois principais tipos de formatos de pixel são o YUV (que representa os sinais de luminância e crominância) e o RGB (que representa os componentes de cor vermelho, verde e azul). Os sistemas YUV (PAL) e YIQ (NTSC) derivam do RGB e utilizam a representação da luminância separadamente, e como conseqüência, apresentam vantagens na transmissão como, por exemplo: compatibilidade com os sinais de TV Preto e Branco e facilidade de redução de largura de banda para os sinais chroma (de cor), mesmo mantendo a mesma banda para a luminância. Isto ocorre devido ao fato da luminância ser visualmente mais significativa para o Sistema Visual Humano (HVS - Human Visual System) (Allebach, 1998). Assim, a amostragem pode ser feita a diferentes taxas para os sinais de luminância e crominância sem que isto acarrete grandes perdas de qualidade, sendo normalmente os sinais de luminância amostrados com maior quantidade de bits que os de crominância.

\subsubsection{COMPRESSÃO}

Compressão de dados é o processo de codificar um conjunto de informações digitais dentro de uma representação menor, da qual, a original pode ser reconstituída em momento posterior. Ao referirmos a técnicas ou algoritmos de compressão, normalmente nos referimos a dois algoritmos: o de compressão que, a partir da entrada $X$, gera a representação $X c$, que requer menos bits e o algoritmo de descompressão que, a partir da representação $X c$, gera a reconstrução $Y$.

As técnicas de compressão de dados de vídeo podem ser divididas em duas 
grandes famílias: "sem perdas" (lossless) - após a operação de descompressão, obtêm-se dados idênticos aos originais $(X=Y)$ e "com perdas" (lossy) - que não reconstituem o conteúdo ao seu original $(X \neq Y)$ (Furht, 1995).

\section{COMPRESSÃO SEM-PERDAS}

As técnicas de compressão sem perdas são geralmente aplicadas em informações como texto, dados gerados por computador e alguns tipos de imagem e vídeo, ou seja, em ocasiões em que gostaríamos que a informação recuperada é idêntica a original.

Os tipos de compressão sem-perdas mais utilizados são:

- Codificação de Comprimento (RLE - do inglês Run Length Encoding), (Taylor; Johnson; Crawford, 2006) ;

- Codificação de Huffman (Puri; Chen, 2000), (Parhi; Nishitani, 1999).

\section{CODIFICAÇÃO DE COMPRIMENTO RLE (RUN LENGHT ENCODING)}

A técnica de compressão RLE foi desenvolvida na década de 1950, e consiste em realizar compressão através da eliminação de redundância espacial. No caso das imagens, representando locais de idêntica intensidade como pares de Run-Lenght, em que cada par especifica o início de uma nova intensidade e o número de pixels consecutivos que possuem a mesma intensidade. Por exemplo, a seqüência a seguir:

A B B B D C C C C C

Poderia ser comprimida através do RLE para uma seqüência de pares:

\section{A 1 B 3 D 1 C 6}

Quando há poucos, ou nenhum pixel idêntico, a compressão RLE resulta em expansão de dados (Gonzalez; Woods, 2007). 


\section{CODIFICAÇÃO DE HUFFMAN}

Em 1952, D.A. Huffman publicou um método para construir formas de compressão instantâneas altamente eficientes. Seu algoritmo considera a probabilidade de ocorrência de determinados símbolos e utiliza representações mais curtas para aqueles de maior probabilidade de ocorrência. A compressão pelo método de Huffman consiste em construir uma árvore binária através dos seguintes passos (Puri; Chen, 2000):

- Primeiro passo: Os símbolos são colocados em cada nó. Cada nó é nomeado com a probabilidade de ocorrência do símbolo e os nós são arranjados em ordem crescente de probabilidade de ocorrência;

- Segundo passo: os nós mais à esquerda são conectados por um novo nó, acima destes, que recebe a soma das probabilidades daqueles;

- Terceiro passo: o processo é repetido de forma enquanto houver mais de um nó a ser inserido na árvore, de forma que, os nós de nível mais alto estão em ordem crescente de probabilidades;

- Quarto passo: O nó restante é definido como nó raiz e a árvore está pronta.

Os dados comprimidos com a técnica de Huffman apresentam tamanho variável sem símbolos de separação, gerados através da comparação dos dados fonte com uma tabela de acordo com a árvore gerada para compressão. A codificação Huffman costuma ser utilizada em conjunto com outras técnicas de compressão, como por exemplo, compressão de imagens, texto e áudio sem perdas. Os codificadores sem perdas utilizados em padrões como MPEG (Moving Pictures Experts Group), H.261, H.263 são baseados na codificação de Huffman ou Codificação Aritmética.

A tabela 3 apresenta dados de ocorrência de um conjunto de símbolos, seu comprimento fixo original, e seu comprimento após a aplicação da codificação de Huffman. A figura 1 apresenta a árvore de Huffman correspondente, utilizada na geração do código de Huffman da tabela 3. 
Tabela 3: Exemplo de Codificação de Huffman: Probabilidade de símbolos e comprimentos fixos e correspondente de Huffman

Símbolo Probabilidade Comprimento Fixo Código Huffman

\begin{tabular}{cccc}
\hline A & $60 \%$ & 000 & 0 \\
\hline$B$ & $15 \%$ & 001 & 100 \\
\hline C & $5 \%$ & 010 & 1010 \\
\hline D & $5 \%$ & 011 & 1011 \\
\hline$E$ & $4 \%$ & 100 & 1100 \\
\hline$F$ & $4 \%$ & 101 & 1110 \\
\hline$G$ & $4 \%$ & 110 & 1111
\end{tabular}

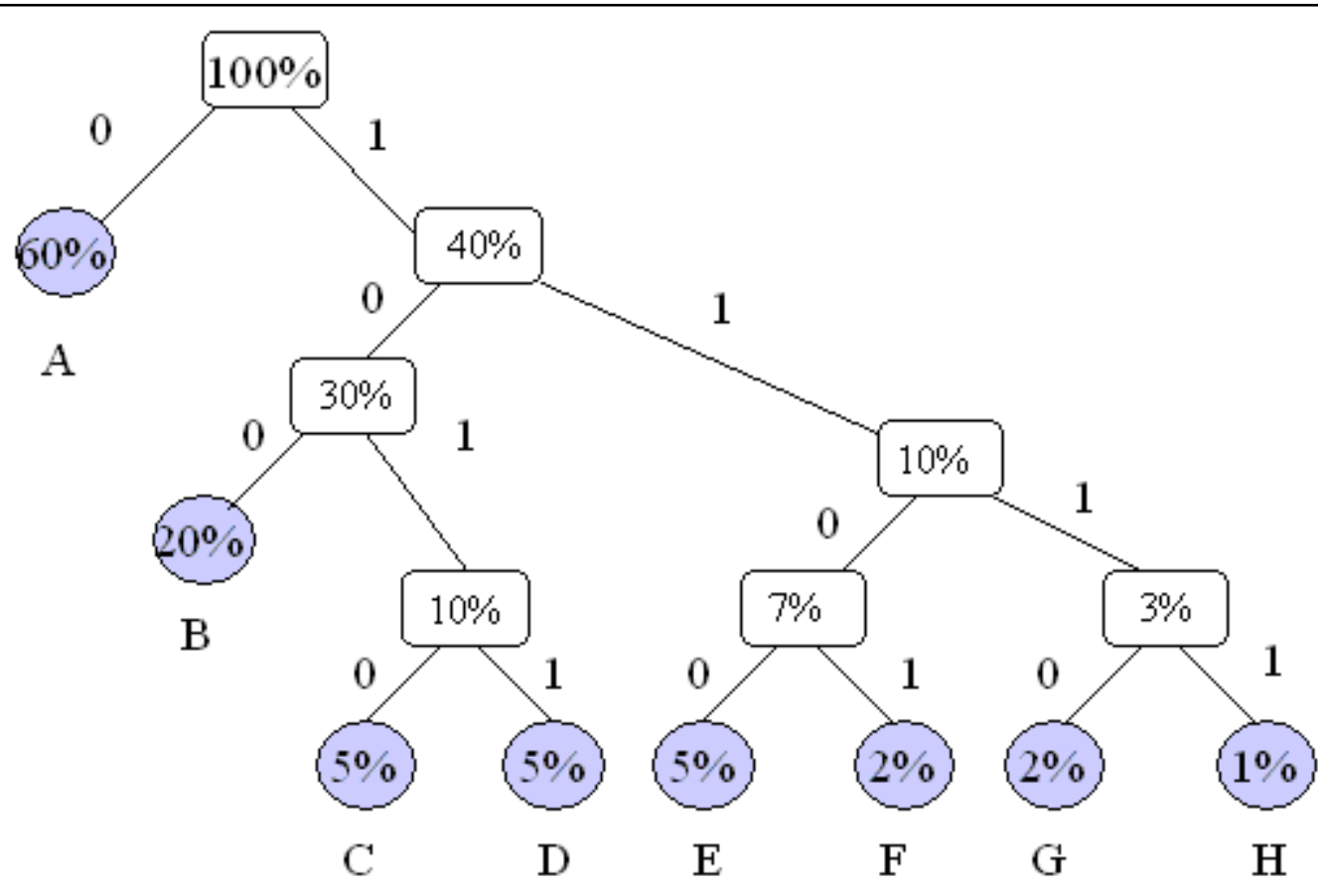

Figura 1: Árvore de Códigos Huffman 
Utilizando a codificação de Huffman para uma seqüência de caracteres "AAABCA", por exemplo, teríamos a geração dos códigos "00010010100", ao invés de 6 códigos de 3 bits de comprimento. A codificação Huffman mapeia as palavras-código e as concatena em fluxo de bits contínuo. Nela, nenhuma palavra código é prefixa de outra palavra-código. Desta forma, os códigos são unicamente decodificáveis (Parhi; Nishitani, 1999).

\section{COMPRESSÃO COM PERDAS}

As técnicas de compressão com perdas envolvem alguma perda de informação. Os dados comprimidos utilizando-se tais técnicas não podem ser reconstruídos exatamente. Em compensação às distorções geradas, obtém-se taxas de compressão superiores ao que é possível utilizando-se técnicas sem perdas. Em situações onde a reconstrução exata da informação não é necessária, ou as perdas não acarretam problemas, como, por exemplo, a transmissão de voz por meio de um telefone, ou vídeos em geral, utiliza-se as técnicas de compressão com perdas.

Os tipos de compressão com-perdas mais utilizados são:

- Amostragem e Quantização;

- Codificação por Transformada;

- Compensação de Movimento.

\section{AMOSTRAGEM E QUANTIZAÇÃO}

O modelo de imagem $f(x, y)$ é uma função de luminância bidimensional de variáveis espaciais $\mathrm{x}$ e y. Se esta função for digitalizada espacialmente é referida como amostragem de imagem. Quando a imagem é digitalizada em amplitude é chamada de quantização de nível.

Em processamento de imagens, imagens são assumidas como regiões retangulares para simplicidade matemática. Cada elemento da matriz $N \times N$ da imagem é referido como picture element (pixel). $N$, que é o número de pixels em cada coluna, é frequentemente escolhido como uma potência inteira de 2 , ou seja, $2^{m}$. Com tal 
escolha de $N$ e $m$, a quantidade total de bits para armazenar uma imagem de dimensões $N \times N$ com $2^{m}$ níveis para sua representação é como mostrado na equação (1).

$$
b=N \times N \times m
$$

Se $N=512$ e $m=8$ (256 níveis de cinza), então para transmitir uma imagem digital em uma taxa de padrão de TV analógica, teríamos a taxa de transmissão de:

$512 \times 512 \times 8 \times 30 \times 24=1510 M B($ Bow, 2002).

A Figura 2 apresenta um trecho de imagem da colméia do BBBee sob diferentes níveis de quantização de nível.

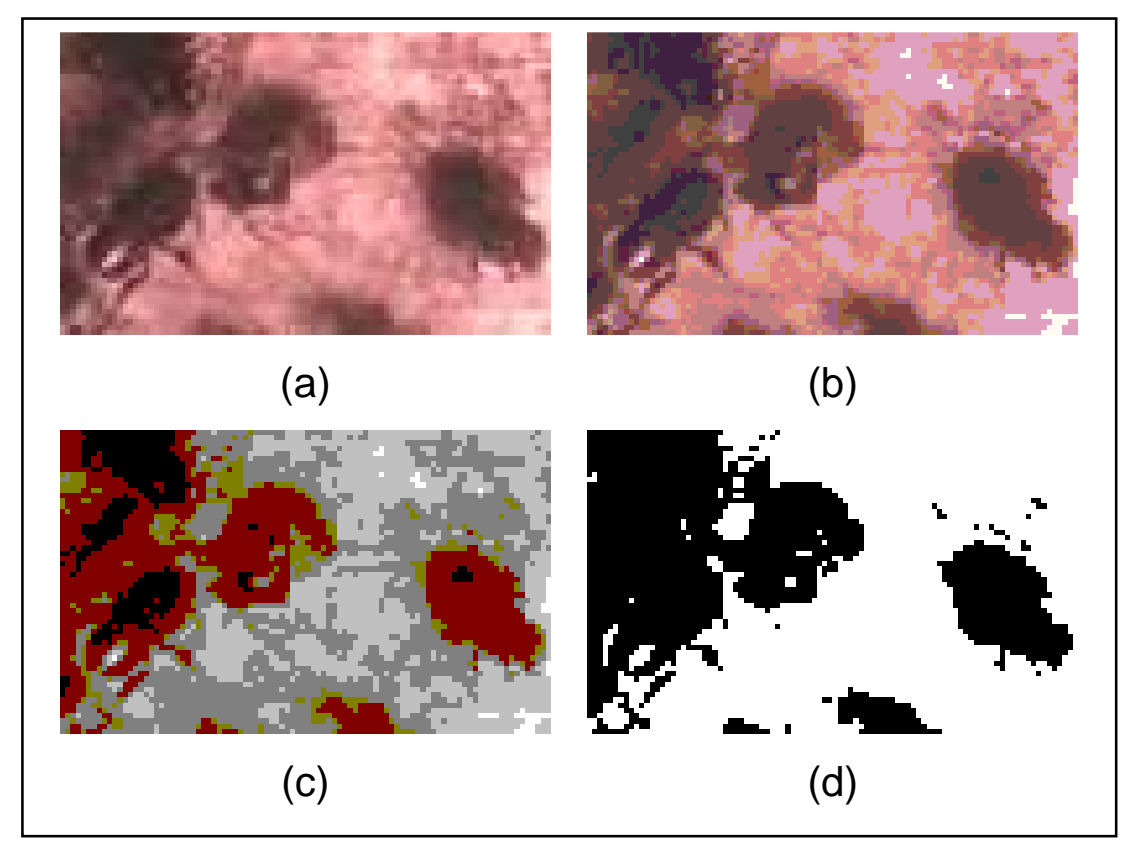

Figura 2: (a): imagem original; (b): 256 cores; (c): 16 cores; (d): monocromática

\section{CODIFICAÇÃO POR TRANSFORMADA}

A Codificação de Transformada é uma técnica de compressão largamente usada para remover redundância de dados. As amostras dos dados são transformadas linearmente em um conjunto de coeficientes de transformada, os quais são posteriormente quantizados e codificados por entropia (Puri; Chen, 2000).

Uma Codificação por Transformada bastante comum na compressão de imagens é a 
Transformada Discreta de Co-senos, DCT (Discrete Co-sine Transform).

Nos padrões de compressão de vídeo, após a obtenção dos coeficientes da DCT, estes são quantizados, ocasionando perdas de informação. O domínio de freqüência mais baixo, o DC (Direct Current) determina a cor fundamental do bloco de 64 pontos. Os demais componentes AC (Alternating Current) indicam freqüências em pelo menos uma dimensão. Geralmente, a maior parte da energia se concentra nos coeficientes de baixa freqüência, que, com a quantização, são arredondados para 0 .

\section{COMPENSAÇÃO DE MOVIMENTO}

A codificação por transformada reduz a redundância espacial dentro de cada quadro, é, portanto, referida como codificação Intra (Puri, 2000). Em um vídeo, entretanto, as imagens costumam conter uma grande quantidade de redundância temporal, sendo os quadros temporalmente próximos, em geral, bastante similares. Portanto, a transmissão da diferença entre os vários quadros usualmente irá requerer menor quantidade de informação que a transmissão dos quadros completos. A obtenção das diferenças pode ser gerada através de operações como subtração de quadros contendo os objetos em movimento de um quadro definido de fundo ou calculandose a diferença entre o dois quadros separados temporalmente.

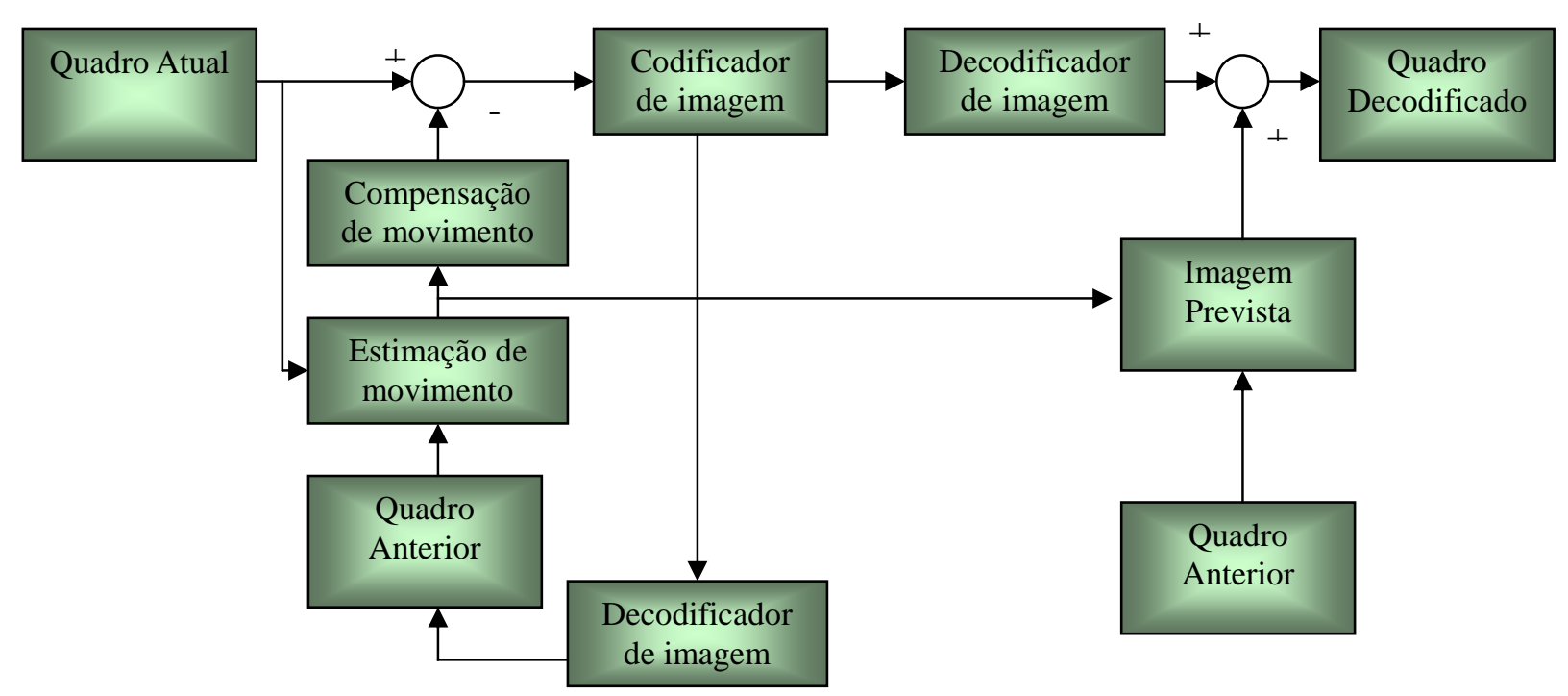

Figura 3: Fluxograma do processo de compressão do MPEG (Barjatya, 2004) 

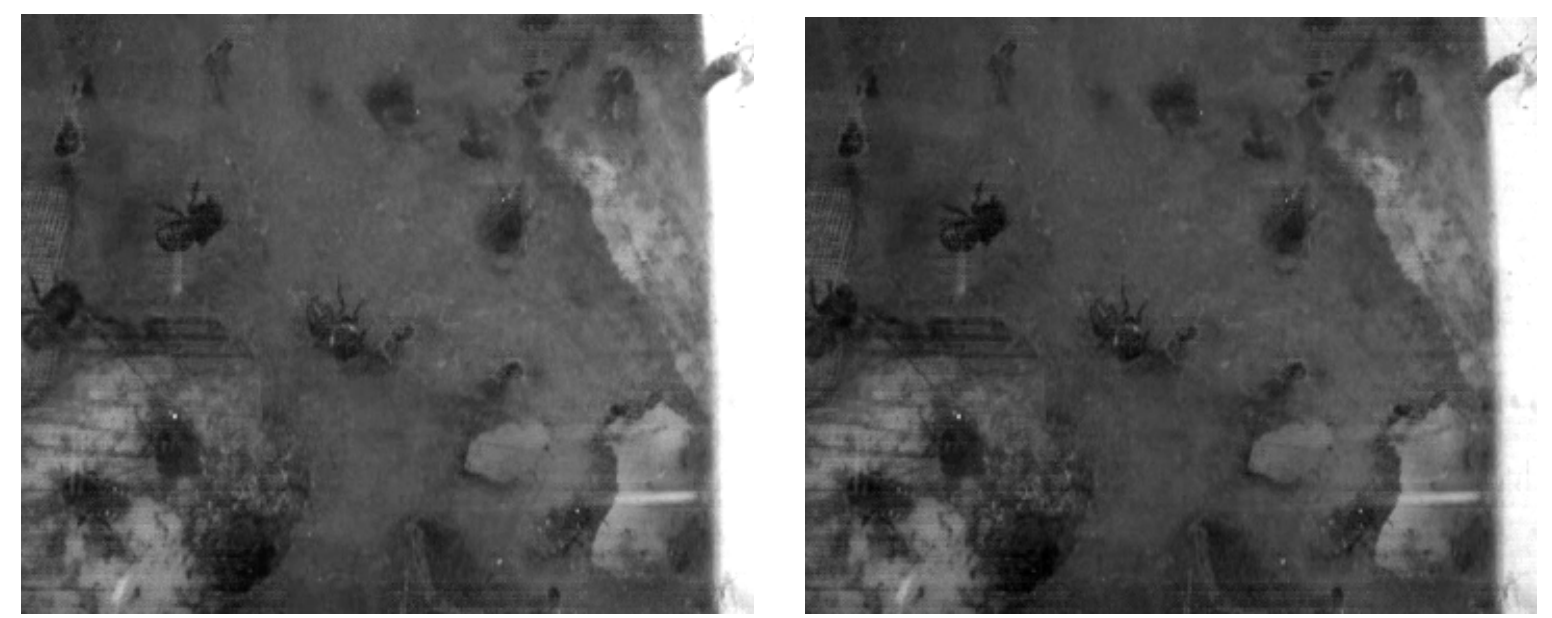

Figura 4: Esquerda: quadro de um vídeo de abelhas; direita: quadro do mesmo vídeo 10 quadros ou 0,3 s após o quadro da esquerda.

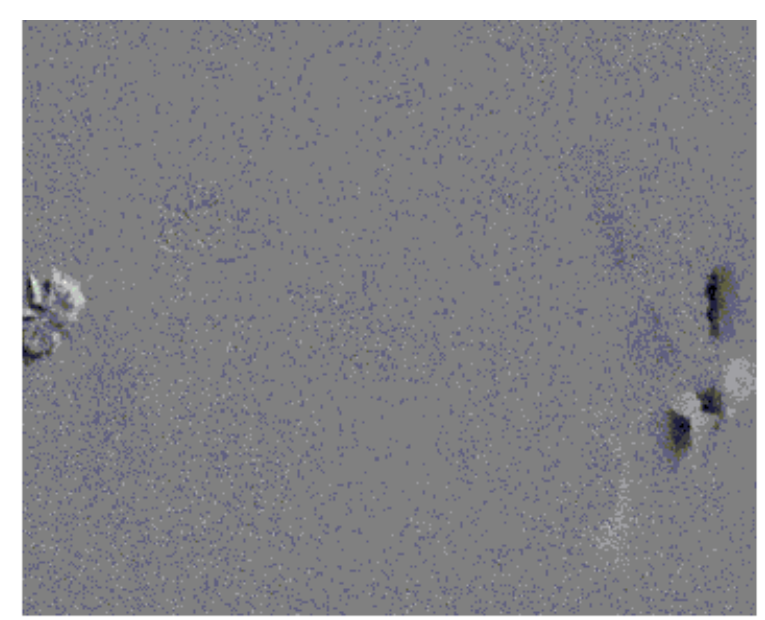

Figura 5: Diferença entre os quadros da Figura 4 realçada por aumento de contraste

A figura 3 apresenta o diagrama de blocos do processo de compressão e descompressão do MPEG que aplica a compensação de movimento em ambos os processos utilizando imagens prévias de um GOP. A figura 4 apresenta imagens de um vídeo obtido no Webbee e estão temporalmente distanciados por 0,3 s ou 10 quadros. Neste vídeo há a movimentação de uma abelha no lado esquerdo. A figura 5 apresenta o valor da diferença obtida pela subtração ponto a ponto das imagens da figura 4, realçada por aumento de contraste, na qual se pode verificar que uma abelha se movimentou. 


\section{AMOSTRAGEM DE LUMINÂNCIA E COMPONENTES DE COR}

Caso não haja compressão, um vídeo no padrão NTSC com dimensões de $720 \times 480$ pixels, requer 345,000 pixels por quadro. Utilizando-se três componentes de cor com 10 bits de amostra cada, teríamos para um único quadro 10.368 .000 bits (Puri, 2000). Sendo mostrados 29,97 quadros por segundo em um vídeo NTSC, a taxa resultante será de 310.728 .960 bits por segundo, ou 140 gigabytes por hora de vídeo.

A amostragem dos sinais analógicos de um sinal de vídeo durante a digitalização pode ser realizada nos componentes de luminância e diferença de cor e, em geral, nas seguintes configurações:

> 4:4:4: Cada pixel é amostrado em luminância e dois sinais de diferença de cores.

> 4:2:2: A luminância é amostrada a cada pixel, enquanto os dois sinais de diferença de cores são amostrados a cada dois pixels. Este é o padrão para a maioria dos equipamentos de vídeo digital.

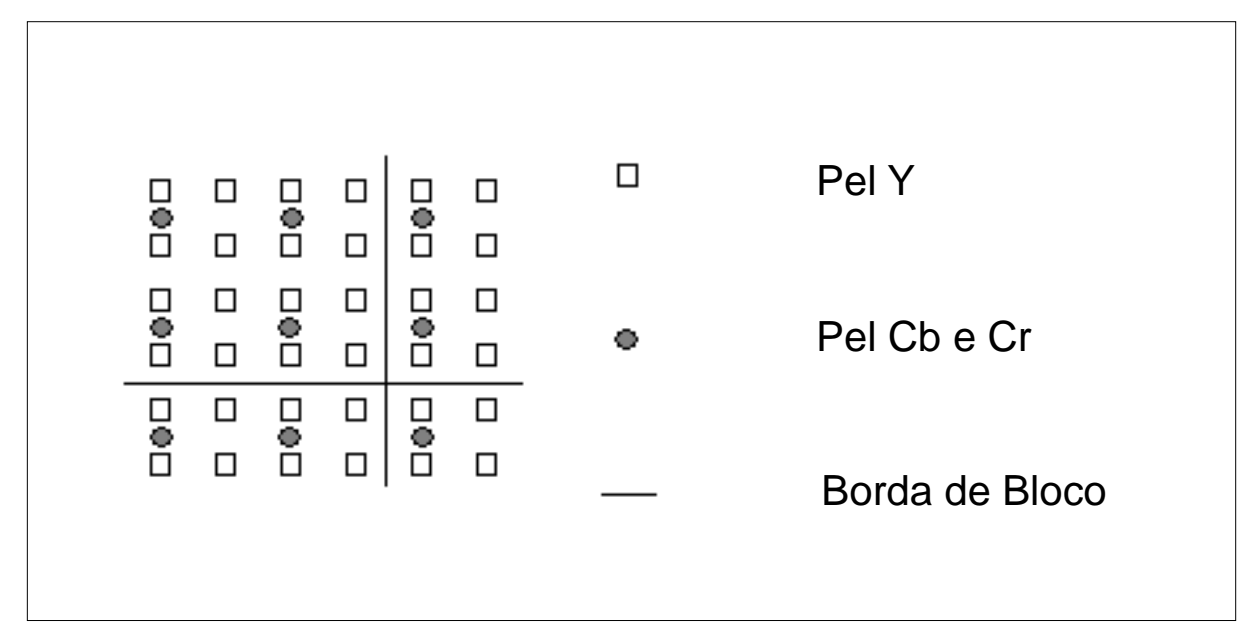

Figura 6: Posições e amostras para 4:2:0

> 4:2:0: A luminância é amostrada a cada pixel. A amostragem de sinais de diferença de cores é alternada a cada linha, sendo o $R^{\prime}-Y^{\prime}$ amostrado linha por linha e o $B^{\prime}-Y^{\prime}$ na linha seguinte. Os sinais de diferença de cor são amostrados a cada dois pixels. Este padrão é utilizado no padrão MPEG2, comumente utilizado no DVDs.

7:1:1: A luminância é amostrada a cada pixel, enquanto os sinais de diferença 
de cores são amostrados a cada quatro pixels. Este é o padrão utilizado em produtos DV e DVCAM.

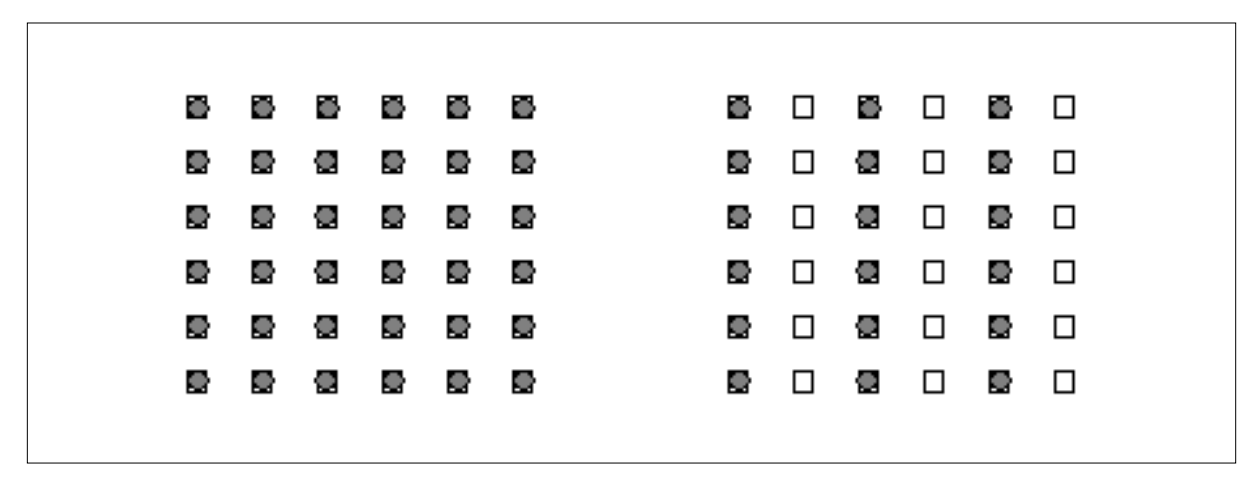

Figura 7: Esquerda: 4:4:4, Direita: 4:2:2

Utilizando-se amostragens de 4:2:2, os requisitos de armazenagem são reduzidos a um terço, sendo o vídeo resultante quase indistinguível do formato original. A subamostragem 4:2:0 e 4:1:1 reduz os requisitos de armazenagem pela metade e o vídeo resultante apresenta qualidade considerada aceitável para aplicações da eletrônica de consumo (CE). O formato 4:2:0 costuma ser o mais utilizado, uma vez que, a percepção de cores do HVS costuma ser inferior à percepção da luminosidade.

No H261, por exemplo, temos os conjuntos formados por um bloco de amostras $\mathrm{Cb}$, um bloco de amostras $\mathrm{Cr}$ e quatro blocos de amostras $\mathrm{Y}$ formando um macrobloco (MB) codificado em 4:2:0 (Figura 6). A figura 7 mostra a representação de amostragem de $\mathrm{Y}, \mathrm{Cb}$ e $\mathrm{Cr}$ em todos os pixels (esquerda) e amostragem de crominância ( $\mathrm{Cb}$ e $\mathrm{Cr}$ ) a cada dois pixels $\mathrm{Y}$. 


\section{IMAGENS, GRUPO DE IMAGENS, FATIAS, BLOCOS, MACROBLOCOS E GRUPOS DE BLOCOS}

No padrão MPEG, O GOP (Group of Pictures), ou grupo de imagens reduz a redundância temporal nos quadros. O GOP costuma conter arranjos de imagens codificados de diferentes formas (intra, preditivas e bidirecionais). As imagens tipicamente não são codificadas de uma vez, sendo em geral, divididas em unidades menores e processadas unidade a unidade (Puri, 2000). A camada de Blocos é a mais baixa na estrutura hierárquica, sendo definidos diferentemente de acordo com o CODEC.

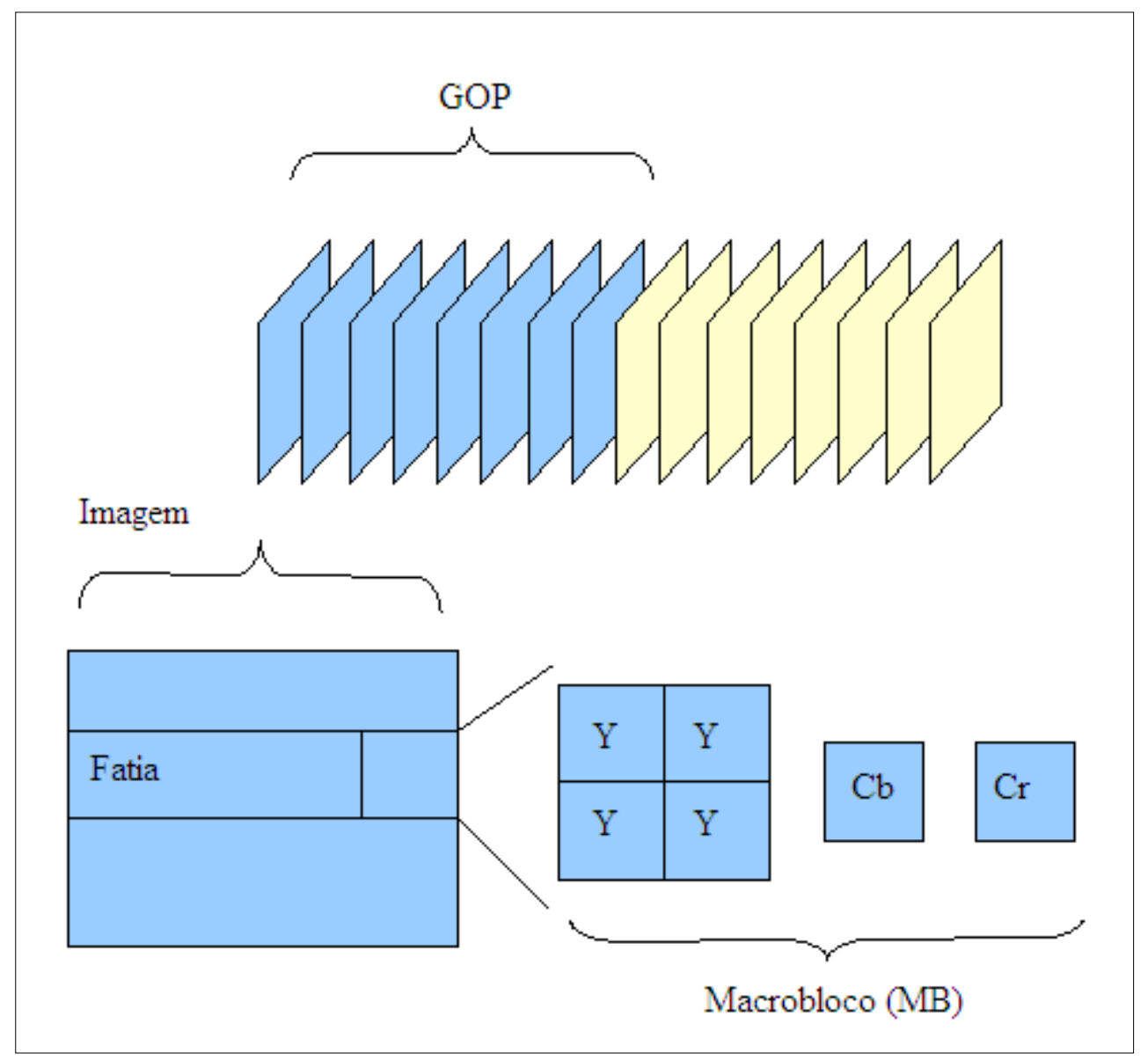

Figura 8: Macroblocos, fatias, imagens e GOPs

Na figura 8 é mostrada a estrutura típica de um GOP no H261 (parte superior). O GOP é composto por diversas imagens estruturadas em Fatias, que são conjuntos de MBs. Neste caso, um MB possui 4 blocos $\mathrm{Y}$ para um par de blocos $\mathrm{Cb} / \mathrm{Cr}$ e cada bloco é formado por um grupo de $8 \times 8$ pixels. 
As principais formas de codificar um Macrobloco (MB) são as seguintes (Puri, 2000):

$>$ Não codificar

- Repetir os blocos não alterados;

Realizar compressão Intra-quadro

- Realizar compressão por Transformada Discreta de Cossenos (DCT -

Discrete Cosine Transform), quantização sobre os coeficientes da DCT, obter uma seqüência através de Zig-Zag, codificar a seqüência por RLE, e sobre esta codificação, aplicar codificação de Huffman.

$>$ Realizar compressão Inter-quadros

- Calcular a diferença entre o bloco no quadro anterior e o atual.

- Estimar o movimento (vetores de movimento).

- Aplicar as técnicas usadas na compressão Intra-quadros, como DCT, quantização ou Huffman sobre os valores das diferenças entre blocos.

\section{TIPOS DE CODIFICAÇÃO DE QUADROS}

Os quadros que compõem um vídeo podem ser codificados ou comprimidos com referência às informações contidas nos mesmos (quadros I ou Intra), ou codificados relacionando suas informações a outros quadros (quadros $\mathrm{P}$ - previstos ou $\mathrm{B}$ bidirecionais - codificação inter-quadros). Dada a alta redundância temporal típica entre os quadros de vídeo, a codificação inter-quadros é mais eficiente que a transmissão dos quadros originais. No MPEG1, por exemplo, cada GOP costuma iniciar com um quadro I e o restante costuma ser um arranjo de quadros $P$ ou $B$ (Furht, 1995).

\section{CODIFICAÇÃO DE QUADROS I}

A codificação de quadros I consiste na aplicação de várias técnicas de compressão sobre a informação que está contida apenas no quadro atual, sem dependências de dados com relação a outros quadros na seqüência de vídeo. O processamento é somente espacial, não sendo realizado processamento temporal e a compressão é similar à codificação JPEG (Joint Photographic Experts Group). 


\section{CODIFICAÇÃO DE QUADROS P}

$\mathrm{Na}$ codificação de quadros $\mathrm{P}$, a imagem é comprimida utilizando-se predição de compensação de movimento de um quadro de referência anterior.

\section{CODIFICAÇÃO DE QUADROS B}

Um quadro codificado bidirecionalmente utiliza predição de compensação de movimento de quadros passados ou futuros.

Dentre estes três tipos de quadros, os "I" são os que apresentam menor taxa de compressão. Os "P" são mais comprimidos que os I e menos comprimidos que os quadros "B" que são os mais comprimidos, mas que necessitam de maior processamento devido ao reordenamento adicional. A Tabela 4 apresenta a compressão típica e a facilidade de edição de vídeo para os tipos de quadros utilizados.

A figura 9 apresenta um GOP típico em que os quadros são comprimidos nas codificações "I", "P" e "B". A estrutura mostrada inicia-se com um quadro "I" seguido por quadros "B" e "P". Os quadros "B" são interpolados por quadros "I", "B" e "P" e os quadros "P" são referenciados de quadros "l" ou "P".

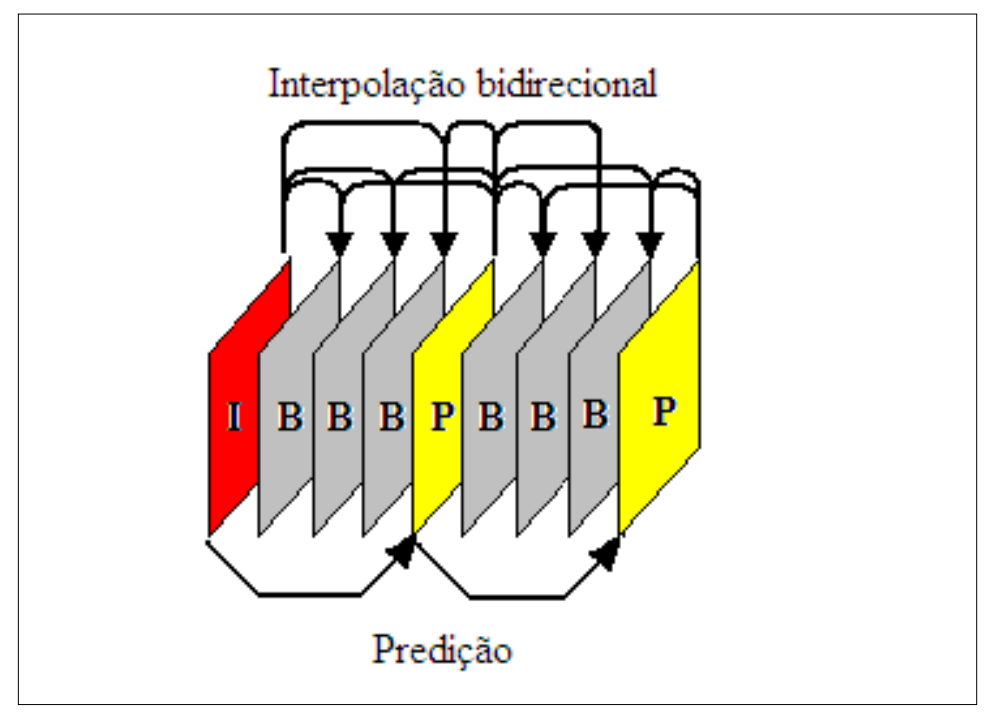

Figura 9: Exemplo de estrutura temporal de imagens 
A codificação de quadros é o principal meio pelo qual se realiza a compressão de vídeos (Puri et al, 2000).

Tabela 4: Tipos de quadros e compressão relacionada

Quadro I Quadros IP Quadros IPB

\begin{tabular}{cccc}
\hline Edição de Vídeo & Boa & Boa & Difícil \\
\hline Taxa de dados & 4 a 6MB/s & 2MB/s & 0,5 a $1,5 \mathrm{MB} / \mathrm{s}$ \\
\hline $\begin{array}{c}\text { Taxa de } \\
\text { Compressão }\end{array}$ & $3 \sim 6: 1$ & $9: 1$ & $15 \sim 30: 1$
\end{tabular}




\subsubsection{O PADRÃO JPEG}

O padrão JPEG segue a recomendação do padrão internacional T.81 do CCITT (The International Telephone and Telegraph Colsultative Committee) I ISO/IEC (International Standards Organization, International Electrotechnical Commission), preparado pelo VIII grupo de estudos do CCITT e pelo Joint Photographic Experts Group da ISO/IEC JTC (Joint Technical Committee) 1/SC 29/WG 10. Este grupo foi formado em 1986 para estabelecer um padrão para codificação seqüencial progressiva de imagens coloridas e de tons de cinza contínuos.

A Compressão e Codificação Digital de Imagens Estáticas de Tons contínuos é publicada em duas partes (ITU-T RECOMMENDATION T.81):

- Requisitos e diretrizes;

- Testes de conformidade.

Este capítulo apresenta os requisitos e diretrizes para a representação codificada de dados JPEG. Estes processos e representações têm a intenção de serem genéricos para serem utilizados em uma ampla faixa de aplicações e sistemas computacionais.

\section{COMPRESSÃO COM PERDAS E SEM PERDAS}

Aspecificação T.81 define duas classes de codificação e decodificação: com perdas e sem perdas. Aquelas baseadas na DCT são com perdas, permitindo substancialmente maiores taxas de compressão, enquanto provêem alta fidelidade visual à imagem original. O processo de codificação mais simples, baseado em DCT, é referido como processo seqüencial baseline. Este processo provê capacidade suficiente para muitas aplicações. Há processos baseados no DCT adicionais que estendem o processo seqüencial baseline para uma faixa de aplicações maior. Em qualquer decodificador usando o processo baseado em DCT, a decodificação baseline deve estar presente para que a decodificação padrão seja possível. A segunda classe de processos de decodificação não se baseia no DCT e é provida para atingir às necessidades de aplicações com compressão sem perdas. Esses processos são usados independentemente dos processos DCT (ITU-T RECOMMENDATION T.81). 


\section{CODIFICAÇÃO BASEADA EM DCT}

Os principais procedimentos para a codificação em todos os processos baseados na DCT são descritos neste item.

No processo de codificação, as amostras dos componentes são agrupados em blocos de 8x8 pixels, e cada bloco é transformado pela forward DCT (FDCT) em um conjunto de 64 valores referidos como coeficientes DCT. Um desses valores é referido como coeficiente DC e os outros 63 como coeficientes AC. Os coeficientes são então quantizados por meio de uma tabela de quantização definida por uma tabela de especificação. Não são definidos valores padrão para tabelas de quantização nesta especificação. Aplicações podem determinar valores específicos para características particulares de suas imagens, dispositivos e condições de visualização. Após a quantização, o coeficiente $D C$ e os 63 coeficientes $A C$ são preparados para codificação por entropia. $O$ valor quantizado $D C$ anterior é utilizado para prever o valor quantizado DC atual e a diferença é codificada. Os 63 coeficientes AC não sofrem esta codificação diferencial, mas são convertidos em uma seqüência zig-zag na qual os coeficientes passam por um procedimento de codificação por entropia que comprime os dados ainda mais. Caso seja usada a codificação Huffman, a tabela Huffman deve ser provida juntamente com o codificador. Se for usada codificação aritmética, as especificações de tabela de condicionamento devem ser fornecidas. Caso contrário, uma tabela de especificações padrão será utilizada.

\section{CODIFICAÇÃO SEM PERDAS}

Um preditor combina os valores reconstruídos de até três amostras vizinhas para formar a predição da amostra em uma posição dada. Esta predição é subtraída do valor real da amostra $x$ e a diferença é então subtraída do valor real da amostra na posição $x$ e a diferença é codificada sem perdas por entropia ou codificação aritmética Huffman. Este processo de codificação pode também ser usado de forma ligeiramente modificada, na qual, a precisão das amostras de entrada é reduzida por um ou mais bits antes da compressão sem perdas. Isto leva a atingir maior compressão que o processo sem perdas, mas reduz a compressão do processo baseado na DCT para fidelidade visual equivalente e limita a imagem reconstruída ao pior caso de erro de amostra da redução de precisão. 


\section{MODOS DE OPERAÇÃO}

Há quatros modos de operação distintos sob os quais os processos são definidos: baseado em DCT seqüencial, baseado em DCT progressivo, sem perdas e hierárquico. O modo de operação sem perdas foi descrito em Codificação sem perdas. Os demais modos são comparados a seguir.

Para o modo baseado em DCT seqüencial, blocos de amostra de $8 \times 8$ são tipicamente blocos de entrada. Após um bloco ter sido transformado pela DCT, quantizado e preparado para codificação por entropia, todos os 64 coeficientes quantizados da DCT podem ser imediatamente codificados por entropia, resultando nos dados de imagem comprimida, assim, minimizando os requisitos de armazenagem.

Para o modo baseado em DCT progressivo, blocos de amostra de $8 \times 8$ pels são também codificados, mas por meio de múltiplas varreduras através da imagem. Isto é realizado por meio da adição de um buffer em memória entre o quantizador e o codificador por entropia. Uma vez que cada bloco é transformado pela DCT e quantizado, seus coeficientes são armazenados em buffer e parcialmente codificados em cada varredura. Há dois procedimentos pelos quais os coeficientes quantizados no buffer podem ser parcialmente codificados dentro de uma varredura. Primeiro, somente uma banda de coeficientes específica da seqüência zig-zag precisa ser codificada. Este procedimento é chamado de seleção espectral, pois cada banda tipicamente contém coeficientes que ocupam uma parte do espectro de freqüências do bloco. Segundo, os coeficientes dentro da banda atual não necessitam de precisão total dentro de cada varredura. Em uma codificação inicial de um coeficiente, um número específico dos bits mais significantes é codificado primeiro. Nas varreduras subseqüentes, os bits menos significantes são codificados. Este procedimento é chamado de aproximação sucessiva. Qualquer procedimento pode ser utilizado separadamente, ou misturados em combinações flexíveis.

No modo Hierárquico, uma imagem é codificada como uma seqüência de quadros. Estes quadros provêem componentes de referência reconstruídos que são normalmente necessários para predição de quadros subseqüentes. Exceto pelo primeiro quadro de um componente dado, quadros diferenciais codificam a diferença entre os componentes de origem e os componentes de referência reconstruídos. 
A codificação de diferenças pode ser feita pelos processos baseados em DCT, processos somente sem perdas, ou processos baseados em DCT com um processo final sem perdas para cada componente. $O$ modo hierárquico oferece uma apresentação similar ao modo baseado em DCT progressivo, mas é mais útil em ambientes que possuem requisitos multi-resolução. $O$ modo hierárquico também oferece a capacidade de codificação progressiva para um estágio final sem perdas.

\section{PRECISÃO DAS AMOSTRAS}

Para o processo baseado em DCT, duas precisões de amostras alternativas são especificadas: 8 bits ou 12 bits por amostra.

Aplicações que utilizam amostras com outras precisões podem converter para 8 ou 12 bits por amostra de precisão. Para processos sem perdas, a amostra é especificada de 2 a 16 bits (ITU-T RECOMMENDATION T.81). 


\subsubsection{PADRÕES DE VÍDEO DIGITAL}

O primeiro padrão de codificação de vídeo digital foi o H.120, que consistia em utilizar técnicas de modulação de códigos de pulsos diferencial (DPCM), quantização escalar e codificação de tamanho variável (Huffman). Em 1988, a compensação de movimento e a predição de fundo foram adicionadas. Atualmente, a maioria das técnicas utilizadas no H.120 é encontrada nos padrões de compressão modernos.

Em 1984, o ITU-T, conhecido previamente como CCITT, iniciou seus trabalhos para definição de um padrão de codificação de vídeo para telefonia conhecido formalmente como H.261 e informalmente como px64, onde $p=1 \sim 30$.

\subsubsection{MPEG1}

O padrão H.261, tendo atingido um estágio de desenvolvimento maduro em 1988, foi superado por novos padrões a partir de 1989. Em 1988, a ISO formou o grupo Moving Pictures Experts Group, com o objetivo de desenvolver técnicas de codificação de vídeo e áudio para atingir qualidade comparável a dos vídeos NTSC ou PAL a taxa de 1,2 Mbit/s, tendo o Compact Disc (CD) como sua aplicação alvo. O MPEG1 apresentou sua versão final em setembro de 1989, tornando-se padrão internacional em novembro de 1992 (Puri, 2000).

Além da codificação de vídeo a taxas de 1 a $1,5 \mathrm{Mbit} / \mathrm{s}$ e áudio a taxas de 128 a 256kbps, o MPEG1 apresenta também como características:

- Acesso aleatório a um quadro dentro de um intervalo de tempo limitado (pontos de acesso a cada $0,5 \mathrm{~s}$ );

- Capacidade de avanço rápido e retroação rápida, permitindo busca e execução progressiva ou retroativa, a velocidades múltiplas vezes superiores a normal;

- Sistema para reprodução e acesso sincronizado;

- Padrão para ser implementado em decodificadores de tempo real com custos de hardware e software razoáveis. 
Também conhecido como norma ISO 11172, o MPEG1 foi organizado em cinco partes:

$\begin{array}{ll}\text { Parte 1 } & \text { Sistemas } \\ \text { Parte 2 } & \text { Vídeo } \\ \text { Parte 3 } & \text { Áudio } \\ \text { Parte } 4 & \text { Consistência } \\ \text { Parte 5 } & \text { Software }\end{array}$

A parte de sistemas especifica a camada de codificação que combina (multiplexa) e sincroniza os fluxos de áudio (camada 3) e vídeo (camada 2). Inclui campos de dados para a sincronia após acessos aleatórios, gerenciamento de buffers de decodificação e identificação da temporização do programa codificado através de marcas temporais de apresentação de áudio e de vídeo.

A parte 4 define o significado de conformidade do sistema, ou seja, como os testes devem ser projetados para verificar se os fluxos de bits e decodificadores atingem os requisitos das partes 1,2 e 3 , sendo usados por manufaturadores de codificadores.

A parte 5 é referida como Simulação de Software, que consiste em sistemas de simulação de software, vídeo e áudio, e consiste em software para codificar e decodificar os fluxos de transporte.

O vídeo MPEG1 foi originalmente projetado para codificação em formato Source Intermediate Format (SIF) de resolução de $352 \times 240$ pontos a 30 quadros não entrelaçados por segundo ou de resolução de 352x288 pontos a 35 quadros não entrelaçados por segundo. Visando outras aplicações, a sintaxe MPEG1 foi estendida para suportar resoluções de até 4096x4096 pontos, a diversas taxas de quadros $(23,97 ; 24 ; 25 ; 29,97 ; 50 ; 59,94 ; 60)$.

Diferentemente do H.261, que utiliza quadros I e P somente, os padrões MPEG suportam os três tipos de imagens codificadas: I, $P$ e $B$, o que permite maior eficiência de compressão. 


\subsubsection{MPEG2}

O MPEG2, também conhecido como norma ISO 13818, é o padrão atual para a TV digital e dos DVD's (Disco Versátil Digital) convencionais. O objetivo original do MPEG2 era a aplicação em vídeos com taxas de 4 até 15Mbits/s para aplicações de TV por difusão e DVD's. Além das características de acesso e busca do MPEG1, o MPEG2 é compatível retroativamente com aquele padrão, suporta formatos de vídeo entrelaçado e não entrelaçado, diferentes estruturas de crominância, robustez a erros, intercâmbio entre atraso de codificação e qualidade (Puri, 2000).

O MPEG2 é organizado nas seguintes partes:

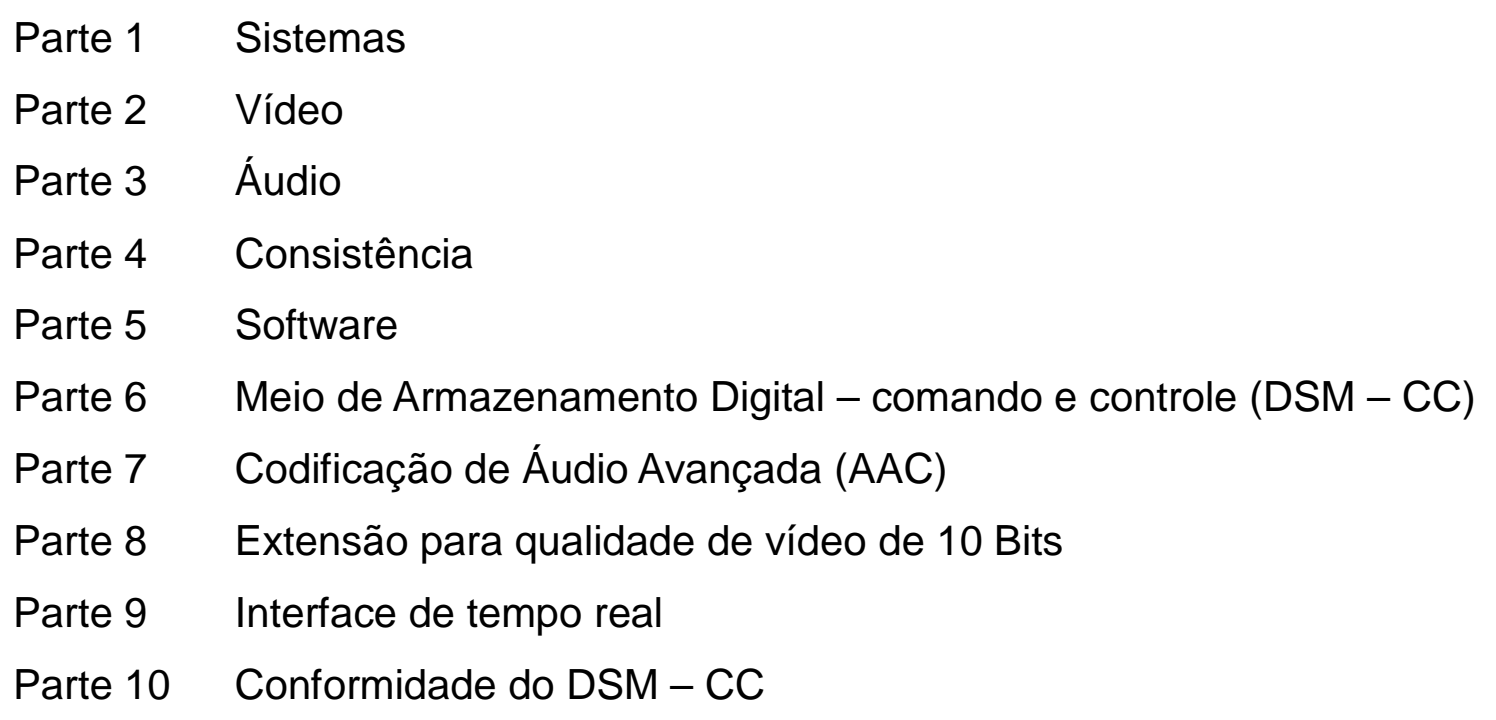

A parte 6 representa um conjunto de protocolos que controla os fluxos do MPEG1 e MPEG2. Uma sintaxe para controlar acesso aleatório ao disco é definida, incluindo comandos como "congelar" quadro, avanço rápido, ir até uma posição etc.

A parte 7 representa uma especificação de algoritmo para codificação multicanal de áudio que não é compatível com o MPEG1.

A parte 8 introduz uma extensão de vídeo de 10-bits cuja aplicação primária é em estúdio de vídeos que requerem precisão de amostra de 10 bits. $O$ trabalho na parte 8 foi descontinuado por falta de interesse da indústria. 
A parte 9 define a especificação da interface de tempo real para transporte de sinais de controle de vídeo sob demanda entre servidores e clientes.

A parte 10 se relaciona com a parte 6 e foi desenvolvida originalmente para ser um formato de intercâmbio entre rotinas de multimídia.

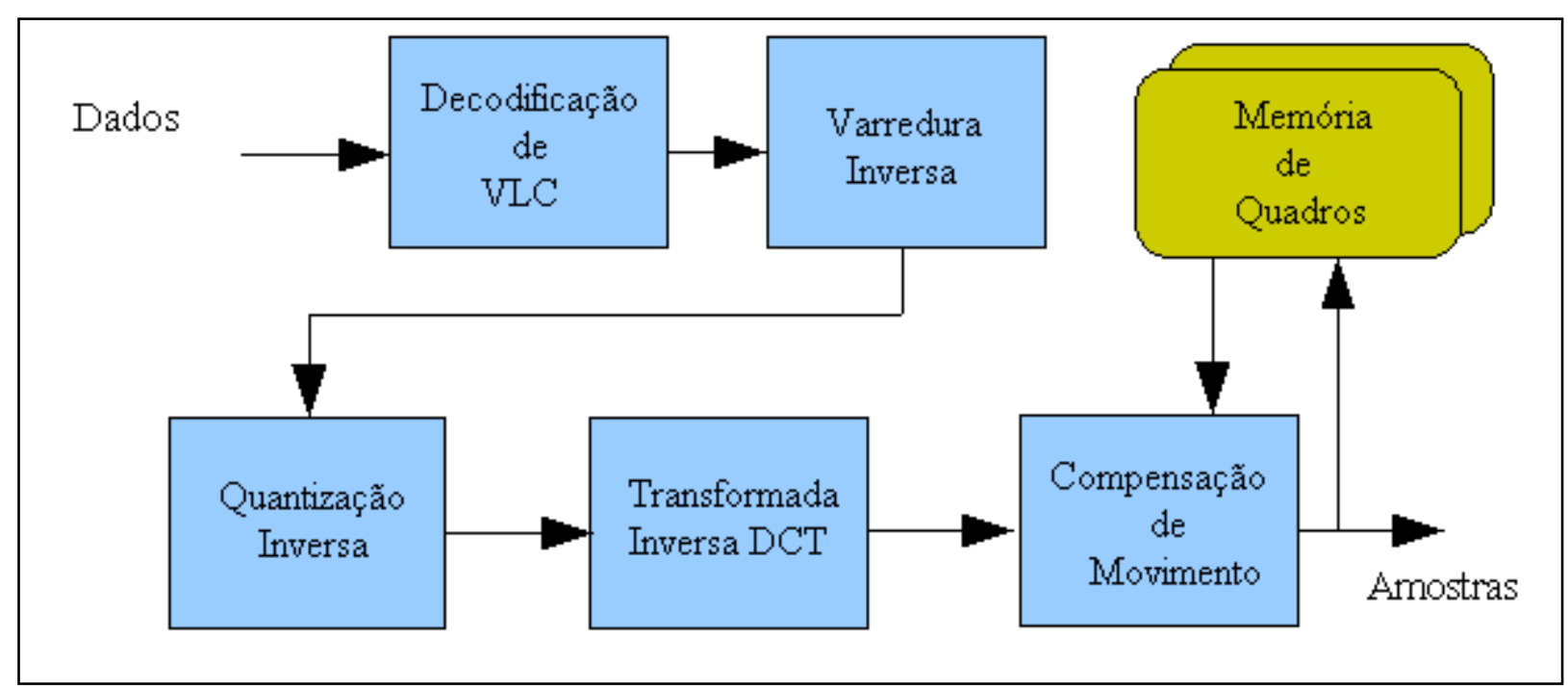

Figura 10: Processo de decodificação simplificado

A figura 10 apresenta o diagrama de blocos do processo de decodificação do MPEG2, mostrando a ordem das operações desde a entrada dos dados até a geração do fluxo de saída (amostras). 


\subsubsection{MPEG 4}

Tendo seu desenvolvimento iniciado a partir de 1993, a $1^{\text {a }}$ versão do MPEG4 surgiu em 1999 (Puri, 2000). As principais funcionalidades para as quais este padrão foi desenvolvido são:

- Eficiência de compressão: esta classe de funcionalidades consiste em melhorias de eficiência e codificação de múltiplos fluxos de dados;

- Interatividade baseada em conteúdo: funcionalidades para permitir acesso e manipulação de dados baseados em conteúdo, edição de fluxos de dados, codificação híbrida e melhorias no acesso aleatório;

- Acesso universal: incluem robustez em ambientes sujeitos a erros e escalabilidade baseada em conteúdo. Desta forma, os dados podem ser acessíveis por vários tipos de mídias com diferentes qualidades para diferentes objetos.

- $\quad$ Referido formalmente como ISO14496, o padrão MPEG4 busca satisfazer as necessidades dos autores, provedores de serviços e usuários, ao implementar ferramentas que visam maior reusabilidade, flexibilidade, proteção de conteúdos e maiores níveis de interação, comparado aos seus antecessores (MPEG1 e MPEG2).

O MPEG4 foi otimizado para taxas de 10kbits/s a 3Mbits/s, tendo sido baseado no H.263 da ITU-T. É mais completo que O H.263 pois permite diversos tipos de aplicações, possui ferramentas que permitem a codificação e integração de objetos naturais e sintéticos.

A mudança de paradigma consiste no fato do MPEG4 tratar uma cena a ser codificada como uma coleção de objetos individuais, com cada objeto podendo ser codificado individualmente.

Os objetos de mídia podem ser:

- Objetos de vídeo (ex: pessoas sem o cenário de fundo);

- Objetos de áudio (ex: vozes, músicas);

- Imagens paradas (ex: cenário de fundo);

- Objetos sintéticos; 
- Textos e gráficos;

- Sons sintéticos;

Os objetos seguem uma organização hierárquica e correspondem às folhas da árvore de hierarquia. Os objetos compostos podem abranger as sub-árvores (ex: imagem e voz de um objeto), o que permite a construção de cenas mais complexas.

\section{SISTEMAS}

A parte 1 do MPEG4 é a que representa maior distanciamento dos padrões MPEG prévios. Devido à sua natureza orientada a objetos, o MPEG4 necessitou de uma nova abordagem ao mesmo tempo em que a multiplexação e sincronização permaneciam assuntos importantes. Na sincronização o MPEG4 é capaz de lidar com grande número de fluxos oriundos de sua típica composição por múltiplos objetos. Outros fatores como gerenciamento e proteção de propriedade intelectual são tratados pela 1a versão do MPEG4.

A parte de sistemas trata a descrição do relacionamento dos componentes audiovisuais que compõem uma cena, em dois níveis principais:

- $\quad$ O formato binário para cenas (BIFS - Binary Format for Scenes) descreve o arranjo espaço temporal dos objetos na cena, que permite composição de primitivas de gráficos e nós para operadores de composição 2D e 3D;

- $\quad$ Descritores de Objetos (OD - Object Descriptors) definem o relacionamento entre os fluxos elementares pertinentes a cada objeto (ex.: fluxos de audio e video dos participantes de uma videoconferencia) e informações adicionais como: características do decodificador, propriedade intelectual e outros.

\section{CODIFICAÇÃO DE VÍDEO AVANÇADO}

A parte 10 do MPEG-4, também conhecida como padrão H.264 é um padrão orientado à melhoria de eficiência na codificação e melhor adaptação à rede, o que é atingido pela distinção entre diferentes camadas conceituais (a camada de codificação de vídeo e a camada de abstração de rede). Enquanto os formatos anteriores de vídeo utilizam blocos de tamanho de 8x8, o H.264 baseia-se primariamente em blocos de $4 \times 4$. 


\section{PLANOS DE OBJETOS DE VÍDEO E OBJETOS DE Vídeo EXTRAÇÃo E CODIFICAÇÃO}

O MPEG4 baseia-se na representação de dados de vídeo baseados em objetos. Os conceitos principais do MPEG4 são: o Objeto de Vídeo (VO - do inglês Video Object) e o Plano de Objeto de Vídeo (VOP - do inglês Video Object Plane) e suas propriedades intrínsecas como forma, textura e movimento. O MPEG4, entretanto, não descreve meios de criar VOs, mas sim a convenção padronizada de descrevêlos para que os decodificadores compatíveis possam decodificá-los.

Os VOPs são codificados de forma similar aos padrões MPEG anteriores. A codificação dos VOPs é implementada em termos de macroblocos (blocos de 16x16 pixels) de formas arbitrárias, contendo dois tipos básicos de informação associados a eles: forma e textura. A informação de forma é especificada em dois componentes: Uma matriz de níveis binários que define quais pixels pertencem ou não ao VOP e uma matriz de transparência para cada pixel em tons de cinza, cujos valores vão de 0 (totalmente transparente) a 255 (opaco). A informação de textura é informada por meio de uma componente de luminância $(\mathrm{Y})$ e dois de crominância $(\mathrm{U}, \mathrm{V})$.

Em cenas naturais, VOPs são obtidos por segmentação semi-automática ou automática. A representação da informação de forma pode ser feita através de máscara de forma binária. Os VOs podem também ser subdivididos em representações múltiplas ou camadas de objetos de vídeo (VOL's - do inglês Video Object Layers), permitindo representações escaláveis de objetos de vídeo. Se a cena inteira é considerada um objeto e todos os VOP's forem retangulares e do mesmo tamanho como cada imagem, então um VOP é idêntico a imagem. Adicionalmente, grupos de planos de objetos de vídeo (GOV - Group of Video Object Plane) opcionais podem ser adicionados à estrutura de codificação de vídeo para ajudar nas operações de acesso aleatório.

A codificação básica do MPEG4 emprega compensação de movimento e transformada DCT. A definição dos macroblocos é idêntica ao MPEG1 e MPEG2. 


\section{CODIFICAÇÃO DE SPRITES E COMPENSAÇÃO DE MOVIMENTO GLOBAL}

Em gráficos de computadores, um sprite é uma imagem gráfica que pode ser animada ou movida individualmente dentro de uma imagem ou grupo de imagens maiores. No contexto do MPEG4, um sprite é geralmente um objeto de vídeo modelado por um movimento coerente. No caso de vídeos naturais, um sprite é tipicamente uma imagem composta resultante da mistura de pixels pertencentes a várias instancias temporais do objeto de vídeo. No caso de vídeos sintéticos, é simplesmente um objeto gráfico. O processo de geração de sprites não é, entretanto, especificado pelo padrão MPEG4. 


\subsubsection{AVI}

O formato AVI (Audio/Video Entrelaçado) é um formato definido pela Microsoft em 1992 para executar vídeos entrelaçados no Windows 95, sem hardware especializado. Os dados de vídeo são entrelaçados com dados de áudio em cada quadro, no arquivo que contém a seqüência de movimentos, de forma que o conteúdo de áudio permaneça sincronizado ao vídeo. O formato AVI não é um ambiente aberto e extensível, e necessita de maior detalhamento para ambientes de edição (Robbins, 2006; Vaughan, 2006) e foi substituído pelo Windows Media como padrão para o Windows.

Em geral, os arquivos $\mathrm{AVI}$ contém múltiplos fluxos de diferentes tipos de dados. A maioria das seqüências usa ambos os fluxos de áudio e vídeo. Os arquivos AVI usam o formulário AVI RIFF, que é identificado pelo código 'AVI'. Todos os arquivos incluem duas listas obrigatórias de trechos, que definem o formato do fluxo de dados e os dados.

A listagem seguinte mostra um exemplo de estrutura de um arquivo AVI (DV Data in the AVI File Format Specification, Version 1.01 - Microsoft Corporation - June 25, 1997):

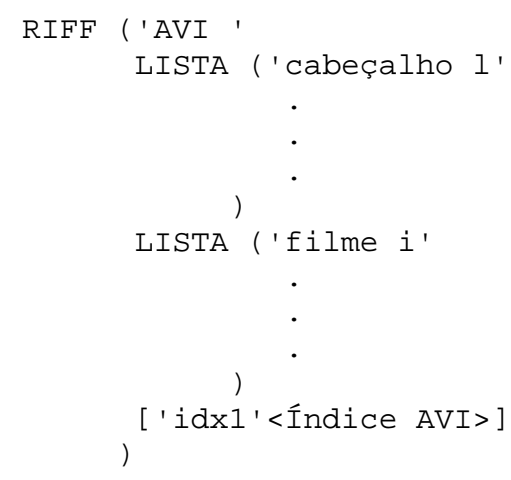




\subsubsection{WMV/VC1}

Lançado em 2003, o Windows Media Vídeo 9 (WMV), é uma implementação do padrão VC-1 (Loomis, Wasson, 2007). O codec VC-1 foi projetado para taxas entre 10Kbps a 135Mbps e de resoluções entre 160x120 até 2048x1536 pixels.

A funcionalidade básica do VC-1 envolve compensação de movimentos baseada em blocos e transformada espacial similar a utilizada desde o padrão MPEG1 e H261.

\section{NÍVEIS E PERFIS}

O VC-1 apresenta três possíveis perfis: Simples, Principal e Avançado. Nos perfis Simples e Principal, uma seqüência consiste em uma série de uma ou mais imagens codificadas (figura 11). No perfil avançado, uma seqüência consiste de uma série de um ou mais segmentos de ponto de entrada, onde cada segmento de ponto de entrada é uma série de uma ou mais imagens, sendo que a primeira imagem de cada segmento de ponto de entrada provê acesso aleatório. Uma fatia contém uma ou mais linhas contíguas de macroblocos.

O perfil determina as características do codec que estão disponíveis, determinando a complexidade requerida do decodificador. A tabela 5 lista os perfis e níveis do VC1 , bem como os bitrates para cada perfil. No VC-1, além dos quadros I, P e B, cada imagem pode ser codificada também como BI (Bidirecional Intra). Uma Imagem BI é uma imagem $B$ que contem somente macroblocos intra-codificados.

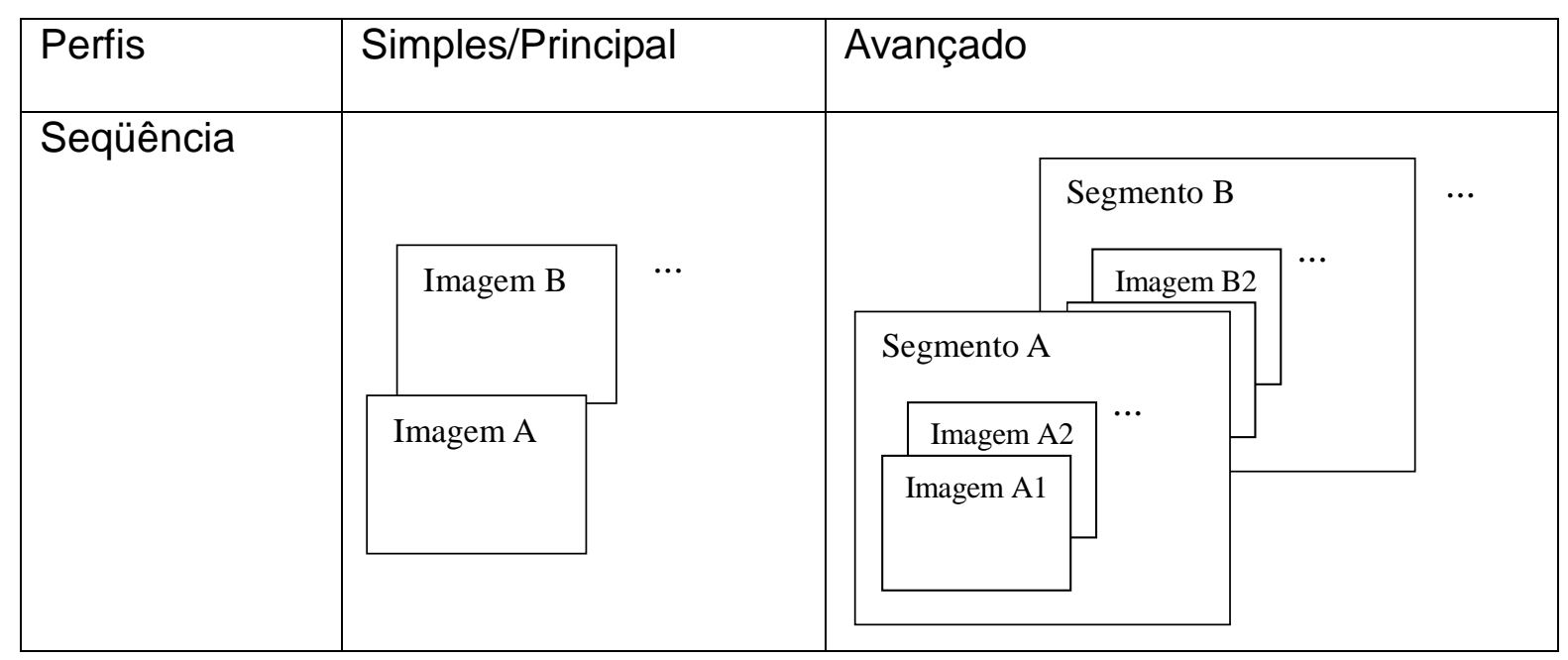

Figura 11: Perfis e seqüências do VC-1 
Tabela 5: Perfis e níveis do VC-1

\begin{tabular}{|c|c|c|c|}
\hline Perfil & Nível & $\begin{array}{l}\text { Taxa de Bits } \\
\text { máxima }\end{array}$ & $\begin{array}{c}\text { Resoluções Representativas } \\
\text { por Taxa de Quadros }\end{array}$ \\
\hline \multirow[t]{3}{*}{ Simples } & Baixo & $96 \mathrm{~kb} / \mathrm{s}$ & 176x144@15Hz (QCIF) \\
\hline & Médio & $384 \mathrm{~kb} / \mathrm{s}$ & 240x176@30Hz \\
\hline & & & $352 \times 288 @ 15 \mathrm{~Hz}$ \\
\hline \multirow[t]{4}{*}{ Principal } & Baixo & $2 \mathrm{Mb} / \mathrm{s}$ & $320 x 240 @ 24 \mathrm{~Hz}$ \\
\hline & Médio & $10 \mathrm{Mb} / \mathrm{s}$ & $720 x 480 @ 30 \mathrm{~Hz}$ \\
\hline & & & $720 x 576 @ 25 \mathrm{~Hz}$ \\
\hline & Alto & $20 \mathrm{Mb} / \mathrm{s}$ & 1920x1080@30Hz \\
\hline \multirow[t]{10}{*}{ Avançado } & LO & $2 \mathrm{Mb} / \mathrm{s}$ & $352 x 288 @ 30 \mathrm{~Hz}$ \\
\hline & L1 & $10 \mathrm{Mb} / \mathrm{s}$ & 720x480@30Hz \\
\hline & & & $720 x 576 @ 25 \mathrm{~Hz}$ \\
\hline & $\mathrm{L} 2$ & $20 \mathrm{Mb} / \mathrm{s}$ & 720 x $480 @ 60$ Hz (480p) \\
\hline & & & 1280 x $720 @ 30$ Hz (720p) \\
\hline & L3 & $45 \mathrm{Mb} / \mathrm{s}$ & $\begin{array}{c}1920 \text { x } 1080 @ 24 \mathrm{~Hz} \\
(1080 p)^{\star}\end{array}$ \\
\hline & & & 1920 x $1080 @ 30$ Hz (1080i) \\
\hline & & & 1280 x $720 @ 60$ Hz (720p) \\
\hline & L4 & $135 \mathrm{Mb} / \mathrm{s}$ & $\begin{array}{c}1920 \times 1080 @ 60 \mathrm{~Hz} \\
(1080 \mathrm{p})^{*}\end{array}$ \\
\hline & & & 2048 x $1536 @ 24$ Hz \\
\hline
\end{tabular}




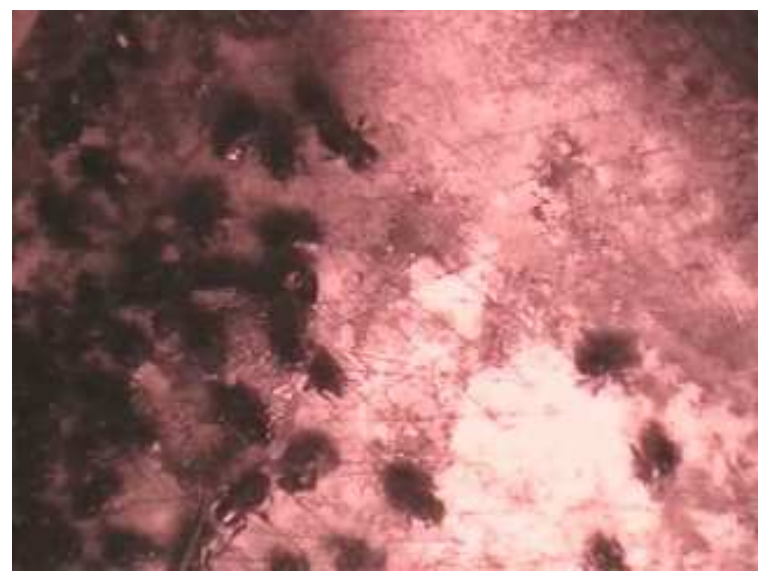

(a)

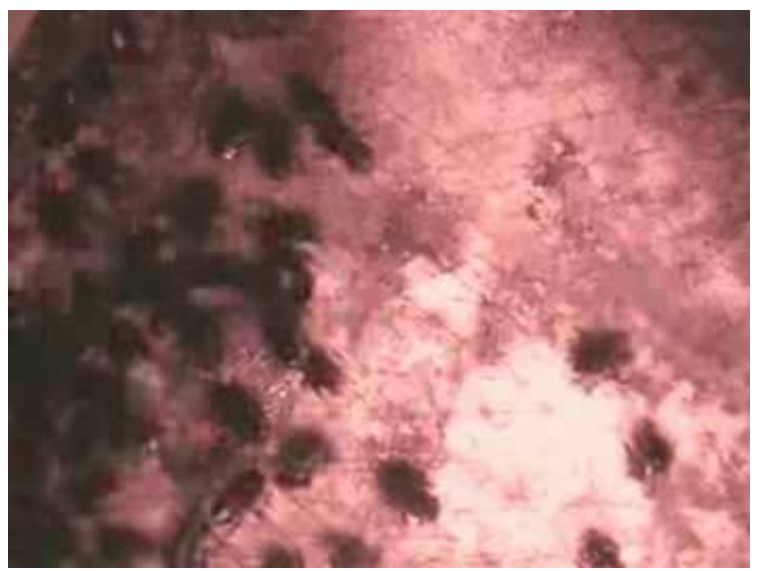

(b)

Figura 12: Comparação entre o vídeo sem compressão (a) e após compressão com o WMV9 a $92 \mathrm{kbps}$ (b).

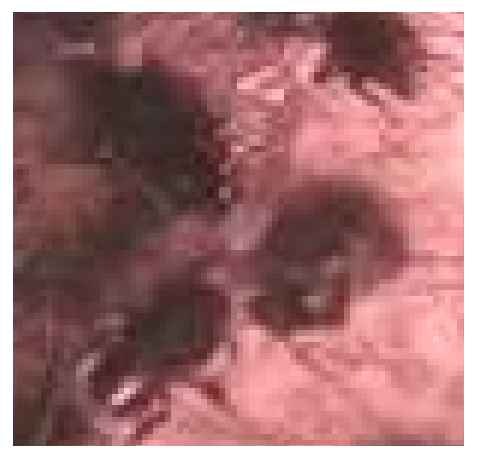

(c)

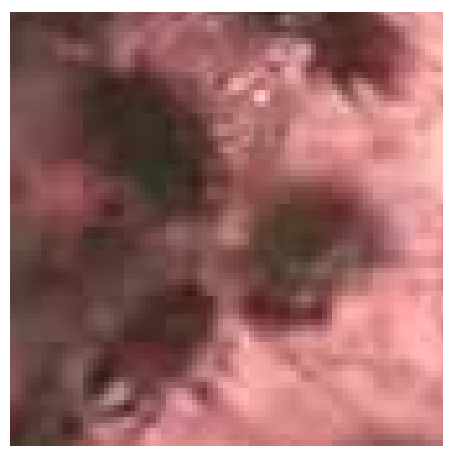

(d)

Figura 13: Detalhe ampliados da figura 13

Nas figuras 12, e 13 são mostrados quadros de um mesmo vídeo e em um mesmo instante do interior de uma colméia, sem compressão e após a compressão com o padrão WMV9 a taxa de 92kbps. 


\subsection{MÉTRICAS PARA AVALIAÇÃO DE QUALIDADE DE IMAGENS}

As diversas características envolvidas nos vídeos necessitam ser parametrizadas para que seja possível avaliar os CODECs de vídeo com relação à qualidade das imagens. Desta forma, é necessário avaliar objetivamente a qualidade das imagens do vídeo gerado. Dentre as diversas métricas existentes para avaliar objetivamente os codecs, após o processo de compressão e descompressão, as mais utilizadas são:

- Erro Quadrático Médio (MSE)

- Relação de Sinal Ruído de Pico (PSNR)

- Similaridade Estrutural (SSIM)

Introduzida mais recentemente, a Similaridade Estrutural tem sido mais citada por ser considerada mais adequada devido às características das imagens naturais e do sistema visual humano, conforme apresentado nos itens 3.2.1. e 3.2.2.

\subsubsection{RELAÇÃO SINAL-RUÍDO DE PICO (PSNR) E ERRO QUADRÁTICO MÉDIO (MSE)}

Sejam: $\quad F=I m a g e m$ de entrada, de dimensões $j \times k$

$\mathrm{F}^{\prime}=$ Imagem de saída, ou processada, de dimensões $j \times k$

O erro quadratico médio (MSE) é dado por:

$$
M S E=\sum \sum \frac{\left(F(j, k)-F^{\prime}(j, k)\right)^{2}}{(j \times k)}
$$

E o valor da relação de sinal ruído de pico (PSNR):

$$
P S N R=10 \times \log \left(\frac{255^{2}}{M S E}\right)
$$

Para imagens coloridas, deve-se calcular os valores para os 3 componentes (RGB), divididos por $3 \times j \times k$. 


\subsubsection{SIMILARIDADE ESTRUTURAL (SSIM)}

O princípio fundamental implícito nas tentativas de se avaliar a qualidade de imagens é o fato de o HVS ser altamente adaptado para extrair informações estruturais de uma cena visual, portanto, uma métrica de similaridade ou distorção estrutural deverá prover uma boa aproximação da qualidade perceptível da imagem. A SSIM é um framework para projeto de métrica de qualidade que se baseia na adaptação do HVS para extração de informações estruturais, ela avalia as alterações estruturais diretamente a partir de dois sinais complexos.

Podem haver diferentes definições de informação estrutural e distorção estrutural. A SSIM (Wang et al, 2003; Mai et al, 2005) utilizada neste trabalho é uma implementação específica da perspectiva de formação de imagem.

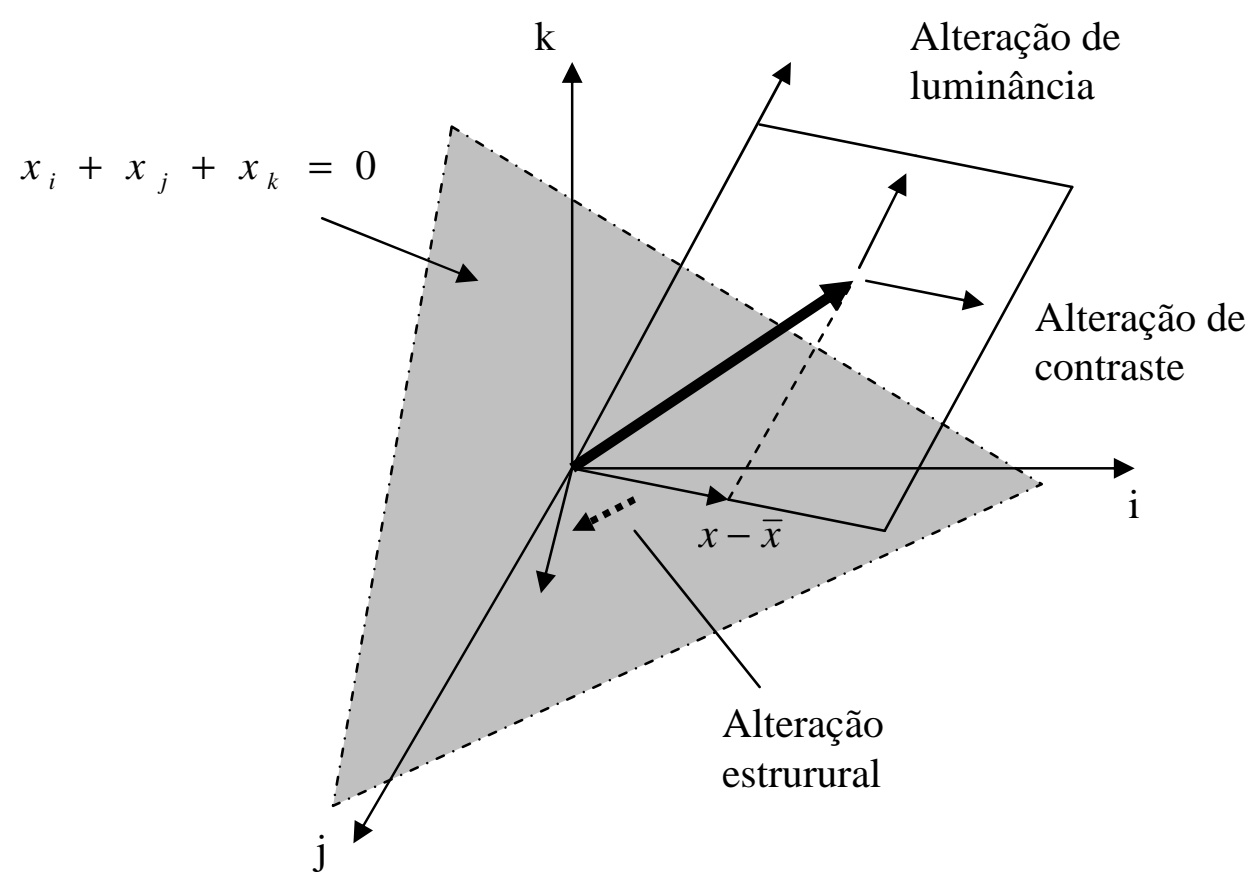

Figura 14: Separação de luminância, contraste e alterações estruturais de uma imagem $x$ de referência no espaço para um espaço tridimensional

A figura 14 ilustra como as alterações de luminância e contraste podem ser separadas de distorções estruturais no espaço de imagens. Alterações de luminância podem ser caracterizadas por movimentos ao longo da direção definida 
por $x_{1}=x_{2}=\ldots=x_{N}$. Alterações de contraste são definidas pela direção $x-\bar{x}$. A formulação da Similaridade Estrutural é dada a seguir:

Inicialmente, a luminosidade de cada sinal é estimada como uma intensidade média: $\mu_{x}=\bar{x}=\frac{1}{N} \sum_{t=1}^{N} X i$

A função de comparação $l(x, y)$ de luminância é uma função de $\mu_{x}$ e $\mu_{y}$

$$
l(x, y)=l\left(\mu_{x}, \mu_{y}\right)
$$

A seguir, é removido o valor médio de intensidade do sinal, conforme a figura 14 . Utilizamos o desvio padrão como estimativa de contraste:

$$
\sigma_{x}=\left(\frac{1}{N-1} \sum_{i=1}^{N}\left(x_{i}-\mu_{x}\right)^{2}\right)^{\frac{1}{2}}
$$

A comparação de contraste $c(x, y)$ é, portanto, a comparação de $\sigma_{x}$ e $\sigma_{y}$ :

$$
c(x, y)=c\left(\mu_{x}, \mu_{y}\right)
$$

O sinal é normalizado para que tenha desvio padrão unitário e a comparação é feita entre os sinais normalizados:

$$
s(x, y)=s\left(\frac{x-\mu_{x}}{\sigma_{x}}, \frac{y-\mu_{y}}{\sigma_{y}}\right)
$$

E os componentes são combinados para gerar a métrica geral de similaridade:

$$
S(x, y)=f(l(x, y), c(x, y), s(x, y))
$$

As três funções $l(x, y), c(x, y), s(x, y)$ são definidas de forma que satisfaçam as seguintes condições:

1- Simetria: $S(x, y)=S(y, x)$ a ordem de entrada dos sinais não deve afetar o resultado.

2- Ligação: $\quad S(x, y) \leq 1$ uma ligação superior pode servir como indicação de sinais perfeitamente idênticos. Em geral, estas métricas não são 
ligadas.

3- Máximo único: $S(x, y)=1$ se e se $x=y$ a métrica quantifica quaisquer variações existentes entre os sinais de entrada.

Os sinais de luminância, contraste e comparação da medida de estrutura são dados por:

$$
\begin{aligned}
& l(x, y)=\frac{2 * \mu_{x} * \mu_{y}+c_{1}}{\mu_{x}^{2}+\mu_{y}^{2}+c_{1}} \\
& c(x, y)=\frac{2 * \sigma_{x} * \sigma_{y}+c_{2}}{\sigma_{x}^{2}+\sigma_{y}^{2}+c_{2}} \\
& l(x, y)=\frac{\sigma_{x y}+c_{3}}{\sigma_{x} * \sigma_{y}+c_{3}}
\end{aligned}
$$

Onde: $c_{1}, c_{2}$ e $c_{3}$ são constantes dadas por:

$c_{1}=\left(K_{1} * L\right)^{2}, c_{2}=\left(K_{2} * L\right)^{2} \mathrm{e}^{c_{3}=c_{2} / 2}$

$L$ : faixa de valores dinâmicos dos valores dos pixels $(L=255 p / 8$ bits por pixel em imagens cinza), $K_{1}<<1$ e $K_{2}<<1$ são constantes escalares. Portanto a SSIM entre um sinal $x$ e $y$ é:

$$
\operatorname{SSIM}(x, y)=\left[l(x, y)^{2}\right]^{\alpha} *[c(x, y)]^{\beta} *[s(x, y)]^{\gamma}
$$

Onde: $\alpha, \beta$ e $\gamma$ são parâmetros que definem a importância relativa dos três componentes. Especificamente, se ajustarmos $\alpha=\beta=\lambda=1$, o SSIM resultante fica:

$$
\operatorname{SSIM}(x, y)=\frac{\left(2 * \mu_{x} * \mu_{y}+c_{1}\right) *\left(2 * \sigma_{x y}+c_{2}\right)}{\left(\mu_{x}^{2}+\mu_{y}^{2}+c_{1}\right) *\left(\sigma_{x}^{2}+\sigma_{y}^{2}+c_{2}\right)}
$$

Neste trabalho foi utilizada a métrica SSIM que é citada como sendo de melhor qualidade (Wang, 2003). Um breve estudo comparativo sobre a qualidade obtida após a aplicação de padrões de compressão MPEG1, MPEG2, MPEG4, WMV e Theora (Amâncio, Hirakawa, 2006), por meio das métricas SSIM e PSNR 
demonstrou que os resultados são semelhantes para os mesmos, uma vez que, os CODECs utilizam praticamente os mesmos mecanismos em suas versões comerciais. Os vídeos foram capturados a resoluções de $352 \times 240$ pixels, no Instituto de Biociências da USP, em taxas elevadas de compressão para geração de fluxos de baixas taxas de bits. A baixa qualidade verificada dificulta a observação e identificação das abelhas. O gráfico 1 apresenta os valores médios (média dos valores obtidos para todos os quadros do vídeo testado) de SSIM para taxas de bits na faixa dos 64 a $384 \mathrm{kbps}$.

\section{Valores médios de SSIM}

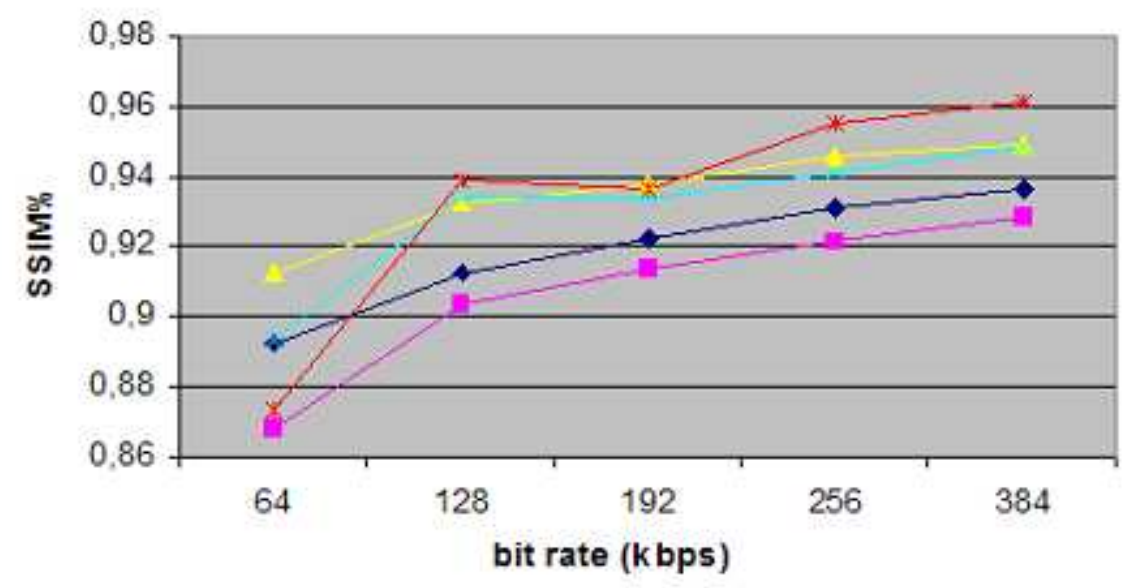

$\rightarrow-$ Mpeg1 $\rightarrow$ Mpeg2 $\_$Mpeg4 Theora $*$ WMV9

Grafico 1: Valores de SSIM obtidos para diferentes codecs em um vídeo de resolução de $352 \times 240$ pixels (Amâncio; Hirakawa, 2006) 


\subsection{ALGORITMOS DE IDENTIFICAÇÃO E RASTREAMENTO DE OBJETOS EM VÍDEOS DIGITAIS}

Objetos em movimento são geralmente caracterizados por um movimento coerente que se distingue da imagem de fundo. O movimento é, portanto, uma característica útil para segmentar seqüências de vídeo, principalmente quando complementado por outras características, tais como cor, bordas, intensidade, etc (Giusto et al, 2002).

Os padrões MPEG-1, MPEG-2, H.261 e H.263 são técnicas de baixo nível, que não realizam tarefas de segmentação ou análise de cenas. O padrão MPEG-4 permite funções baseadas em conteúdo ao introduzir o conceito de planos de objetos de vídeo (VOPs). As aplicações de vídeo baseadas em conteúdo utilizam a segmentação e rastreamento de objetos como tarefas básicas na identificação e rastreamento de objetos.

A segmentação pode ser realizada do cenário de fundo com relação aos objetos em movimento que serão rastreados. Para cenários de fundo estáticos, pode-se utilizar a subtração de quadros com conteúdo de um modelo do cenário de fundo sem objetos de interesse. Entretanto, esta técnica está sujeita a interferências devido às alterações de iluminação, tremores e ruídos. Para a separação do cenário de fundo, a utilização de mapas binários, técnicas de detecção de bordas (Kim et al, 2002, Izquierdo et al 2002, Kalafatic et al) assim como o Fluxo Óptico (item 3.4.) são bastante conhecidas e citadas como úteis em ambientes monitorados, requerendo elevado processamento. O rastreamento de objetos envolve ainda a manutenção efetiva da identificação ao longo do tempo, que requer que sejam tratadas ocorrências como oclusões, ruídos, etc. Processos com a utilização de determinados filtros de partículas demonstram um melhor rastreamento ao longo do tempo por serem robustos em ambientes desordenados. Os filtros de partículas utilizam múltiplas hipóteses simultaneamente, com modelos probabilísticos de movimento para prever posições. 


\subsection{FLUXO ÓPTICO}

O fluxo óptico, ou campo de velocidade instantânea, é definido como movimento aparente do padrão de brilho no plano 2D da imagem (HORN, 1981), sendo calculado a partir de imagens em movimento. O fluxo óptico é utilizado como etapa fundamental em processamento de imagens seqüenciais, sendo utilizada em tarefas como interpretação de cenas, navegação exploratória, segmentação de objetos, visão de robôs, avaliação de tempo para colisão e outros.

Campos de fluxos ópticos identificam o movimento aparente, ou seja, alterações na intensidade da imagem ao longo do tempo. O campo é mostrado graficamente em um diagrama chamado de mapa de agulhas (needle map). Movimentações reais, que significam translações no espaço 2D ao longo do tempo são mais difíceis de serem detectadas, uma vez que estão sujeitas as alterações de iluminação, inexistência de texturas e ruídos.

Sendo computado a cada ponto da imagem, a porcentagem de pontos sem movimento ou com movimento global simples no fluxo óptico é geralmente alta, desta forma é mais eficiente e econômico localizar e focalizar a análise nas áreas que apresentam movimentação. Com cenários de fundo praticamente estáticos é possível removê-los por meio de uma operação de diferenças simples. Este método é usado principalmente na segmentação para codificação baseada em objetos e conteúdos, evitando assim a computação de gradientes diferenciais do fluxo óptico, que não é confiável (Zhang; Lu). 


\subsection{DISCUSSÃO SOBRE CODIFICAÇÃO DE VÍDEO}

Os diversos padrões de compressão apresentados nesse capítulo utilizam técnicas de compressão em comum, tendo os padrões mais recentes, como o MPEG4 e o WMV apresentado melhores resultados com relação à qualidade medida pela SSIM e foram desenvolvidos considerando sua utilização em aplicações para a Internet (tabela 6). Estes padrões normalmente apresentam elevados bitrates e quando aplicados a vídeos para obter altas taxas de compressão, os CODECs causam grandes reduções na qualidade objetiva medida, que pode dificultar a visualização de detalhes (Gráfico 1) das abelhas.

Tabela 6: Padrões, resoluções e aplicações típicas

\begin{tabular}{|c|c|c|c|c|}
\hline & MPEG1 & MPEG2 & MPEG4 & WMV9 \\
\hline Resolução & $352 \times 240$ & $352 \times 288 a$ & Variadas & $160 \times 120$ a $2048 \times 1536$ \\
\hline Recomendada & (CIF) & $1920 \times 1152$ & & \\
\hline $\begin{array}{l}\text { Aplicações } \\
\text { Típicas }\end{array}$ & VCD & TV, DVD & $\begin{array}{c}\text { Internet, HDDVD, } \\
\text { TV }\end{array}$ & Internet, HDDVD \\
\hline $\begin{array}{l}\text { Otimizado para } \\
\text { taxas de }\end{array}$ & $\begin{array}{l}1 \text { a } 1,5 \\
\text { Mbps }\end{array}$ & 4 a $100 \mathrm{Mbps}$ & 10kpbs a 3Mbps & 10kbps a 135Mbps \\
\hline
\end{tabular}

$\mathrm{Na}$ aplicação ao weblab de abelhas, os efeitos de blurring (efeito de borramento causado nas bordas da imagem quando ocorre compressão excessiva) e blocking (resultado da quantização dos coeficientes da DCT, medidos como bordas de blocos com grande degrau de transição em contraposição às bordas naturais que são suaves) dificultam ou impedem a correta identificação destas (Figura 13).

Conforme Dong, e Ngan, vídeos que contenham riqueza de detalhes assim como grandes regiões homogêneas apresentam grande variação na correlação espacial (como os em HD) e podem se beneficiar do uso de transformadas de blocos de tamanho variável. Os sistemas de codificação existentes utilizam blocos de tamanho máximo de até $8 \times 8$ pixels, os autores demostraram em seu estudo que transformadas de blocos maiores apresentam grande eficiiencia na codificação em tais condições. 
Nos CODECS comercialmente disponíveis, a taxa de bits é mantida em torno do valor definido, mesmo quando não há movimentação observada nos vídeos. Aplicando-se a segmentação de objetos, baseada nas alterações, é possível reduzir ainda mais este valor quando não ocorrem alterações na imagem, e conseqüentemente, não realizar o envio de imagens estáticas. A aplicação de tamanhos de blocos variáveis também é pode reduzir a taxa de bits (Wien, 2003). $O$ padrão MPEG4 apresenta, em sua especificação, a segmentação de objetos e planos para compor uma cena, entretanto, tal característica não está facilmente disponível para uso público, devendo ser implementada considerando-se as condições específicas da aplicação e das imagens.

As aplicações típicas de segmentação de vídeo, que podem incluir vigilância em diversos cenários (tráfego, segurança, monitoramento entre outros), apresentam como característica crucial a qualidade da segmentação (Jiang et al, 2006), não havendo um sistema que comporte os diferentes modelos de cenários de fundo, além disso, é comum a necessidade de se balancear a robustez do sistema (qualidade) contra a performance do mesmo (taxa de quadros, resolução, etc). 


\section{ALGORITMO PARA SEGMENTAÇÃO E COMPRESSÃO DE VÍDEO}

Considerando-se os processos de codificação de vídeo existentes e as necessidades específicas da aplicação em Weblab de abelhas, a proposta da aplicação do processo de segmentação de imagens surge como alternativa para melhorar a qualidade dos vídeos deste laboratório, principalmente na região em que as abelhas se encontram. $O$ algoritmo baseia-se na separação entre os objetos em movimento e o plano de fundo estático, aplicando-se a compressão destes elementos separadamente, são eliminadas as imagens repetidas ou com poucas alterações, tendo como resultados listas de localidades com movimentos, objetos de vídeo e planos de fundo. Dentre as características da proposta, pode-se destacar a realização da segmentação das imagens de abelhas do fundo, a compressão da imagem de fundo de forma acentuada (uma vez que não requer qualidade) e de forma menos intensa na região de interesse de forma a manter a qualidade para a pesquisa.

Os vídeos utilizados para teste do algoritmo proposto foram originalmente obtidos por meio de uma câmera digital de resolução de 720x480 pixels e armazenados no formato AVI sem compressão, tendo sido redimensionados para a resolução de $352 \times 288$ para realização de testes. 


\subsection{CONFIGURAÇÃO DA COLMÉIA}

Os vídeos aos quais o algoritmo foi aplicado foram obtidos no weblab de abelhas do Instituto de Biociências da USP, participante do ViNCES. Atualmente, este laboratório realiza a transmissão de fluxos de vídeo via Internet em uma estrutura conforme apresentada nas figura 15 e 16, em resoluções de 320x240 e 160×120 pixels, a taxas de 15 e 30 quadros por segundo.

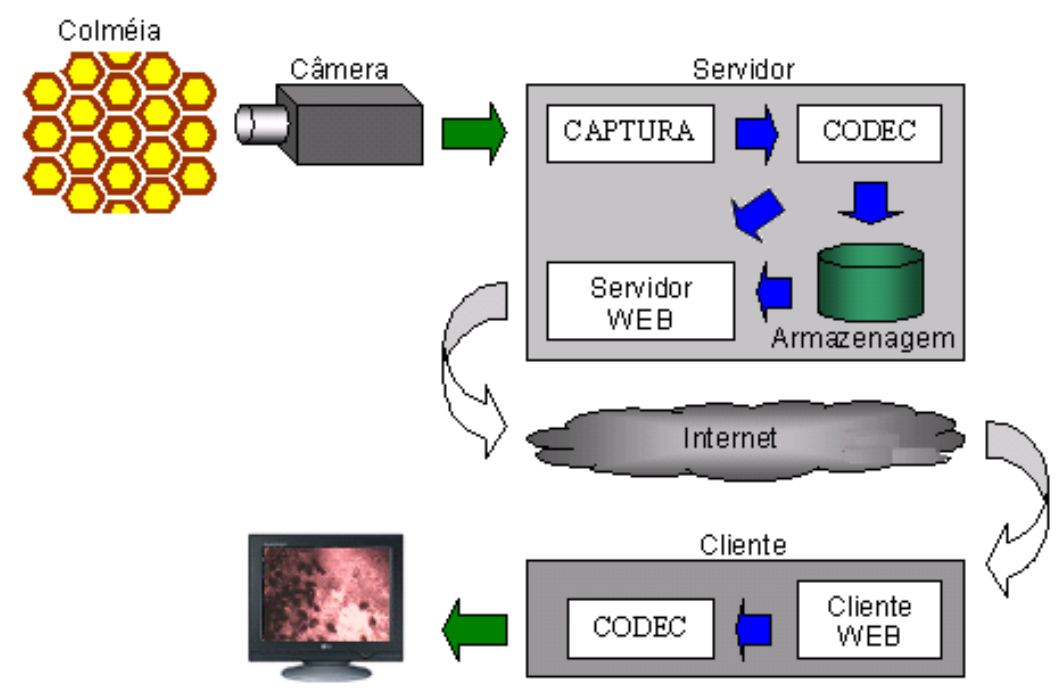

Figura 15: Estrutura da transmissão de vídeo do BBBee

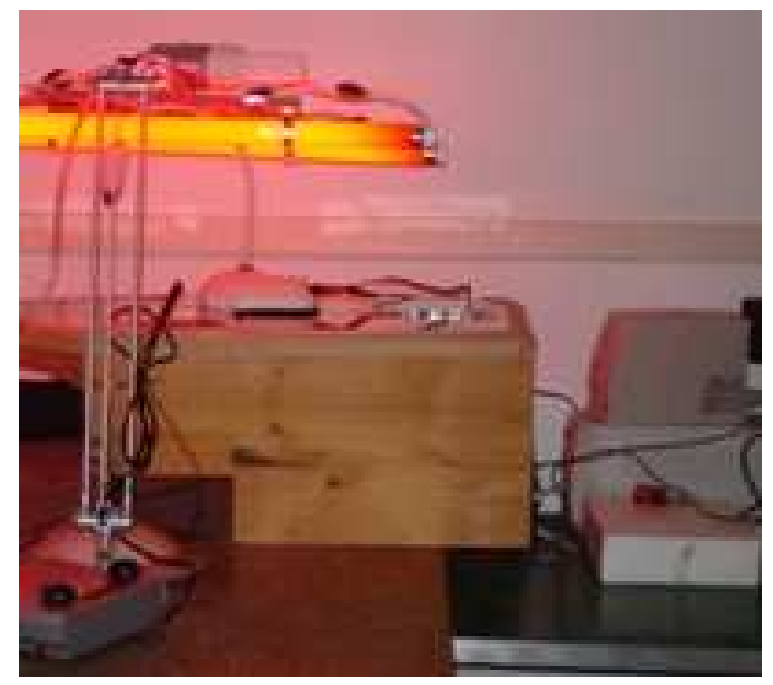

(a)

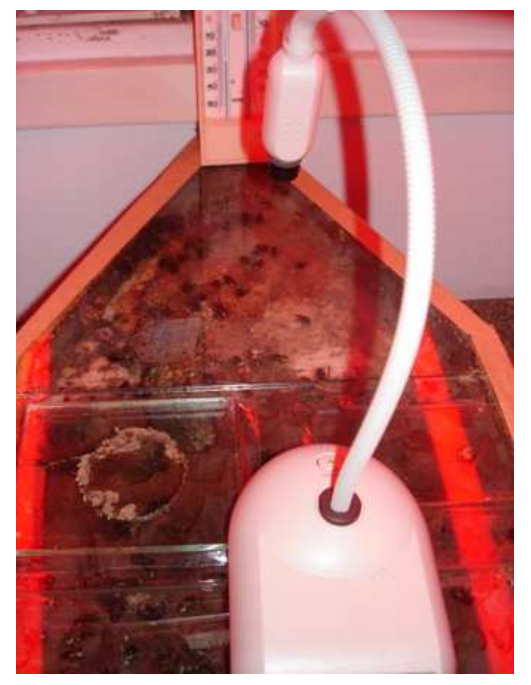

(b)

Figura 16: Estrutura do weblab BBBee do Laboratório de Abelhas do IB: (a) vista lateral; (b) - vista superior do arranjo da colméia, câmera e lâmpada 
O vídeo transmitido pela Internet via weblab é obtido por uma câmera Sony modelo CCD-PC1, instalada em um computador Pentium IV $3.0 \mathrm{GHz}$, com 1Gb RAM, e comprimido no formato WMV9 a taxas de até $512 \mathrm{kbps}$. A configuração física atual desta colméia é apresentada na Figura 16. Devido ao fato das abelhas serem sensíveis a determinados espectros de luz (Figura 16a), a iluminação deste ambiente é feita por uma lâmpada halógena equipada com filtro de cor vermelha. $A$ câmera está posicionada de forma a filmar a entrada da colméia (área de recrutamento) que é coberta por uma tampa de vidro (Figura 16b). O local não possui outras fontes de iluminação, desta forma, as imagens são compostas somente por tonalidades de vermelho. A entrada da colméia possui dimensões de cerca de $30 \mathrm{~cm}$ por $30 \mathrm{~cm}$ e o tamanho das abelhas desta espécie costuma ser em torno de $1 \mathrm{~cm}$ a $2 \mathrm{~cm}$.

As características das imagens apresentadas nos vídeos dependem dos parâmetros de instalação da câmera (posição e zoom), variando também de acordo com a resolução em que são capturadas. O algoritmo foi aplicado em vídeos de resoluções de $352 \times 288$ e $740 \times 480$ pixels. O algoritmo desenvolvido foi testado para diversos trechos de vídeos com quantidades variadas de abelhas em movimento. 


\subsection{FORMATO DE COMPRESSÃO E ALGORITMOS}

Considerando-se as características dos vídeos sem compressão obtidos do BBBee, a cena foi definida como sendo composta basicamente por: um plano de fundo estático e os objetos em movimento (abelhas). O principal fator que diferencia 0 fundo da colméia das abelhas é a ausência de movimentos. Estes movimentos podem ser detectados através da aplicação de fluxo óptico ou pela subtração entre quadros separados temporalmente (Giusto et al, 2002). Por motivos de simplicidade computacional, a subtração de planos é realizada para alguns quadros selecionados no GOP, sem que sejam realizadas operações de busca, uma vez que tais algoritmos (por exemplo o BMA - Block Matching Algorithm) exigem grande computação (Zhu, Li).

A utilização de blocos de tamanho variável é citada como uma forma de melhorar a qualidade de vídeos ao mesmo tempo em que se realiza economia de taxas de bits. Wien, em 'Variable Block-Size Transforms for H.264/AVC' apresentou economias de até $12 \%$ nas taxas e $0,9 \mathrm{~dB}$ na relação sinal-ruído de pico, Dong e Ngan, apresentam em '16 Integer Cosine Transform for HD Video Coding' ganhos de 0,2dB na codificação de conteúdo HD, desta forma, o tamanho do bloco foi definido em função do tamanho das abelhas observadas no vídeo.

Objetivando-se obter maior compressão nos vídeos e melhorias de qualidade nas regiões de interesse, somente os blocos relacionados aos locais onde houve movimentação são gravados e comprimidos. Pretende-se que as taxas de compressão e a qualidade do codec desenvolvido sejam variáveis, e em condições de baixa movimentação, superiores à dos padrões WMV9 e MPEG4. 


\subsection{ALGORITMO DE COMPRESSÃO DESENVOLVIDO}

$\mathrm{Na}$ figura 17 é mostrada a estrutura do algoritmo proposto. Este algoritmo foi elaborado baseado no processo de compressão do MPEG, em que, para um grupo de quadros, é armazenada uma imagem de referência, sobre a qual é aplicada compressão no formato JPEG (compressão intra).

Com base nesta imagem de referência, são realizadas operações de subtração com os quadros posteriores daquele GOP para verificar em quais pontos houve alterações superiores a um threshold. Valores acima deste limiar são considerados como tendo alterações suficientes para gravar o trecho naquela localidade. Posteriormente, para cada um dos trechos gravados, é realizada a compressão MPEG4 utilizando somente quadros I (de maior qualidade) para redução da quantidade de dados necessária (Figura 18). A informação de posicionamento de cada objeto é registrada para permitir a posterior reconstrução do vídeo.

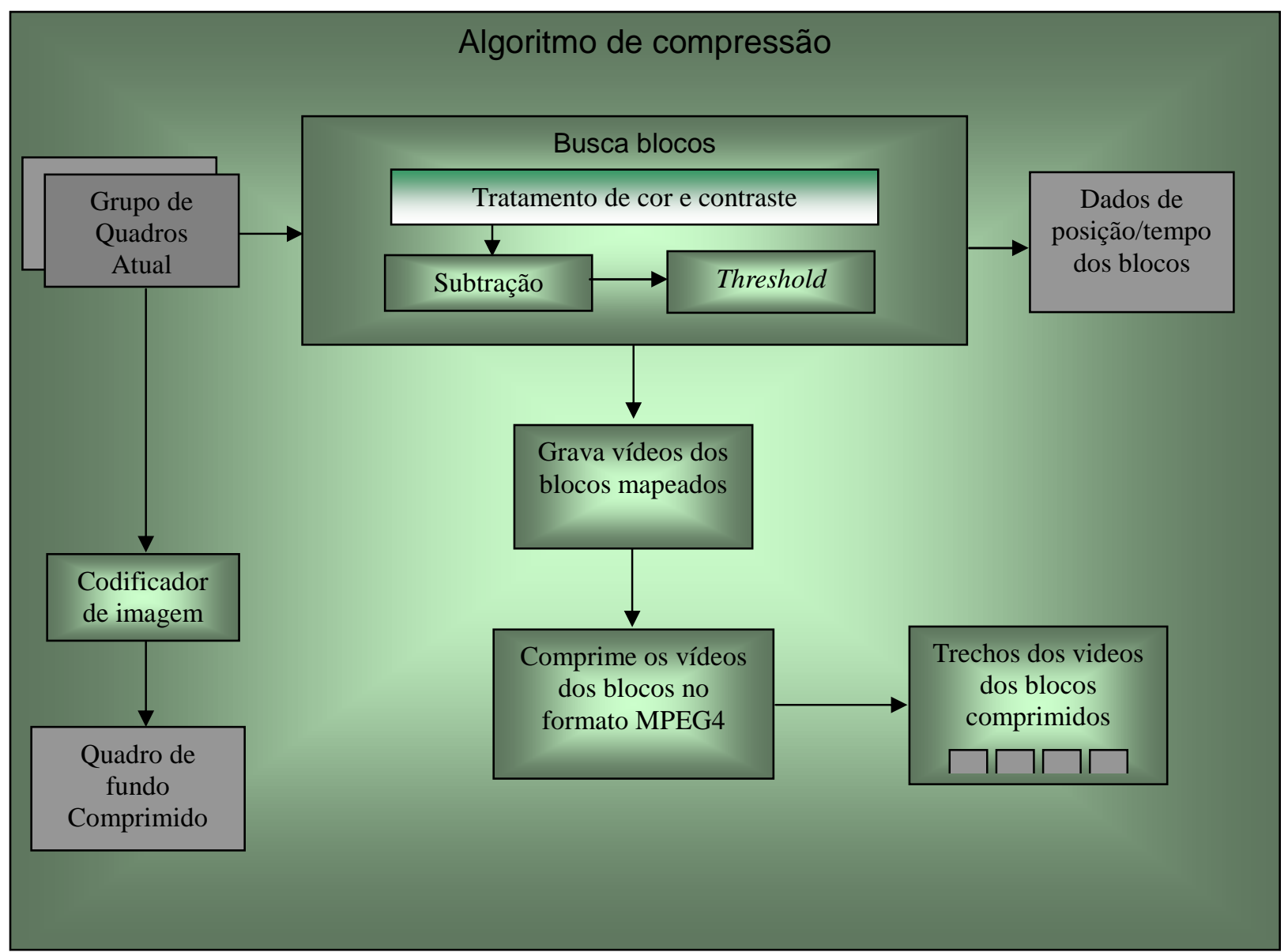

Figura 17: Estrutura do algoritmo de compressão desenvolvido 


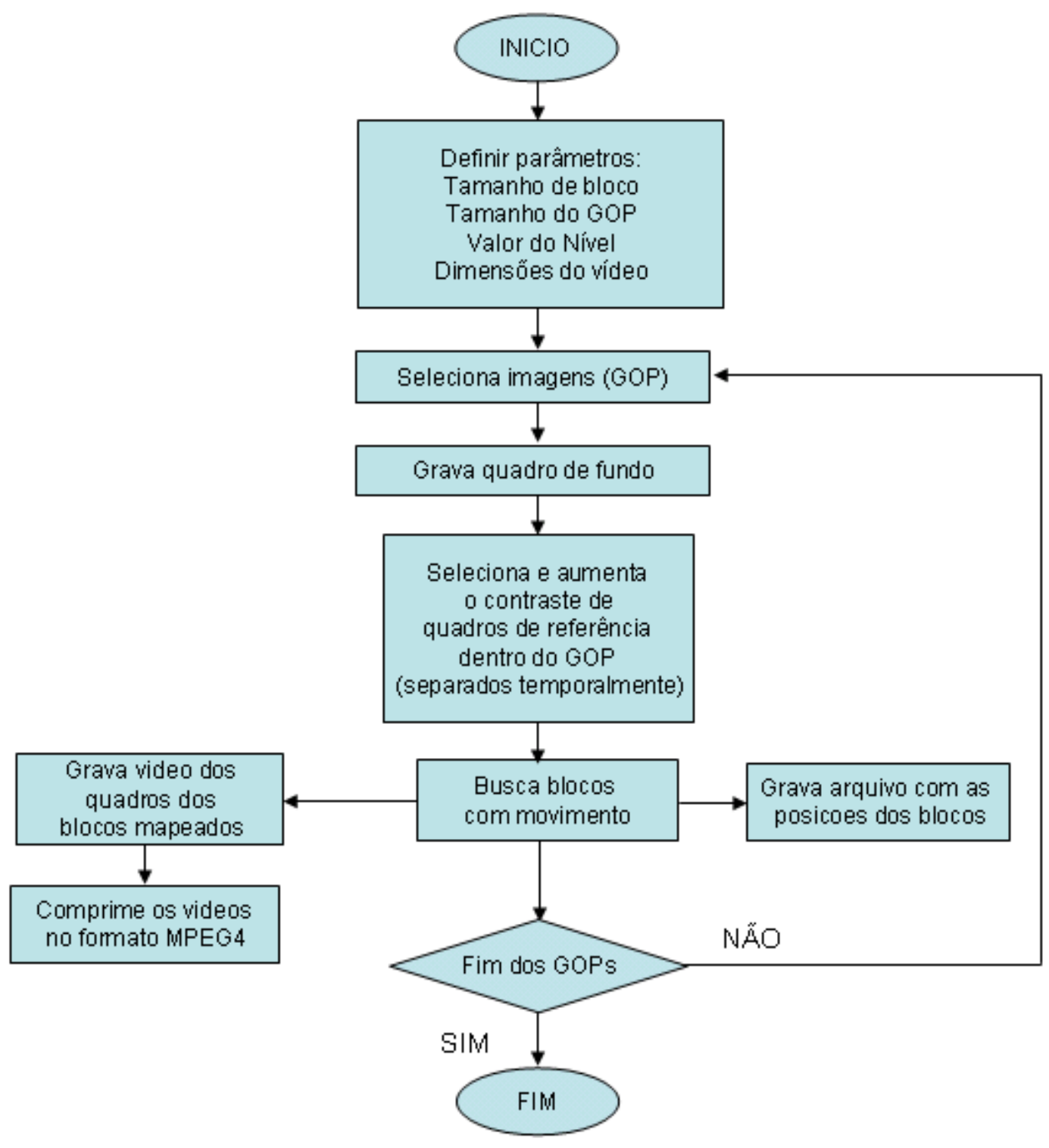

Figura 18: Fluxograma do algoritmo desenvolvido

$\mathrm{Na}$ figura 18, os principais blocos funcionais do algoritmo são identificados e a descrição dos principais fluxos é apresentada a seguir:

- Definir parâmetros: os parâmetros de tamanho de bloco, GOP, valor de limiar e dimensões do vídeo são definidos para melhor ajuste às características do vídeo a ser comprimido.

- Seleciona Imagens do GOP: definida a duração do GOP, todos os quadros deste grupo são convertidos para imagens de tons de cinza e carregadas em memória. A $1^{\underline{a}}$ destas imagens é gravada como 
quadro de fundo, aplicando-se a compressão no formato JPEG. Outros 4 quadros são definidos como quadros de referência para subtração com o quadro de fundo.

- Grava quadro de fundo: A $1^{\text {a }}$ imagem do GOP, tratado pela etapa de busca por diferenças, é comprimida no formato jpeg (item 3.1.6.), para ser aplicada como plano de fundo. Esta imagem servirá como base para geração dos demais quadros do GOP na reconstrução do vídeo.

- Seleciona e aumenta o contraste de quadros de referência no GOP: os quadros definidos como quadros de referência na seleção de imagens do GOP têm seu contraste aumentado (equação 17).

- Busca blocos com movimento: Nesta etapa, o GOP é analisado para avaliar os prováveis locais onde ocorreu movimentação. Cada um dos quadros definidos como referência na etapa anterior são subtraídos com o quadro de fundo em sua resolução original (subtração ponto a ponto - equação 18), o que gera imagens de tonalidades para as diferenças. Estas imagens são somadas e reduzidas de forma que cada ponto represente um bloco (com as dimensões definidas na etapa de definição de parâmetros equação 20), e os pontos que ultrapassaram o valor do threshold (também definido na etapa de definição de parâmetros) são marcados em uma matriz de blocos como tendo se movimentado (Figura 20). Para a subtração, os 4 quadros selecionados estão separados mesma distância temporal dentro do GOP, para que seja possível detectar movimentos com maior precisão. A figura 19 detalha o algoritmo de Busca para os blocos com movimento. 


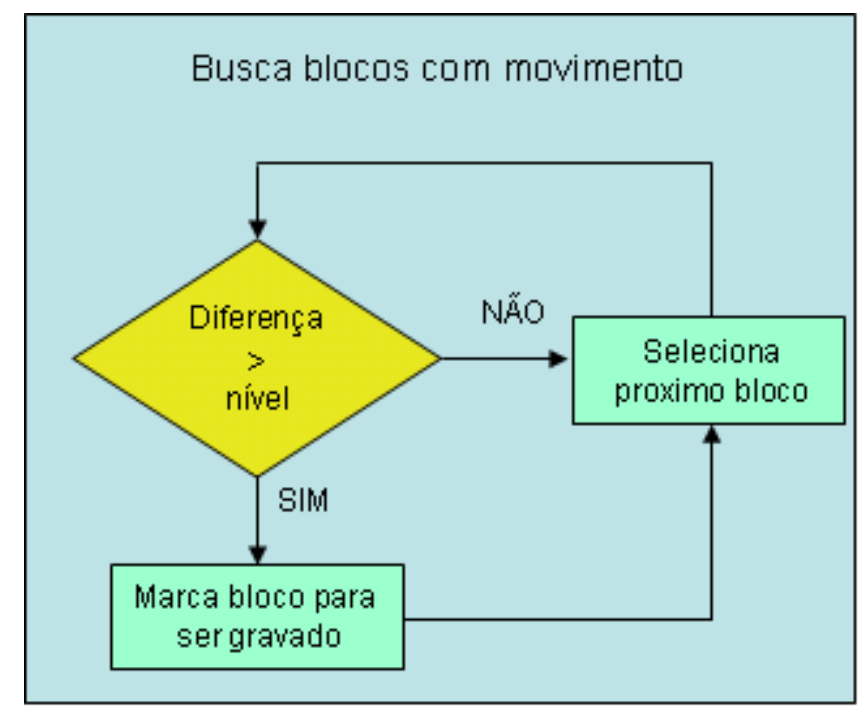

Figura 19: Detalhe da busca por blocos com movimento

Após as etapas de segmentação e compressão, as informações distintas são armazenadas em formato específico conforme as seguintes ações:

- Grava arquivo com as posições dos blocos: A matriz de informações de blocos existentes, gerada na busca de blocos com movimento, é gravada em um arquivo.

- Grava vídeos dos quadros dos blocos mapeados: Para cada um dos bits do mapa, marcado na etapa 'Busca blocos com movimento', os blocos de todo o GOP relacionado são gravados no formato AVI (item 3.1.7.4), sem compressão (Figura 21). Para cada valor "1" no mapa, o bloco correspondente na imagem é marcado em uma matriz para ser transmitido

- Comprime os vídeos no formato MPEG4: Os vídeos no formato AVI, gerados na etapa de gravação de vídeos dos quadros dos blocos mapeados, são comprimidos no formato MPEG4 somente com quadros 'l', para obter maior qualidade nos pontos de interesse - as abelhas (Figura 20). 


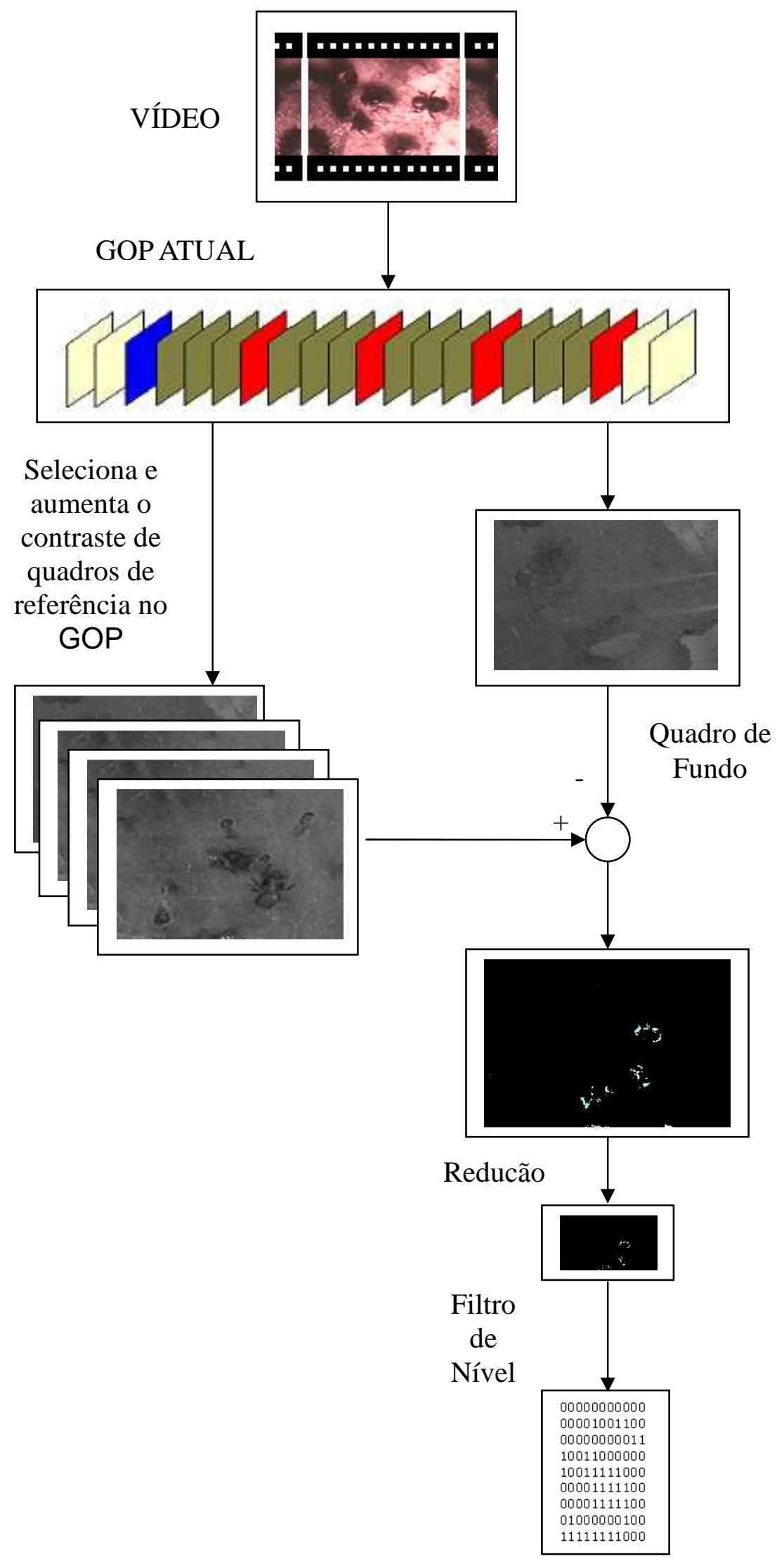

Figura 20: Estrutura do processo de busca blocos com movimento 
As imagens do GOP são convertidas em tonalidades de cinza de 8 bits (256 níveis) para que seja realizada a subtração entre quadros a partir da luminosidade das imagens. Esta conversão não acarreta perdas de informação, uma vez que, o vídeo original contém somente imagens em tonalidades de vermelho.

A subtração entre dois quadros é realizada ponto a ponto (eq. 19). Como resultado, obtém-se um quadro de diferenças também em tonalidades de cinza. Para que sejam mapeados os blocos correspondentes, este quadro de diferenças é reduzido de acordo com o tamanho dos blocos (ou seja, caso o bloco seja do tamanho 8x8, a imagem é reduzida $8 X$ na dimensão $x$ e $8 X$ na dimensão $y$ ), de forma que, cada ponto daquela imagem represente um bloco.

Ao resultado da redução, é aplicado o threshold, que define a presença ou ausência de movimento em cada bloco (valores acima ou abaixo do valor limiar, respectivamente). $\mathrm{O}$ valor do threshold pode variar de 0 a 255 , e será mais próximo de 0 se houver maior quantidade de pontos de baixa intensidade em cada bloco subtraído, porém, o valor deve ser suficientemente alto para eliminar ruídos do vídeo. Como resultado, são geradas matrizes de blocos com movimento.

Conversão para cinza:

$$
\text { QuadroC }=\left(\frac{\text { QuadroR }+ \text { QuadroG }+ \text { QuadroB }}{3}\right)
$$

Ajuste de contraste

$$
\text { QuadroC }=(\text { Quadro }-\min C) \times\left(\frac{255}{\max C-\min C}\right)
$$

Onde:

$\min C=$ valor de intensidade mínimo no quadro

$\max C=$ valor de intensidade mínimo no quadro

Desta forma, o contraste do quadro será maximizado (a tonalidade mais clara será branca: valor $=255$ e a mais escura será preta: valor $=0$ )

A operação de subtração ponto a ponto é definida como:

$$
\text { Subtração }(\mathrm{x}, \mathrm{y})_{\text {Quadro i }}=\left|(\mathrm{x}, \mathrm{y})_{\text {Quadroi }}-(\mathrm{x}, \mathrm{y})_{\text {QuadroFundo }}\right|
$$


Como são 4 quadros a serem subtraídos com o plano de fundo, temos, para o GOP:

$$
\text { Subtração }_{\text {GOP }}=\sum_{i=1}^{4} \text { Subtração }_{\text {Quadroi }}
$$

E o valor médio do bloco é definido por:

$$
\operatorname{Média}_{\text {Bloco }(i, j)}=\frac{\sum_{i=1, j=1}^{\operatorname{dim} x, \operatorname{dim} y}\left|\left(x_{i}, y_{j}\right)\right|}{\operatorname{dim} x \times \operatorname{dim} y}
$$

Onde:

$\operatorname{dim} x \mathrm{e}^{\operatorname{dim} y}$ são as dimensões dos blocos (x e y, respectivamente) 


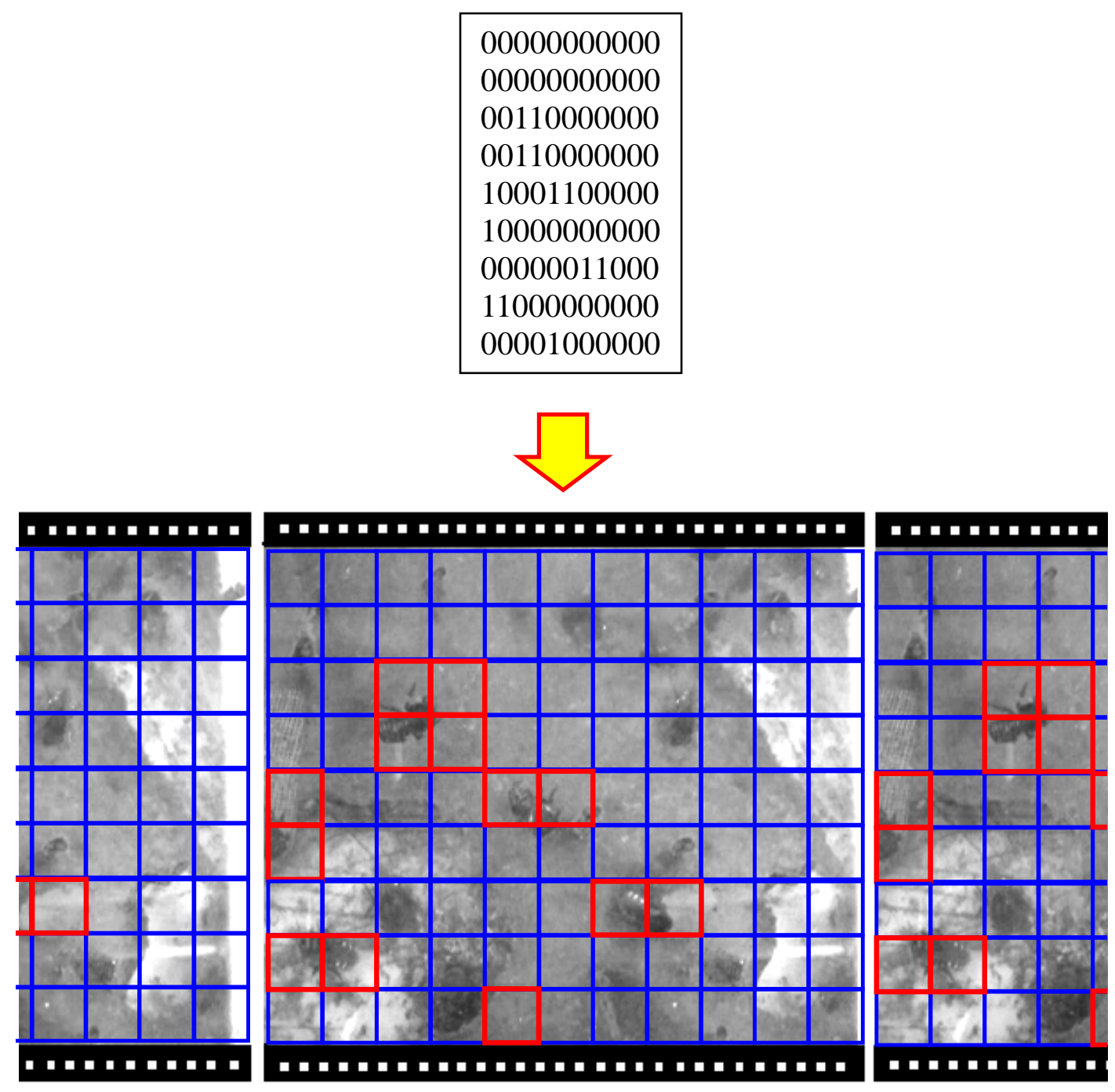

Figura 21: Pontos marcados como movimento e mapeamento aos quadros do vídeo

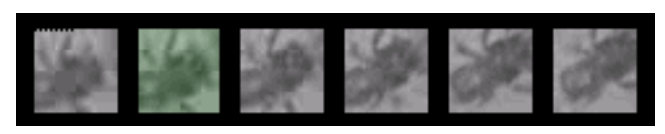

Figura 22: Trecho de vídeo de um bloco do GOP (dimensões de $32 \times 32$ pels) 


\section{RESUMO DO ALGORITMO}

O algoritmo de segmentação e compressão desenvolvido, em resumo, realiza as tarefas de:

- Segmentação de objetos - utilizando-se dos parâmetros configuráveis definidos no início da execução do programa (limiar e tamanhos de bloco e GOP), os blocos contendo movimento são detectados através da subtração entre quadros de imagem distantes temporalmente. Os quadros são tratados para aumentar seu contraste, o que facilita a detecção.

- Compressão de vídeos - os blocos detectados como movimento são armazenados em formato de vídeo sem compressão e a seguir comprimidos no formato MPEG4 para transmissão (Figura 22);

- Compressão de quadros de fundo - os quadros iniciais de cada GOP são gravados como quadros de fundo, comprimidos no padrão JPEG.

- Gravação de dados de posição dos blocos - as informações de posição e GOP de cada arquivo de vídeo são mapeados em um arquivo texto, que armazena também as informações de tamanho do GOP, bloco e quantidade total de frames do vídeo)

A seguinte listagem apresenta um exemplo de arquivo de informações de um vídeo comprimido. O formato geral do arquivo é composto de:

\{uantidade de frames; tamanho do GOP; tamanho do bloco; valor do limiar; matrizes\}

$\{240,40,32,55$

00000000000

00000000000

00000000001

00000000000

00000000000

00000000000

00000000000

00000000000

10000000000 
$\cdots$

\}

A tabela 7 apresenta a estimativa de tamanho dos vídeos gerados para um trecho de duração de 1s e quantidades variáveis de locais com movimentação, idealmente, o tamanho final gerado deveria ser equivalente à fração correspondente de blocos contendo movimentação. Por exemplo, a matriz de movimento da figura 21 marcou 13 de 99 (ou 13,1\%) blocos com movimento, desta forma, poderíamos considerar que, caso o algoritmo funcione perfeitamente, para uma taxa de bits equivalente a $13 \%$ de um fluxo MPEG, teríamos a mesma qualidade neste caso, entretando, a codificação e gera diversos cabeçalhos que aumenta este valor além disso a ocorrência de identificação incorreta dificulta o atingimento desta meta.

Neste trabalho, o tamanho dos blocos foi definido como um tamanho aproximado de uma abelha, ou seja, no caso dos vídeos de resolução de 720×480 pixels, o tamanho médio é de $60 \times 60$ pontos. No caso dos vídeos de resolução de $352 \times 288$ pixels, o tamanho médio é de $32 \times 32$ pontos.

Tabela 7: Estimativa de quantidade de dados gerada para um trecho de $1 \mathrm{~s}$ na resolução de 352x288 pixels

\begin{tabular}{ccc}
$\begin{array}{c}\text { Quantidade } \\
\text { de blocos em } \\
\text { movimento }\end{array}$ & $\begin{array}{c}\text { Tamanho dos trechos } \\
\text { de vídeo (blocos) } \\
\text { comprimido (KB) }\end{array}$ & $\begin{array}{c}\text { Tamanho esperado } \\
\text { final (kBps) }\end{array}$ \\
\hline 0 & 0 & 35 \\
\hline 5 & 25 & 60 \\
\hline 10 & 50 & 85 \\
\hline 50 & 250 & 285 \\
\hline 99 & 495 & 530
\end{tabular}

Os valores de Tamanho dos quadros "l", Tamanho dos trechos de vídeo e dos blocos 
foram estimados tomando-se como base compressões realizadas em arquivos dos vídeos das abelhas, uma vez que, devido à compressão, tais valores costumam variar. Para os quadros "I", um quadro do vídeo foi selecionado e ao mesmo foi aplicada compressão JPEG (item 3.1.6).

Para o tamanho dos Trechos de vídeo, um trecho de um vídeo extraído dos vídeos da colméia, de dimensões de $32 \times 32$ pixels e 30 quadros por segundo foi comprimido no formato MPEG4. 


\subsection{ALGORITMO DE RECONSTRUÇÃO DESENVOLVIDO}

No processo de reconstrução do vídeo (cujo algoritmo é representado na Figura 23), para cada quadro a ser reconstruído, as informações de posição e existência de trechos de vídeo e intervalos entre quadros intra definem quais blocos devem ser descomprimidos por meio de um decodificador MPEG4. Para os demais blocos (onde não houve movimentação), a imagem é gerada a partir do quadro de fundo. As imagens são inseridas quadro a quadro no vídeo reconstruído sem compressão e reconstituindo o vídeo original.

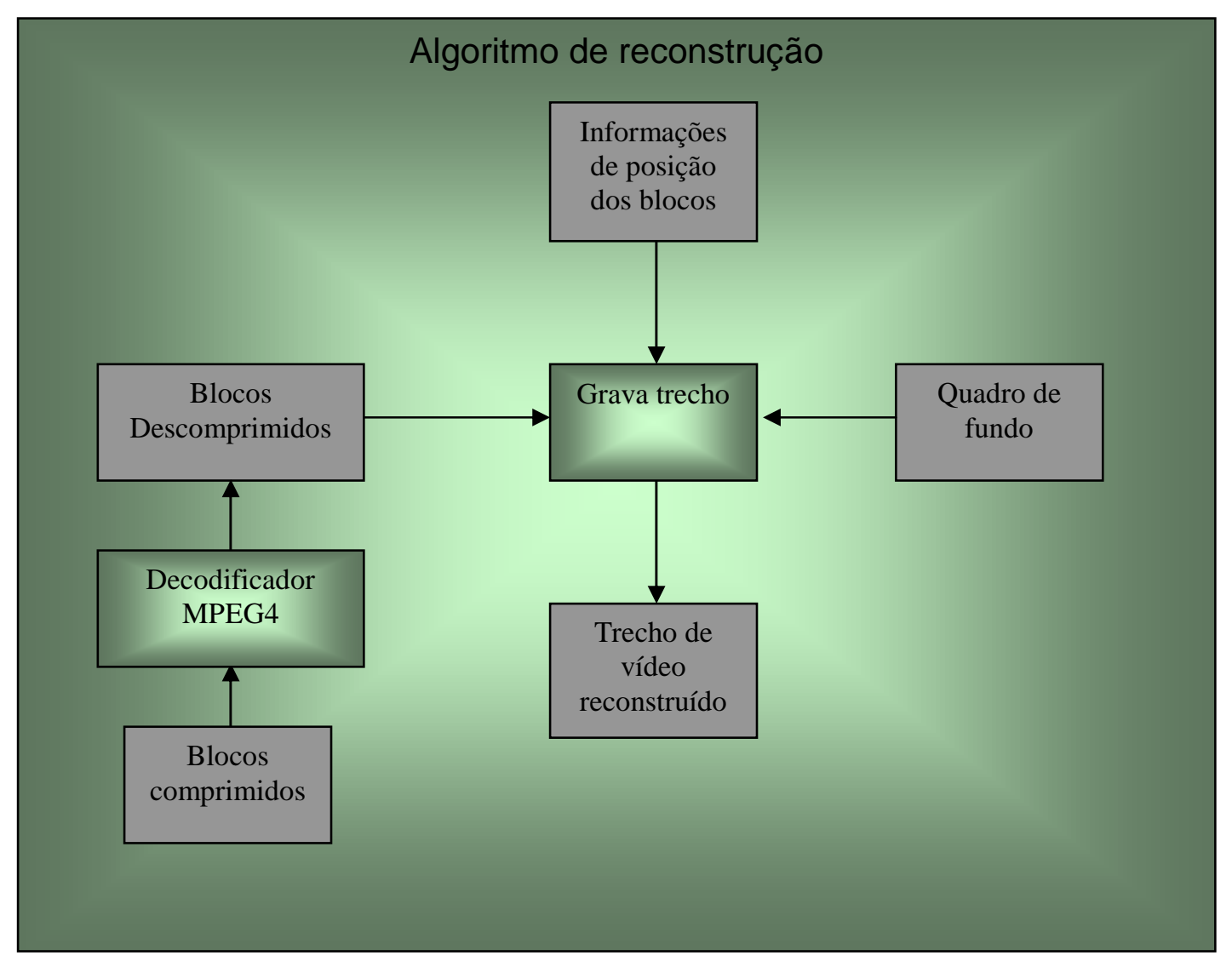

Figura 23: Estrutura do algoritmo de reconstrução desenvolvido

A figura 24 apresenta o algoritmo detalhado do processo de reconstrução do vídeo. 


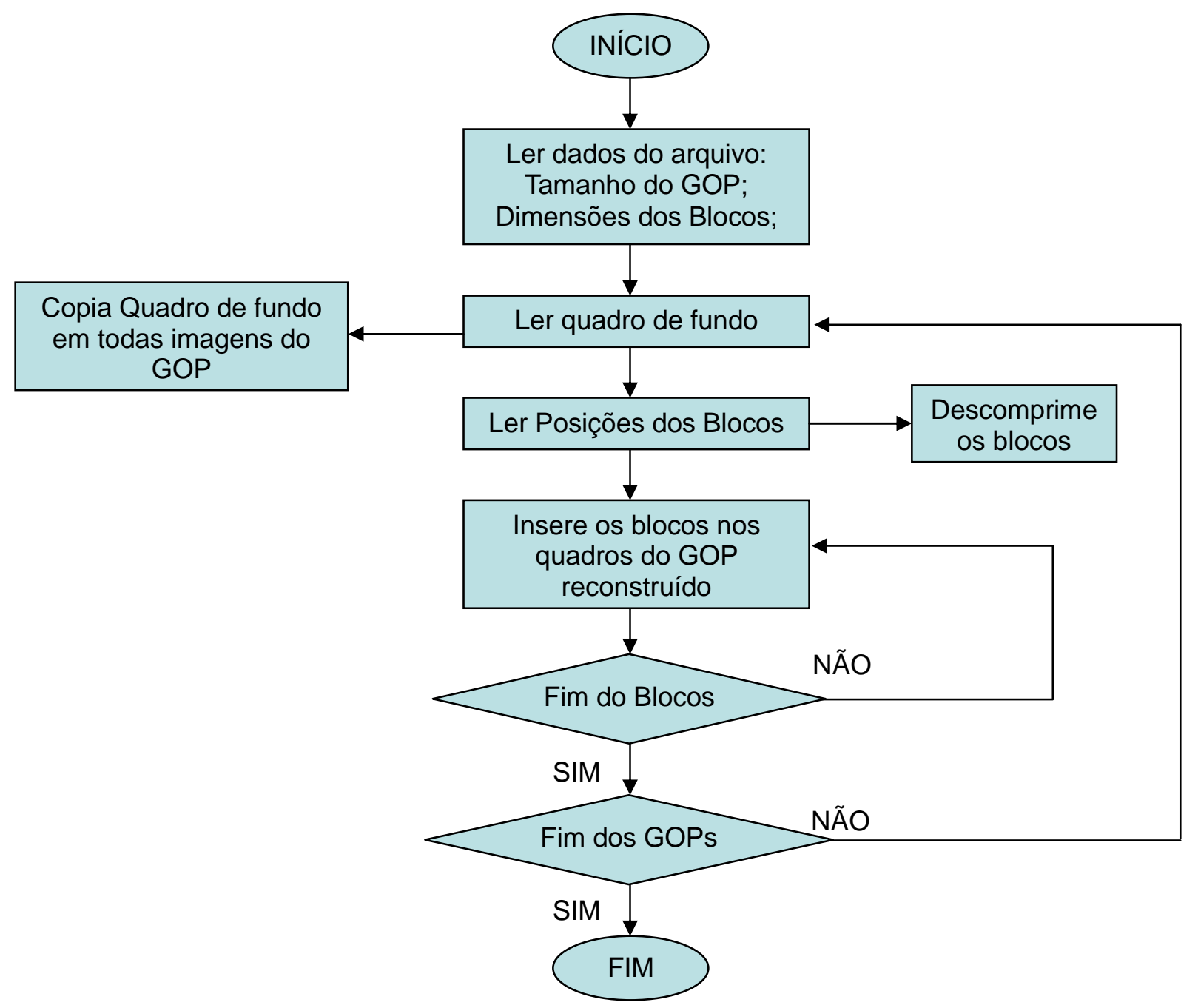

Figura 24: Algoritmo de reconstrução desenvolvido

$\mathrm{O}$ arquivo de informações de entrada contém as seguintes informações, conforme listagem originária do processo de codificação:

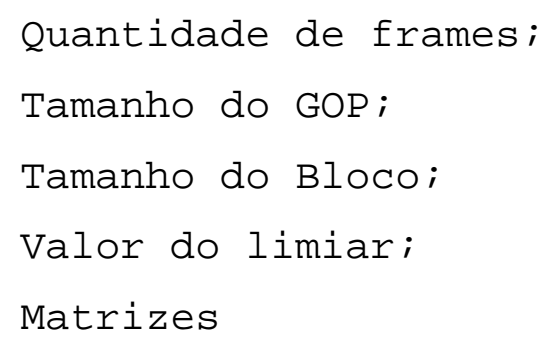

Considerando-se a entrada no formato anterior, a partir do processo "Ler dados do arquivo", são efetivadas as seguintes ações: 
Ler dados do arquivo: Inicialmente, são lidas informações de configuração do vídeo: dimensões, tamanho dos Blocos e quantidade de quadros dos GOPs. Estas informações são carregadas na memória e são utilizadas enquanto o algoritmo permanecer em execução.

Ler quadro de fundo: Enquanto houver GOPs a serem reconstruídos, será lido, para cada GOP, o quadro de fundo (imagem no formato jpeg). Este quadro de fundo é carregado em memória e replicado em todos os quadros do GOP em reconstrução.

Ler Posições dos Blocos: Para cada GOP, as informações de posições dos blocos que foram detectados como contendo movimento são lidas a partir do arquivo e mantidas em memória. Esta informação é utilizada no processo Descomprime os blocos e Insere os blocos nos quadros do GOP reconstruído.

Descomprime os blocos: Os blocos referenciados no arquivo de posições dos blocos possuem trechos de vídeos associados comprimidos no formato MPEG4. Utilizando-se um descompressor do mesmo padrão, estes vídeos são transformados em vídeos no formato AVI sem compressão.

Insere os blocos nos quadros do GOP reconstruído: Cada quadro dos vídeos dos blocos gerados na etapa de descompressão dos blocos é inserido no quadro de fundo (gerado em Ler quadro de fundo) no instante e posição correspondentes, no vídeo reconstruído.

O processo de reconstrução do vídeo é finalizado quando não houver mais GOPs para gerar o vídeo. 


\subsection{TESTES COM O ALGORITMO DESENVOLVIDO}

O ambiente de teste considera uma configuração em que os processos de codificação e decodificação do algoritmo proposto são avaliados e não consideram os meios de comunicação. Assim, foram realizados testes utilizando a plataforma de um computador pessoal com trechos de vídeos obtidos no Webbee, nas resoluções de $352 \times 288$ pixels e $720 \times 480$ pixels. O tamanho de cabeçalho dos arquivos que foi descontado nestes calculos é de 8kB por arquivo de vídeo MPEG.

Para avaliação da qualidade, a métrica SSIM foi utilizada. A formulação e cálculo do SSIM são apresentados no item 3.2.2. (eq. 15); valores de SSIM mais próximos de $100 \%$ significam maior similaridade com a imagem original (melhor qualidade).

Parâmetros definidos para este teste:

Threshold $=50$

Bloco $=32 \times 32$

$\mathrm{GOP}=30$

Os três vídeos utilizados têm duração de 8,30 s e 241 quadros (a 29 quadros por segundo).

Tabela 8: Estimativa versus resultados obtidos de quantidades de dados obtidas nas simulações para um trecho de $1 \mathrm{~s}$ de vídeo de resolução de 352×288 pels

\begin{tabular}{cccccc}
$\begin{array}{c}\text { Quantidade } \\
\text { de abelhas } \\
\text { em } \\
\text { movimento }\end{array}$ & $\begin{array}{c}\text { Quantidade } \\
\text { média de } \\
\text { blocos } \\
\text { esperada }\end{array}$ & $\begin{array}{c}\text { Bitrate } \\
\text { esperado } \\
\text { (sem } \\
\text { overhead) } \\
\text { (kBps) }\end{array}$ & $\begin{array}{c}\text { Número de } \\
\text { blocos } \\
\text { verificado } \\
\text { (desvio } \\
\text { padrão) }\end{array}$ & $\begin{array}{c}\text { Bitrate } \\
\text { verificado } \\
\text { (kBps) }\end{array}$ & $\begin{array}{c}\text { Bitrate } \\
\text { verificado } \\
\text { (sem } \\
\text { overhead) } \\
\text { (kBps) }\end{array}$ \\
\hline 0 & 0 & 35 & $0(0)^{*}$ & 37 & 37 \\
\hline $2 \sim 3$ & $4 \sim 9$ & $55 \sim 80$ & $6,6(0,7)$ & 139 & 87 \\
\hline $4 \sim 5$ & $8 \sim 15$ & $75 \sim 115$ & $10,9(2,1)$ & 201 & 114 \\
\hline $5 \sim 6$ & $10 \sim 18$ & $85 \sim 125$ & $19,6(2,9)$ & 344 & 187 \\
Em todos & & 59 & & 1345 & 553 \\
blocos & 99 & $99(0) * *$ & & \\
* simulado alterando o valor do threshold para 255 & & \\
** simulado alterando o valor do threshold para 0 &
\end{tabular}

Os dados foram estimados tomando-se como base: o tamanho das abelhas, 0 
tamanho dos blocos, a movimentação média das abelhas (movimento entre blocos) e tamanho médio de um quadro comprimido no formato JPEG, conforme as colunas da Tabela 8. Nas colunas 4 e 5, são mostradas as quantidades de blocos e taxas de bits verificadas por meio das simulações.

Por exemplo, na $3^{\text {a }}$ linha da tabela, para uma quantidade média de 4 a 5 abelhas em movimento no vídeo, espera-se que cerca de 8 a 15 blocos serão detectados em média (de acordo com a velocidade de movimentação da abelha, estimamos que uma abelha irá se mover entre 2 a 3 blocos para um mesmo GOP de 30 quadros), gerando uma taxa de 75 a $115 \mathrm{kBps}$, incluindo o overhead causado pelos headers (cabeçalhos) dos arquivos. Os testes demonstraram que cerca de 6 blocos foram detectados como movimento, o que gerou uma taxa de $139 \mathrm{kBps}$, ou cerca de $87 \mathrm{kBps}$ sem headers, valor ligeiramente superior ao esperado.

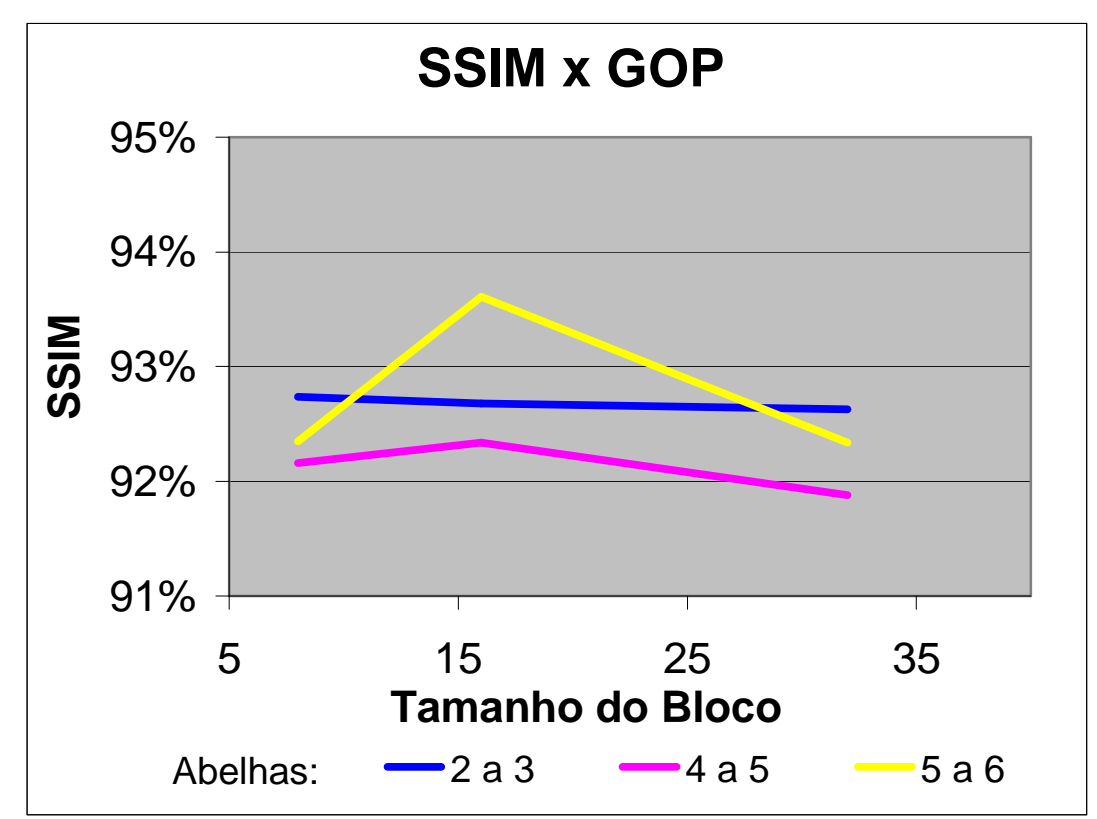

Gráfico 2: Número de quadros do GOPxSSIM

Os valores de threshold dos testes foram selecionados por apresentarem melhores resultados (menores quantidades de dados $\mathrm{x}$ maior SSIM). 


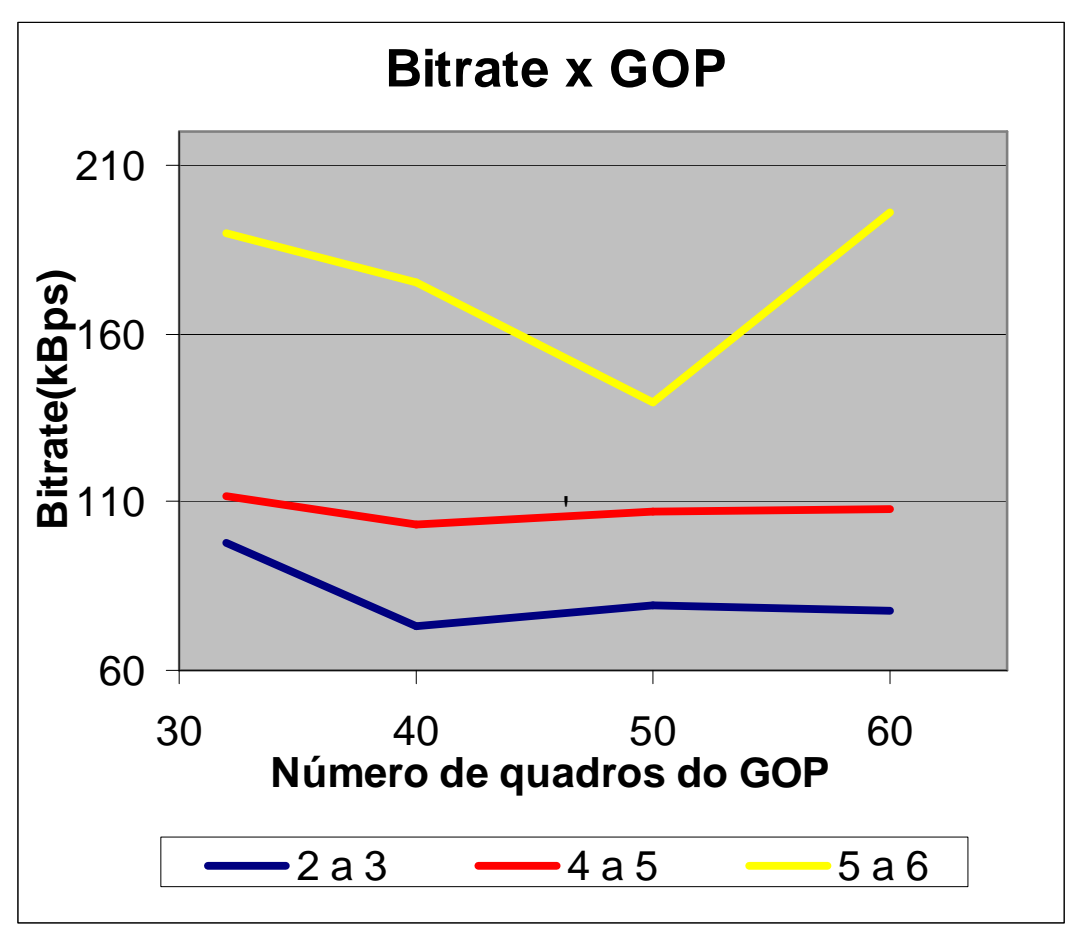

Gráfico 3: Número de quadros do GOPxBitrate

Conforme o esperado, constatamos que o bitrate resultante é basicamente definido pelo threshold (o bitrate aumenta ao reduzir o threshold), sendo a qualidade obtida (SSIM) maior para menores níveis de threshold e GOPs com menores quantidades de quadros. Alterações no tamanho do GOP permitem gerar economias entre 10 a $25 \%$ no bitrate, com variações de qualidade relacionadas abaixo de $1 \%$ (SSIM). 
Tabela 9: Alteração de quadros I versus Bitrate e SSIM

\begin{tabular}{cccc}
$\begin{array}{c}\text { Quantidade de abelhas no } \\
\text { quadro }\end{array}$ & $\begin{array}{c}\text { BITRATE } \\
\text { (kBps) }\end{array}$ & SSIM & $\begin{array}{c}\text { Duração do } \\
\text { GOP (quadros) }\end{array}$ \\
\hline \multirow{2}{*}{ 2 a 3 abelhas } & 98 & $93,07 \%$ & 32 \\
\cline { 2 - 4 } & 73 & $92,93 \%$ & 40 \\
\cline { 2 - 4 } & 79 & $92,63 \%$ & 50 \\
\hline \multirow{3}{*}{ 4 a 5 abelhas } & 78 & $92,69 \%$ & 60 \\
& 112 & $92,82 \%$ & 32 \\
\hline \multirow{2}{*}{5 a 6 abelhas } & 103 & $92,56 \%$ & 40 \\
& 107 & $91,88 \%$ & 50 \\
\hline & 108 & $92,45 \%$ & 60 \\
\hline & 190 & $92,57 \%$ & 32 \\
\hline & 175 & $92,58 \%$ & 40 \\
\hline & 140 & $92,34 \%$ & 50 \\
\hline & 196 & $92,42 \%$ & 60
\end{tabular}

Os vídeos apresentados nas tabelas 8 e 9 são segmentos dos vídeos obtidos na coleta, e selecionados de acordo com a quantidade de abelhas em movimento na maior parte dos mesmos. O bitrate também sofreu grande aumento ao se reduzir o tamanho do bloco. O aumento na SSIM resultante, entretanto, foi pequeno (tabela 8). Para efeito de comparação, o mesmo vídeo utilizado nos testes com o algoritmo proposto foi comprimido utilizando-se um codec MPEG4, a diferentes taxas de bits, conforme a tabela 10 e Gráfico 4, em que podemos constatar o aumento do SSIM à medida que o bit rate é elevado.

Tabela 10: Compressão com o padrão MPEG4 versus SSIM

\begin{tabular}{ccc} 
Bit-Rate (kBps) & SSIM & Tamanho total (MB) \\
\hline 320 & $95 \%$ & 18,5 \\
\hline 256 & $93,7 \%$ & 14,5 \\
\hline 192 & $91,4 \%$ & 10,9 \\
\hline 160 & $89,77 \%$ & 9,4 \\
\hline 128 & $87,59 \%$ & 7,6 \\
\hline 102,4 & $86,08 \%$ & 6,1 \\
\hline 76,8 & $81 \%$ & 4,7 \\
\hline 64 & $77,9 \%$ & 3,9 \\
\hline 51,2 & $73,6 \%$ & 3,2 \\
\hline 38,4 & $72,3 \%$ & 3
\end{tabular}




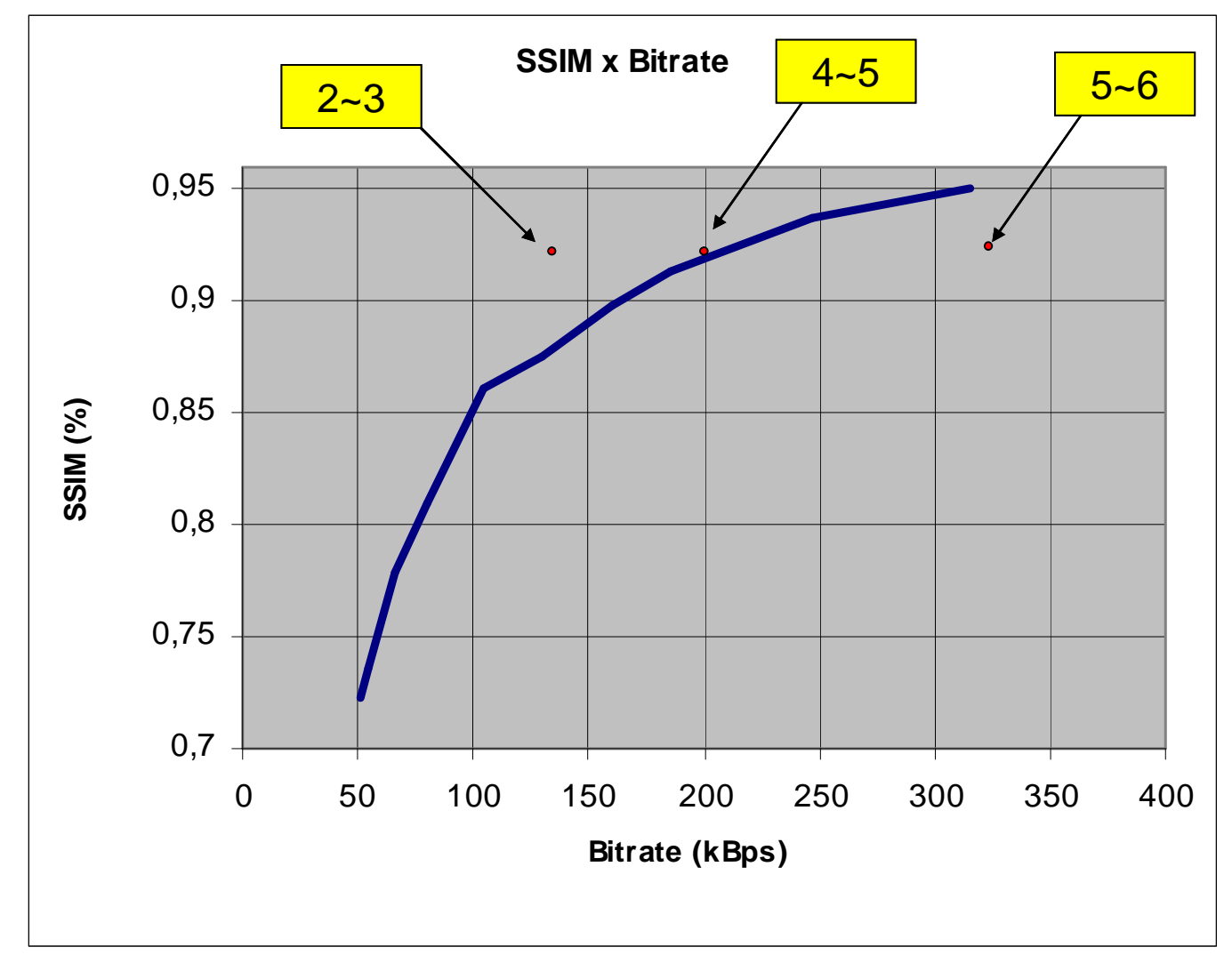

Gráfico 4: Relação SSIMxTamanho final do vídeo comprimido com MPEG4

Nas tabelas 11 e 12, os resultados do CODEC desenvolvido são comparados com o padrão MPEG4, utilizando os critérios de qualidade (SSIM) e quantidade de dados para diferentes trechos do mesmo vídeo, que apresentam diferentes quantidades de abelhas em movimento. Podemos constatar que o aumento da quantidade de abelhas em movimento presentes no vídeo não interfere no tamanho final do padrão MPEG4, mas aumenta a quantidade de dados do CODEC desenvolvido, conforme esperado. 
Tabela 11 Compressão com o padrão MPEG4 x Codec desenvolvido, em resolução de $352 \times 288$ pixels.

MPEG 4

Codec Desenvolvido

\begin{tabular}{ccccccccc}
\hline $\begin{array}{c}\text { Qt de } \\
\text { abelhas }\end{array}$ & $\begin{array}{c}\text { Tamanho } \\
\text { (MB) }\end{array}$ & SSIM & $\begin{array}{c}\text { Tamanho } \\
\text { (MB) }\end{array}$ & SSIM & $\begin{array}{c}\text { Tamanho } \\
\text { (MB) }\end{array}$ & SSIM & $\begin{array}{c}\text { Tamanho } \\
\text { MB }\end{array}$ & SSIM \\
\hline 2 a 3 & 1,4 & $89,92 \%$ & 1,7 & $91,57 \%$ & 2,2 & $93,59 \%$ & 0,71 & $92,63 \%$ \\
\hline 4 a 5 & 1,4 & $89,72 \%$ & 1,7 & $91,31 \%$ & 2,2 & $93,44 \%$ & 0,96 & $92,22 \%$ \\
\hline 5 a 6 & 1,4 & $89,71 \%$ & 1,7 & $91,26 \%$ & 2,2 & $93,43 \%$ & 1,30 & $92,34 \%$ \\
\hline
\end{tabular}

Tabela 12 Compressão com o padrão MPEG4 x Codec desenvolvido, em resolução de $720 \times 480$ pixels

\begin{tabular}{ccccccccc}
\hline \multicolumn{1}{c}{ MPEG 4 } & \multicolumn{3}{c}{ Codec } \\
\hline $\begin{array}{c}\text { Qt de } \\
\text { abelhas }\end{array}$ & $\begin{array}{c}\text { Tamanho } \\
\text { (MB) }\end{array}$ & SSIM & $\begin{array}{c}\text { Tamanho } \\
\text { (MB) }\end{array}$ & SSIM & $\begin{array}{c}\text { Tamanho } \\
\text { (MB) }\end{array}$ & SSIM & $\begin{array}{c}\text { Tamanho } \\
\text { (MB) }\end{array}$ & SSIM \\
\hline 2 a 3 & 2,25 & $85,87 \%$ & 3,27 & $89,44 \%$ & 10,3 & $96,38 \%$ & 3,607 & $86,11 \%$ \\
\hline 4 a 5 & 2,24 & $85,32 \%$ & 3,26 & $89,01 \%$ & 10,3 & $96,28 \%$ & 4,227 & $85,49 \%$ \\
\hline 5 a 6 & 2,24 & $85,22 \%$ & 3,25 & $88,99 \%$ & 10,27 & $96,27 \%$ & 8,347 & $86,42 \%$ \\
\hline
\end{tabular}




\subsection{DISCUSSÃO}

Como podemos observar, na figura 21, apenas uma fração dos blocos que compõem um vídeo são detectadas como movimento em um dado instante, o que permite considerar que o bitrate será reduzida para uma fração equivalente a este valor em um vídeo, entretanto, isto não ocorre devido a diversos fatores, dentre eles, o principal é o overhead, causado pelos dados redundantes existentes nos diferentes arquivos que comporão o vídeo, além disso, a incorreta detecção de movimento deverá gerar trechos de vídeo sem informações úteis e também ocasionar perdas de qualidade.

Os testes foram realizados com 0 algoritmo de segmentação que realizou a compressão somente dos objetos detectados em movimento. A medida do threshold foi realizada para cada bloco, em tamanho fixo (32×32 pels no caso dos vídeos de resolução de $352 \times 288$ pels e $60 \times 60$ pels para os vídeos de resolução de $720 \times 480$ pels). Conforme apresentado no item 4.3, os valores de threshold foram obtidos por meio da média simples nos pontos pertinentes a cada bloco, para quadros separados por intervalos de tempo fixo.

Conforme os resultados das compressões realizadas sobre os vídeos (tabelas 11e 12 podemos verificar que em boa parte dos casos, a qualidade medida após as operações de compressão e descompressão foram superiores aos do codec MPEG4, quando gerada a mesma quantidade de dados. Esta característica foi observada principalmente quando ocorre pouca movimentação nos vídeos. A vantagem da maior taxa de compressão de vídeo, nestas situações é perdida à medida que ocorrerem mais movimentações em maior quantidade de locais.

Uma das principais limitações constatadas foi a dificuldade de identificação dos blocos contendo abelhas que apresentam movimento, fato esperado devido à simplicidade do algoritmo, implementado para efetuar poucas operações, reduzindo assim o tempo de processamento do vídeo.

A detecção imperfeita leva a duas condições indesejadas: pior qualidade das imagens (ocorrência de 'corte' das abelhas em movimento) e geração de maior quantidade de dados, conforme se pode observar na comparação entre a imagem original, o quadro reconstruído e a similaridade estrutural entre ambos (figuras $25 \mathrm{e}$ 26). 
A diferença mostrada na figuras 25c e 26c mostram a representação gráfica do SSIM entre o quadro original e o quadro reconstruído, ponto-a-ponto (complemento do valor do SSIM multiplicado por 255).

A parte mais clara da figura de similaridade estrutural indica menor similaridade, que ocorreu neste caso devido a não codificação do bloco.

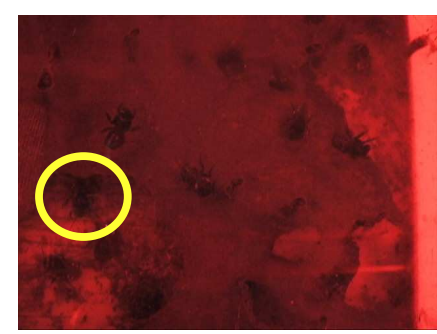

(a)

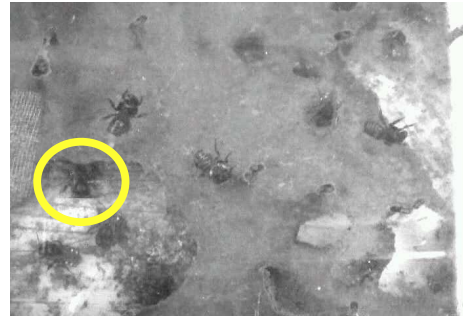

(b)

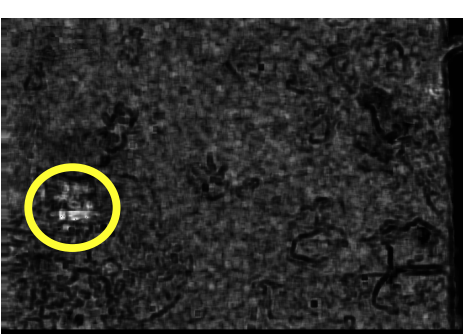

(c)

Figura 25: (a) imagem do vídeo original; (b) imagem após a reconstrução pelo algoritmo; (c) representação gráfica do SSIM*;

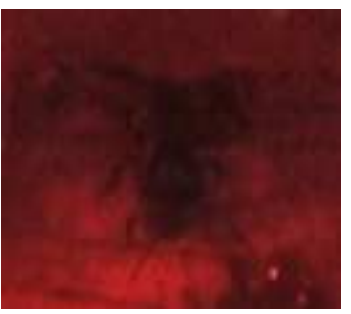

(a)

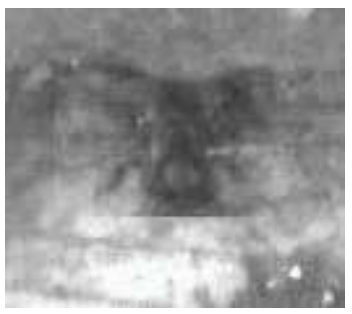

(b)

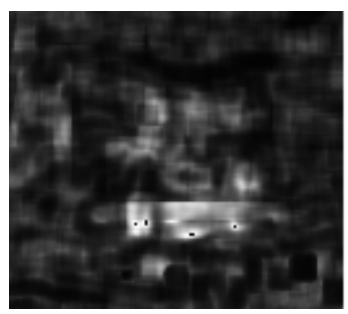

(c)

Figura 26: detalhes das imagens da Figura 25.

*(tons mais claros indicam menor SSIM)

Estas limitações também geraram como resultados: a codificação de blocos e trechos de vídeo com pouca ou nenhuma informação relevante (vídeos sem movimento de abelhas), aumentando a quantidade final dos dados sem que ocorressem melhorias na qualidade medida. 
Como visto no item 4.5, o tamanho dos blocos teve impacto significativo na quantidade de dados gerados e na qualidade medida. Isto pode ser atribuído à quantidade de dados que é gravada sem informações úteis quando se utiliza um bloco de tamanho inadequado (muito grande ou pequeno), o que gera arquivos com vídeos de locais sem movimento ou então muitos arquivos de vídeo para um mesmo objeto em movimento, o que gera maior dados de cabeçalho de arquivos. Uma vez que o algoritmo foi otimizado para baixas resoluções, este efeito foi verificado em maior intensidade nos vídeos de maiores resoluções. 


\section{CONCLUSÕES E SUGESTÕES PARA TRABALHOS FUTUROS}

O desenvolvimento proposto de um algoritmo de compressão de vídeo para ser aplicado ao BBBee - weblab do Instituto de Biociências da USP, que mantivesse maior qualidade nos vídeos ao mesmo tempo em que se obtêm maiores taxas de compressão foi realizado neste trabalho.

O algoritmo proposto pretendeu codificar apenas uma fração dos vídeos que são normalmente transmitidos, identificando de maneira simplificada os movimentos e utilizou para tal: técnicas de segmentação de vídeo, extração e detecção de objetos em movimento, tendo sido desenvolvidos dois sistemas complementares para compressão e descompressão de vídeos, respectivamente. As características de qualidade observadas são inerentes à forma de implementação do algoritmo, em que, se objetivou obter maior qualidade nas localidades especificas que continham movimento de abelhas, porém, conforme o esperado, em algumas situações (como nos casos em que há movimentação em grande parte do vídeo) as vantagens do sistema são perdidas, e se constata menores taxas de compressão ante menores resultados de qualidade. Por motivos de simplicidade, a segmentação foi realizada por meio de uma das principais técnicas verificadas na revisão bibliográfica, ou seja, com a utilização de segmentação de cenário de fundo para identificar as abelhas. Apesar de haver sido testada somente a técnica de segmentação de objetos por meio da diferença entre quadros, na maioria dos casos em que havia pouca movimentação no interior da colméia, a qualidade do vídeo medida foi superior à dos padrões disponíveis.

Para realização de comparação entre o algoritmo desenvolvido e o padrão MPEG4, os vídeos obtidos no BBBee foram testados em diversas configurações de compressão com aquele padrão. Os resultados de métricas de avaliação da qualidade de vídeo, obtidos através da realização de testes com a aplicação do algoritmo a vídeos capturados no BBBee em diferentes situações de movimentação de objetos no vídeo, permitiram avaliar e apontar os pontos fracos e fortes da proposta.

Os principais efeitos verificados sobre a qualidade do vídeo e quantidade de dados gerados foram obtidos por meio da variação de parâmetros de entrada do sistema: 0 limiar de detecção de movimento e o tamanho do GOP. 
Obter a diferença de intensidade entre dois quadros é considerada como uma das formas mais eficientes de se detectar áreas com movimento (Meier, Ngan, 1998), porém, a inexistência de cores neste vídeo (as imagens foram tratadas como intensidades de cinza em 256 níveis) foi um dos fatores que dificultaram a identificação das abelhas e também a movimentação.

Apesar destas limitações, os resultados da aplicação de somente uma das principais técnicas do MPEG4 demonstraram que é possível obter maior compressão e qualidade, em situações de baixa movimentação. 


\section{TRABALHOS FUTUROS}

Podem-se sugerir como prováveis melhorias a serem implementadas ao algoritmo em futuros desenvolvimentos:

- Refinação do tamanho e forma do bloco: Constatou-se que a utilização de blocos de tamanhos mais adequados permite grandes reduções de bitrates sem que haja perdas de qualidade (item 4.5.), desta forma, VO's podem ter formas arbitrárias baseados em contornos de imagens (Kim, Hwang, 2002) ou por meio de operador Canny (Meier, Ngan, 1999), tamanhos definidos de acordo com os objetos em movimento na cena ou ainda tamanhos variáveis. Isto permitiria uma melhor segmentação dos objetos que representam as abelhas no vídeo, reduzindo a ocorrência de deformações e perda de informações verificada na compressão dos objetos.

- Envio de informações somente de posição e orientação: Apesar de não permitir os pesquisadores observar detalhes de movimentação e características das abelhas, o envio somente das posições das abelhas presentes no vídeo ocasionaria grande redução na taxa de transmissão de dados e facilita a contagem, tarefa bastante comum em pesquisa de abelhas.

- Definição de nível automático por medição de histograma: Verificou-se que é necessário definir com precisão o valor de nível para detecção de movimento, neste estudo, o valor foi obtido experimentalmente por meio de testes. O histograma avalia a intensidade da luminosidade em imagens, podendo ser aplicado como métrica automática para determinação do valor ótimo do threshold em detecção de cores de pele (Zhang; Gao), podendo portanto ser aplicado para localizar as abelhas em movimento de forma automatizada. 


\section{REFERÊNCIAS}

Allebach, J. P. Human vision and image rendering: Is the story over, or is it just beginning. in Proc. Symp. on Human Vision and Electronic Imaging III, vol. 3299, San Jose, CA, Jan. 26-29, 1998, 26-37 p.

Amâncio, S. M.; Hirakawa, A. R.; Junior, E. L.; Hilário, S. D.; Kleinert, A. M. P.; Fonseca, V.L.I.; Giannini, T. C.; Study on Real Time Video Transmission for Aid Remote Research of Bees. Computers in Agriculture and Natural Resources, 4th World Congress Conference, Proceedings of the 24-26. July 2006.

Barjatya, A., Student Member, IEEE H.26x - Block Matching Algorithms For Motion Estimation, 2004

Barth, F. G., Hrncir, M., Jarau, S. - Signals and cues in the recruitment behavior of stingless bees (Meliponini). Springer, 2008

Bow, S.T., Pattern Recognition and Image Preprocessing. CRC Press, 2002

De Sutter, R., De Wolf, K., Lerouge, S., Van deWalle, R., Lightweight Object Tracking in Compressed Video Streams Demonstrated in Region-of-Interest Coding, 2006

Dong, J., e Ngan, K., - 16×16 Integer Cosine Transform for HD Video Coding Dept. of Electronic Engineering, The Chinese University of Hong Kong - Hong Kong SAR, 2006

DV Data in the AVI File Format Specification, Version 1.01 - Microsoft Corporation - June 25, 1997 - http://www.microsoft.com/whdc/archive/dvavi.mspx

Furht, B., Smoliar, S. W. and Zhang, H. Video and Image Processing in Multimedia Systems. Kluwer Academic Publishers, 1995 
Gill, T.; Birney, B.; and the Microsoft Windows Media Team. Microsoft Windows Media Resource Kit, Microsoft Press, 2003.

Giusto D. D., F. Massidda, C. Perra. A Fast Algorithm For Video Segmentation And Object Tracking - Multimedia Communications Lab, University of Cagliari, 2002

Gonzalez R.C., Woods, R. E., Digital Image Processing, 2007 - Pearson Prentice Hall

Horn, B. K. P.; Schunck. B. G. Determining Optical Flow. Artificial Intelligence Laboratory, Massachusetts Institute of Technology, Cambridge, MA, U.S.A. - Artificial Intelligence 17 (1981) 185-203

Hrncir, M., Gravel, A., Schorkopf, D., Schmidt, V.M., Zucchi, R., Barth, F., Thoracic vibrations in stingless bees (Melipona seminigra): resonances of the thorax influence vibrations associated with flight but not those associated with sound production. The Journal of Experimental Biology 211, 2008

Hrncir, M., Jarau, S., Zucchi, R., Barth, F., Recruitment behavior in stingless bees, Melipona scutellaris and M. quadrifasciata. II. Possible mechanisms of communication. Apidologie 31 (2000) 93-113

INTERNATIONAL TELECOMMUNICATION UNION / CCITT THE INTERNATIONAL TELEGRAPH AND TELEPHONE CONSULTATIVE COMMITTEE RECOMMENDATION T.81 - TERMINAL EQUIPMENT AND PROTOCOLS FOR TELEMATIC SERVICES INFORMATION TECHNOLOGY - DIGITAL COMPRESSION AND CODING OF CONTINUOUS-TONE STILL IMAGES REQUIREMENTS AND GUIDELINES. (09/92)

Izquierdo, E.; Xia, J. H.; Mech, R. A Generic Video Analysis and Segmentation System. IEEE Int. Conf. on Acoustics, Speech and Signal Processing, Vol. 4, May 2002. 
Jarau, S., Hrncir, M., Zucchi, R., Recruitment behavior in stingless bees, Melipona scutellaris and M. quadrifasciata. I. Foraging at food sources differing in direction and distance. 1999

Jiang H., Öwall, V., Ardö, H., Real-time Video Segmentation with VGA Resolution and Memory Bandwidth Reduction, 2006

Kalafatic, Z.; Ribaric, S.; Stanisavljevic, V.; A System for Tracking Laboratory Animals Based on Optical Flow and Active Contours. Department of Electronics, Microelectronics, Computer and Intelligent Systems, Faculty of Electrical Engineering and Computing - Zagreb, Croatia

Kim, C.; Hwang, J.;. Object Based Video Abstraction for Video Surveillance Systems - IEEE - IEEE TRANSACTIONS ON CIRCUITS AND SYSTEMS FOR VIDEO TECHNOLOGY, VOL. 12, NO. 12, DECEMBER 2002

Loomis, J. ; Wasson, M. VC-1 Technical Overview, 2007 Microsoft Corporation

Mai, Z.; Yang, C.; Xie, S. Improved Best Prediction Mode(s) Selection Methods Based on Structural Similarity In H.264 I-Frame Encoder, October, 2005

Meier, T., Ngan, K.N., Video Segmentation for Content-Based Coding. IEEE TRANSACTIONS ON CIRCUITS AND SYSTEMS FOR VIDEO TECHNOLOGY, VOL. 9, NO. 8, DECEMBER 1999

Meier, T. and Ngan, K. N., Automatic Segmentation of Moving Objects for Video Object Plane Generation. IEEE Transactions on Circuits and Systems for Video Technology, Vol 8, No 5, September 1998.

Parhi, K.K., Nishitani, T., Digital Signal Processing for Multimedia. CRC Press 1999. pp 386,387 
Puri, A.; Chen, T. Multimedia Systems, Standards and Networks. Marcel Dekker, 2000.

SMPTE Technology Committee. Proposed SMPTE Standard for Television: VC-1 Compressed Video Bitstream Format and Decoding Process. Video Compression Technology. 2005-08-23.

Taylor, J. H., Johnson, M. R., Crawford, C. G.m DVD Demystified, McGraw - Hill, 2006

Vaughan, T., Multimedia: Making it Work - Seventh Edition - Mc Grow Hill 2006

Wang, Z.; Simoncelli, E. P.; Bonk, A. C. Multi Scale Structural Similarity for Image Quality Assessment. Center for Neural Science and Courant Inst. Of Math Sci., New York Univ., New York, NY. 2003

Zaletej, J.; Tasic, J. F. Video Object Segmentation Based on Edge Tracking. Faculty of Electrical Engineering, University of Ljubljana Trzaska 25,1000 Ljubljana, SLOVENIA. October, 2001

Zhang, D.; Lu, G., Segmentation of Moving Objects in Image Sequence: A Review. Gippsland School of Computing and Information Technology Monash University, Churchill, Vic 3842, Australia

Zhang, M.; Gao, W., An Adaptive Skin Color Detection Algorithm with Confusing Backgrounds Elimination. Institute of Computing Technology, Chinese Academy of Sciences, Graduate School of the Chinese Academy of Sciences

Wien, M., Variable Block-Size Transforms for H.264/AVC. July, 2003 